\title{
Transcription Factor NRF2 as a Therapeutic Target for Chronic Diseases: A Systems Medicine Approach
}

\author{
Antonio Cuadrado, Gina Manda, Ahmed Hassan, María José Alcaraz, Coral Barbas, Andreas Daiber, Pietro Ghezzi, Rafael León, \\ Manuela G. López, Baldo Oliva, Marta Pajares, Ana I. Rojo, Natalia Robledinos-Antón, Angela M. Valverde, Emre Guney, ${ }^{1}$ \\ and Harald H. H. W. Schmidt ${ }^{1}$
}

Centro de Investigación Biomédica en Red Sobre Enfermedades Neurodegenerativas (CIBERNED), Instituto de Investigación Sanitaria La Paz (IdiPaz), Department of Biochemistry and Instituto de Investigaciones Biomédicas Alberto Sols UAM (Autonomous University of Madrid)-CSIC (Centro Superior de Investigaciones Biomédicas), Faculty of Medicine, Autonomous University of Madrid, Madrid, Spain (A.C., M.P., A.I.R., N.R.-A.); Victor Babes National Institute of Pathology, Bucharest, Romania (A.C., G.M.); Department Pharmacology and Personalized Medicine, School for Cardiovascular Medicine, Faculty of Health, Medicine and Life Sciences, Maastricht University, Maastrich, The Netherlands (A.H., H.H.H.W.S.); Instituto Interuniversitario de Investigación de Reconocimiento Molecular y Desarrollo Tecnológico, Universitat Politècnica de València, Universitat de València, Valencia, Spain (M.J.A.); Centre for Metabolomics and Bioanalysis, Facultad de Farmacia, Universidad CEU (Centro de Estudios Universitarios)-San Pablo, Madrid, Spain (C.B.); Center for Cardiology, Cardiology I-Laboratory of Molecular Cardiology, Medical Center of the Johannes Gutenberg University, Mainz, Germany (A.D.); Brighton and Sussex Medical School, Brighton, United Kingdom (P.G.); Instituto Teófilo Hernando y Departamento de Farmacología

y Terapéutica, Facultad de Medicina, Universidad Autónoma de Madrid, Madrid, Spain (R.L., M.G.L.); Instituto de Investigación

Sanitaria, Servicio de Farmacología Clínica, Hospital Universitario de la Princesa, Madrid, Spain (R.L., M.G.L.); GRIB (Unidad de Investigación en Informática Biomédica), Department of Experimental and Health Sciences, Universitat Pompeu Fabra, Barcelona, Spain (B.O., E.G.); Instituto de Investigaciones Biomédicas Alberto Sols UAM-CSIC and Centro de Investigación Biomédica en Red en Diabetes y Enfermedades Metabólicas Asociadas, Madrid, Spain (A.M.V.); and Structural Bioinformatics Laboratory, Department of Experimental and Health Sciences, Universitat Pompeu Fabra, Barcelona, Spain (E.G.)

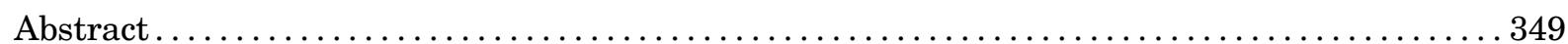

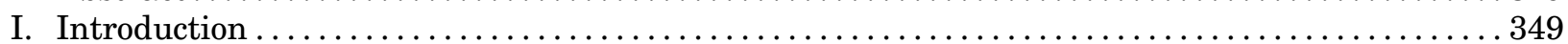

II. From Nuclear Factor (Erythroid-Derived 2)-Like 2 Interactome to Nuclear Factor

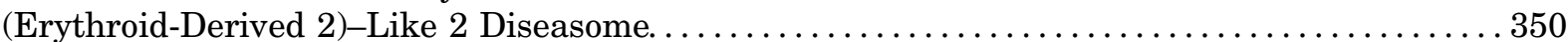

A. Nuclear Factor (Erythroid-Derived 2)-Like 2 as a Master Regulator of Cellular

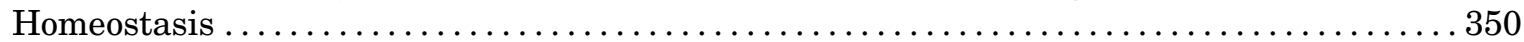

B. Positioning Nuclear Factor (Erythroid-Derived 2)-Like 2 and Its Regulatory Pathway

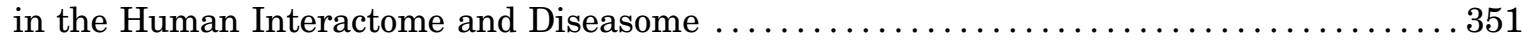

III. Target Validation of Nuclear Factor (Erythroid-Derived 2)-Like 2 in Human Disease

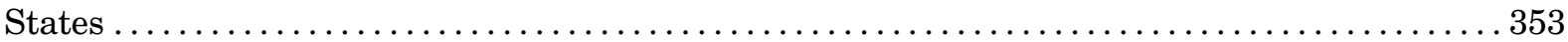

A. Key Role of Nuclear Factor (Erythroid-Derived 2)-Like 2 in Resolution of

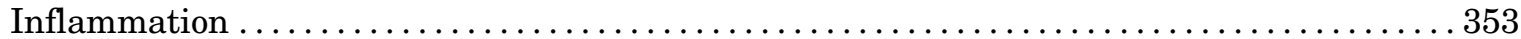

B. Nuclear Factor (Erythroid-Derived 2)-Like 2 in Autoimmune Diseases . ............. 357

C. Nuclear Factor (Erythroid-Derived 2)-Like 2 in Chronic Respiratory Diseases ............ 358

D. Nuclear Factor (Erythroid-Derived 2)-Like 2 in the Digestive System ............... 360

E. Nuclear Factor (Erythroid-Derived 2)-Like 2 in the Cardiovascular System ............ 360

F. Nuclear Factor (Erythroid-Derived 2)-Like 2 in Metabolic Diseases ................. 361

G. Nuclear Factor (Erythroid-Derived 2)-Like 2 in Neurodegenerative Diseases ........... 362

IV. The Kelch-Like ECH-Associated Protein 1 Paradox in Cancer....................... 363

V. Nuclear Factor (Erythroid-Derived 2)-Like 2 Drugome. ......................... 365

Address correspondence to: Dr. Antonio Cuadrado, Instituto de Investigaciones Biomédicas "Alberto Sols" UAM-CSIC, C/ Arturo Duperier 4, 28029 Madrid, Spain. E-mail: antonio.cuadrado@uam.es or Dr. Emre Guney, GRIB, Department of Experimental and Health Sciences, Universitat Pompeu Fabra, Barcelona-08003, Spain. E-mail: emre.guney@upf.edu

This work was supported by Grants SAF2015-71304-REDT, SAF2016-76520-R, SAF2013-4874R, SAF2015-65267-R, and BIO2014-57518 of the Spanish Ministry of Economy and Competiveness; PII4/00372 from the Health Institute Carlos III; PROMETEOII/2014/071 of Generalitat Valenciana; P_37_732/2016 REDBRAIN of the European Regional Development Fund; Competitiveness Operational Program 2014-2020; and the ERC Advanced Grant RadMed 294683 and COST action 15120 OpenMultiMed (H.H.H.W.S.). M.P. is the recipient of a FPU fellowship of Autonomous University of Madrid. E.G. is supported by a European-cofunded Beatriu de Pinos fellowship. R.L. is supproted by the Miguel Servet II fellow (CPII16/00014).

${ }^{1}$ E.G. and H.H.H.W.S. are senior authors who contributed equally to this work.

https://doi.org/10.1124/pr.117.014753. 
A. Electrophilic Nuclear Factor (Erythroid-Derived 2)-Like 2 Inducers ................. 365

B. Protein-Protein Interaction Inhibitors for Nuclear Factor (Erythroid-Derived 2)-Like

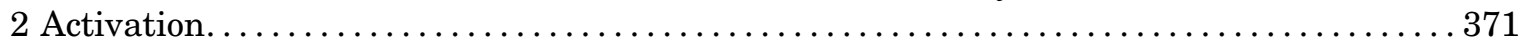

C. Drug Targets Other Than Kelch-Like ECH-Associated Protein 1 for Nuclear Factor

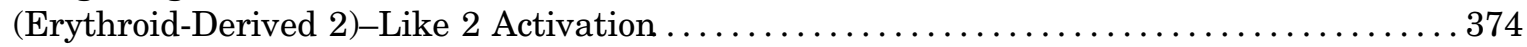

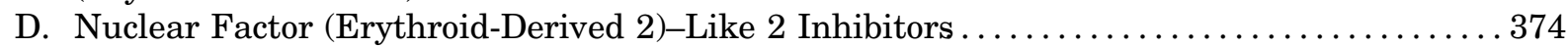

E. Repurposing Instead of De Novo Drug Discovery and Development............... 375

VI. Biomarkers as Nuclear Factor (Erythroid-Derived 2)-Like 2 Signature and for Monitoring

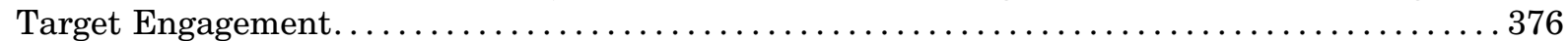

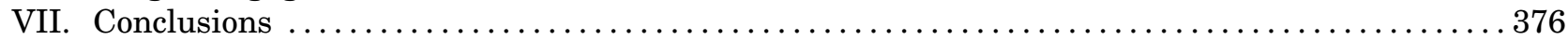

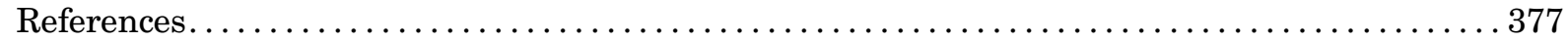

\begin{abstract}
Systems medicine has a mechanism-based rather than a symptom- or organ-based approach to disease and identifies therapeutic targets in a nonhypothesisdriven manner. In this work, we apply this to transcription factor nuclear factor (erythroid-derived 2)-like 2 (NRF2) by cross-validating its position in a protein-protein interaction network (the NRF2 interactome) functionally linked to cytoprotection in low-grade stress, chronic inflammation, metabolic alterations, and reactive oxygen species formation. Multiscale network analysis of these molecular profiles suggests alterations of NRF2 expression and activity as a common mechanism in a subnetwork of diseases (the NRF2 diseasome). This network joins apparently heterogeneous phenotypes such as autoimmune, respiratory, digestive, cardiovascular, metabolic, and neurodegenerative diseases, along with cancer. Importantly, this approach matches and confirms
\end{abstract}

in silico several applications for NRF2-modulating drugs validated in vivo at different phases of clinical development. Pharmacologically, their profile is as diverse as electrophilic dimethyl fumarate, synthetic triterpenoids like bardoxolone methyl and sulforaphane, protein-protein or DNA-protein interaction inhibitors, and even registered drugs such as metformin and statins, which activate NRF2 and may be repurposed for indications within the NRF2 cluster of disease phenotypes. Thus, NRF2 represents one of the first targets fully embraced by classic and systems medicine approaches to facilitate both drug development and drug repurposing by focusing on a set of disease phenotypes that appear to be mechanistically linked. The resulting NRF2 drugome may therefore rapidly advance several surprising clinical options for this subset of chronic diseases.

\section{Introduction}

Life span has almost doubled in the last century, and aging-specific diseases are now becoming prevalent. However, the pathologic mechanisms underlying most of them are poorly understood and treated rather by correcting symptoms or risk factors. Moreover, contrary to a hitherto linear approach that considered one disease, one medicine, chronic diseases demonstrate a high degree of connectedness and a need for more precise, mechanism-based disease definitions rather than the current organ- and symptombased. After the human genome sequencing and the development of molecular networks, a new concept of disease is thus emerging, in which diseases are diagnosed not only by clinical symptoms, but mainly by the underlying molecular signatures (Goh et al., 2007). The fact that different pathophenotypes have a shared molecular mechanism provides also a rationale toward a new concept of therapy summarized as "several diseases, one medicine" and drug repurposing. Network medicine, i.e., the application of network concepts to the analysis of dynamic connections among diseases and drugs, provides a new opportunity to develop this new approach. Chronic diseases in the elderly are most likely characterized by the loss of homeostasis during aging or as a result of environmental factors, all of them leading to low-grade stress by pathologic formation of reactive oxygen species (ROS), chronic inflammation, and metabolic unbalance. Based on a network medicine approach, in this review we will present extensive evidence indicating that the nuclear factor (erythroid-derived 2)-like

\footnotetext{
ABBREVIATIONS: $\mathrm{AD}$, Alzheimer disease; ALS, amyotrophic lateral sclerosis; AMPK, AMP-activated protein kinase; ARE, antioxidant response element; $\beta$-TrCP, $\beta$-transducin repeat containing E3 ubiquitin protein ligase; bZip, basic region-leucine zipper; CDDO, 2-cyano-3,12-dioxo-oleana-1,9(11)dien-28-oate; CDDO-Me, CDDO-methyl ester; COPD, chronic obstructive pulmonary disease; CUL3, Cullin 3; DC, dendritic cell; DMF, dimethyl fumarate; EAE, experimental autoimmune encephalomyelitis; ECH, erythroid cell-derived protein with Cap'n'collar homology; GCLC, $\gamma$-glutamyl cysteine ligase catalytic subunit; GCLM, $\gamma$-glutamyl cysteine ligase modulator subunit; GI, gastrointestinal tract; GSH, glutathione; GSK-3, glycogen synthase kinase 3; HFD, high-fat diet; HNSCC, head and neck squamous cell carcinoma; HO-1, heme oxygenase-1; IBD, inflammatory bowel disease; I $\kappa$ B $\kappa$-B inhibitor; IKK, I $\kappa$ B kinase; IL, interleukin; KEAP1, kelch-like ECH-associated protein 1; LDL, low-density lipoprotein; LPS, lipopolysaccharide; $\mathrm{MAF}$, musculoaponeurotic fibrosarcoma protein; MMF, monomethyl fumarate; MS, multiple sclerosis; NASH, nonalcoholic steatohepatitis; NF- $\kappa$ B, p65 subunit of nuclear factor $\kappa$-light-chain enhancer of activated B cells; NQO1, NADPH:quinone oxidoreductase; NRF2, nuclear factor (erythroid-derived 2)like 2; PD, Parkinson disease; PI3K, phosphatidylinositol 3-kinase; PPI, protein-protein interaction; PTEN, phosphatase and tensin homolog; RA, rheumatoid arthritis; RBX1, RING-box protein 1; RNS, reactive nitrogen species; ROS, reactive oxygen species; SFN, sulforaphane; SLE, systemic lupus erythematous; SNP, single-nucleotide polymorphism; SQSTM1, sequestosome 1; STAT, signal transducer and activator of transcription; T2DM, type 2 diabetes mellitus; TGF, transforming growth factor; Th, T helper; TNF, tumor necrosis factor; Treg, T regulatory.
} 
2 (NRF2), as the master regulator of multiple cytoprotective responses and a key molecular node within a particular cluster of diseases, provides a new strategy for drug development and repurposing.

\section{From Nuclear Factor (Erythroid-Derived 2)- Like 2 Interactome to Nuclear Factor (Erythroid- Derived 2)-Like 2 Diseasome}

\section{A. Nuclear Factor (Erythroid-Derived 2)-Like 2 as a Master Regulator of Cellular Homeostasis}

NRF2 is a basic region-leucine zipper (bZip) transcription factor (Fig. 1) that forms heterodimers with small musculoaponeurotic fibrosarcoma protein (MAF) $\mathrm{K}, \mathrm{G}$, and $\mathrm{F}$ in the nucleus. The heterodimer recognizes an enhancer sequence termed antioxidant response element (ARE) that is present in the regulatory regions of over 250 genes (ARE genes) (Ma, 2013; Hayes and Dinkova-Kostova, 2014). These ARE genes encode a network of cooperating enzymes involved in phase I, II, and III biotransformation reactions and antioxidant mechanisms that generate NADPH, glutathione (GSH), and thioredoxin reactions; lipid and iron catabolism; and interaction with other transcription factors, etc. (Hayes and Dinkova-Kostova, 2014). Recently, NRF2 was also found to regulate the expression of several proteasome subunits and autophagy genes, providing additional interest for its control of proteostasis (Pajares et al., 2015, 2016, 2017; de la Vega et al., 2016).

The great significance of NRF2 from a clinical perspective is that it might be targeted pharmacologically with patient benefit. The main mechanism regulating the transcriptional activity of NRF2 is the control of protein stabilization by the E3 ligase adapter Kelch-like erythroid cell-derived protein with Cap'n'collar homology (ECH)associated protein 1 (KEAP1) (Fig. 2). KEAP1 is a homodimeric protein that bridges NRF2 with the E3 ligase complex formed by Cullin 3 and RING-box protein 1 (CUL3/RBX1). Under homeostatic conditions, the $\mathrm{N}$-terminal domain of the KEAP1 homodimer binds one molecule of NRF2 at two amino acid sequences with low (aspartate, leucine, and glycine; DLG) and high (glutamate, threonine, glycine, and glutamate; ETGE) affinity, and hence presents NRF2 to ubiquitination by CUL3/RBX1 (Tong et al., 2007) and subsequent degradation by the proteasome. KEAP 1 is a redox and electrophile sensor that upon modification of critical cysteines loses its ability to repress NRF2 (Fig. 2; Biomarkers as Nuclear Factor (Erythroid-Derived 2)-Like 2 Signature and for Monitoring Target Engagement). An alternative mechanism of regulation of NRF2 stability is the phosphorylation mediated by glycogen synthase kinase 3 (GSK-3) (Fig. 2). This kinase phosphorylates a domain of NRF2 (aspartate, serine, glycine, isoleucine, serine; DSGIS) and hence creates a recognition motif for the $\mathrm{E} 3$ ligase adapter $\beta$-transducin
A
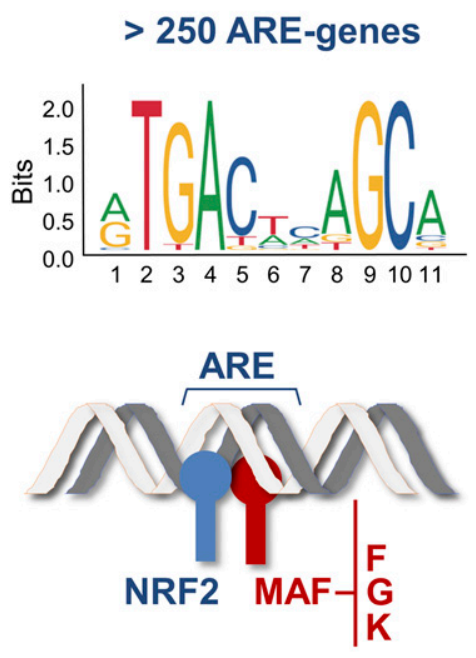

B

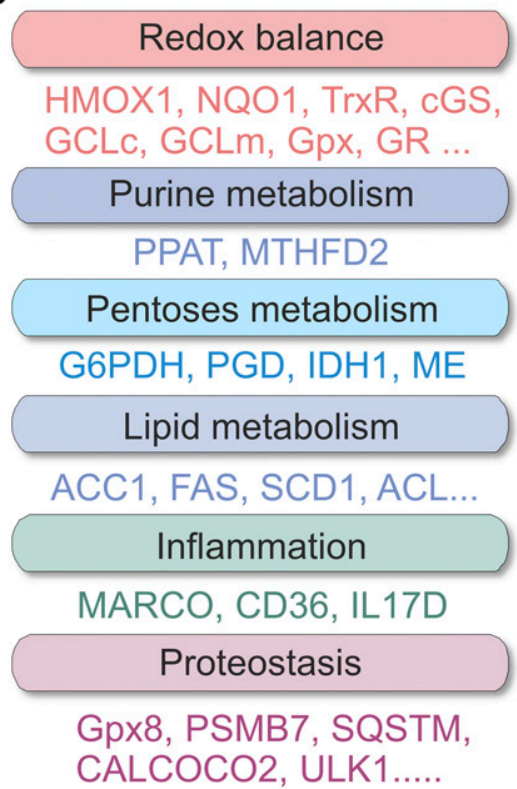

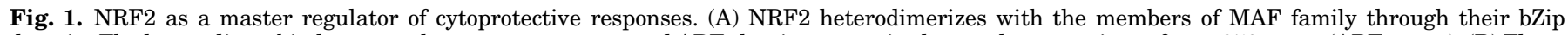

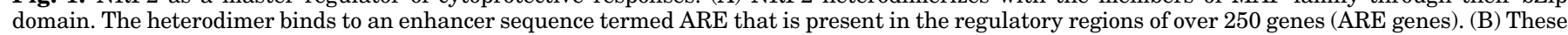

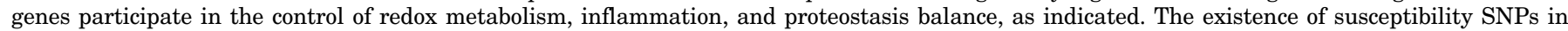

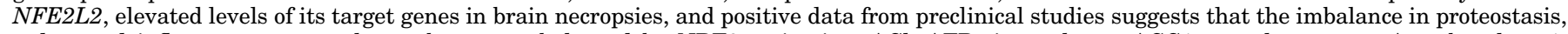

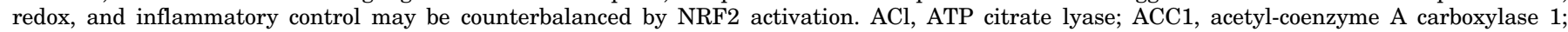

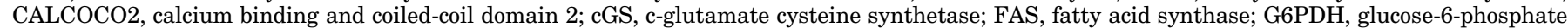

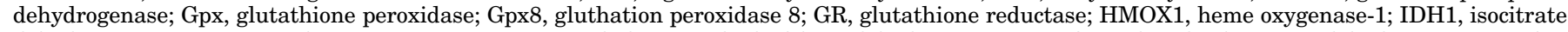

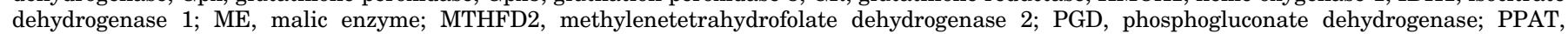

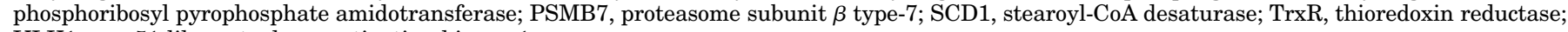
ULK1, unc-51 like autophagy activating kinase 1 . 
A

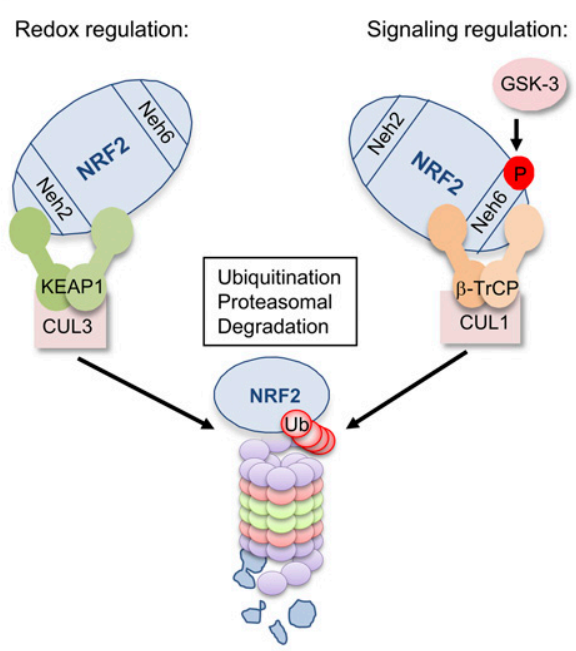

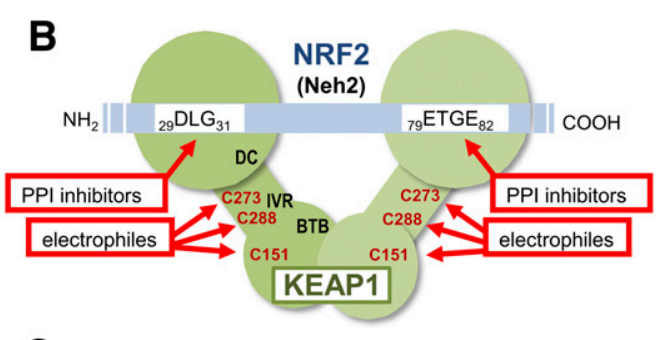

C

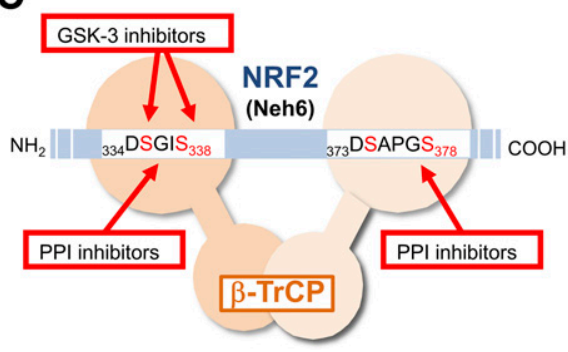

Fig. 2. Regulation of NRF2 stability by KEAP1 and $\beta$-TrCP and its pharmacological targeting. (A) According to the dual regulation model (Rada et al., 2011), two domains of NRF2, termed Neh2 and Neh6, participate in NRF2 degradation in response to redox and electrophile changes (KEAP1) and to signaling kinases $(\beta$-TrCP), respectively. The Neh2 domain binds the E3 ligase adapter KEAP1 that presents NRF2 for ubiquitination to a CUL3/RBX1 complex. The Neh6 domain requires previous phosphorylation by GSK-3 to bind the E3 ligase adapter $\beta$-TrCP and subsequent ubiquitination by a CUL1/RBX1 complex (see text for details). (B) Detail of the binding between NRF2 and KEAP1 and current strategies to target this interaction. The KEAP1 homodimer binds NRF2 at two motifs of the Neh2 domain: the low-affinity (29-DLG-31) and the high-affinity (79-ETGE-82) binding sites. Current strategies to disrupt this interaction include the following: electrophiles that alter sulfhydryl groups of cysteines C151, 273, and 288; PPI inhibitors that alter the docking of NRF2 to the DC domain of KEAP1. (C) Hypothetical binding of NRF2 and $\beta$-TrCP and suggested strategies to target this interaction. The $\beta$-TrCP homodimer binds to the Nhe6 domain at the phospho-motif 334-DSGIS-338 when it is phosphorylated by GSK-3 (Rada et al., 2011, 2012) and at the phospho-motif 373-DSAPGS-378 independently of GSK-3 (Chowdhry et al., 2013). In this figure we postulate that, by analogy with KEAP1, one $\beta$-TrCP homodimer interacts with one molecule of NRF2 at the two phospho-motifs, but experimental evidence is still lacking. Two possible strategies to disrupt this interaction include the use of GSK-3 inhibitors and PPI inhibitors.

repeat containing E3 ubiquitin protein ligase $(\beta$-TrCP) that presents NRF2 to a CUL1/RBX1 complex, leading to an alternative pathway for ubiquitin-dependent proteasome degradation of NRF2. Therefore, KEAP1 and GSK-3/ $\beta$-TrCP tightly control NRF2 protein levels in the context of redox homeostasis and cell signaling, respectively (Cuadrado, 2015). Other mechanisms of NRF2 regulation at protein, mRNA, or gene level have been reported (Hayes and Dinkova-Kostova, 2014), but at least these two are amenable to pharmacological regulation.

\section{B. Positioning Nuclear Factor (Erythroid-Derived 2)- Like 2 and Its Regulatory Pathway in the Human Interactome and Diseasome}

The gene encoding NRF2, termed NFE2L2, is highly polymorphic and presents a mutagenic frequency of 1 per every $72 \mathrm{bp}$. An excellent review on this topic reported in 2015 up to 18 single-nucleotide polymorphisms (SNPs), most of them in the $5^{\prime}$ regulatory region and in intron 1 (Cho et al., 2015). Several of these SNPs might constitute functional haplotypes that are associated with risk at onset or progression of chronic diseases. Variations in functional haplotypes may have a subtle impact on a proportion of individuals who exhibit clinical symptoms of specific diseases, yet they may have a profound effect at the population level and may define specific strategies to target this gene in precision medicine.

Recent advances in network medicine have provided quantitative tools to characterize how the interplay between genes and their interactions (interactome) is related to pathology (Barabasi et al., 2011; Vidal et al., 2011; Guney et al., 2016), how dysregulated molecular networks are common to various diseases (Menche et al., 2015), and how diseases manifest in particular tissues (Kitsak et al., 2016). To understand the relevance of NRF2 in pathology from the systems medicine perspective, first we have generated the human interactome map. We have integrated and curated information on physical interactions among proteins involved in the NRF2-regulating pathway (Hayes and Dinkova-Kostova, 2014; Cuadrado, 2015). The interaction data have been taken from the recently published human interactome that compiles data across several protein-protein interaction (PPI) resources (Turei et al., 2013; Menche et al., 2015). However, the currently available information for development of the NRF2 interactome is limited by the fact that, because NRF2 is a very short half-life protein, some meaningful interactions may be undetected. Nevertheless, some well-known proteins that physically interact with NRF2 are found in the interactome, including KEAP1, $\beta$-TrCP, and MAFs. Another group of NRF2-interacting proteins corresponds to nuclear proteins with functions in regulation of gene expression. These include proteins related with bZip transcription factors, nuclear receptors or coactivators, or proteins involved in histone acetylation. Therefore, the NRF2 interactome evidences additional mechanisms of gene regulation beyond those directly connected to this 
transcription factor. NRF2 is phosphorylated at several residues, and therefore it is expected to interact with several kinases that include GSK-3 and several protein kinase $\mathrm{C}$ isoforms. These kinases are downstream of some membrane receptors and adapter/scaffold proteins. In addition to this physical interaction, we have identified several biologic functions that are enriched in the NRF2 neighborhood, including metabolic processes, such as biosynthesis of pentose, tetrapyrrole, heme, glucose 6-phospate, cysteine, GSH, glyceraldehyde-3-phosphate, and NADPH. Most of these regulatory proteins do not interact directly with each other but are connected through proteins acting as mediators (Fig. 3; a more detailed description of specific interacting molecules can be found at http://sbi.imim.es/data/nrf2/).

Perturbations of the NRF2 interactome have been reported in several diseases. We have developed a diseasome map by curating a list of $37 \mathrm{NRF} 2$-related diseases based on DisGeNET (Pinero et al., 2017) and GeneCards (Stelzer et al., 2016) databases, as well as knowledge from some studies in animal models. We have also retrieved disease-gene associations for these pathologies using DisGeNET, OMIM, and GWAS databases (Menche et al., 2015) (Table 1). The interactome-based proximity (Guney and Oliva, 2014) of NRF2 to known disease genes for each of the NRF2-related disease phenotypes is shown in Fig. 4. NRF2 is significantly closer to the known disease genes of the digestive system and cancers, such as prostate, liver, and lung neoplasms, compared with randomly selected proteins, highlighting the key functional role of NRF2 in these pathologies. Moreover, NRF2 was found to be proximal to various proteins related to metabolic and cardiovascular diseases, such as diabetes, hyperglycemia, ischemia, middle cerebral artery infarction, and atherosclerosis. Protein interactions of NRF2 also connect it to genes associated to respiratory disorders such as asthma, pulmonary fibrosis, and pulmonary emphysema, as well as to neurodegenerative conditions such as Alzheimer disease (AD), Parkinson disease (PD), and amyotrophic lateral sclerosis (ALS).

The interactome-based proximity therefore offers a perspective on how NRF2 can be linked to various pathologic conditions. The relationships among diseases have been previously summarized as a network, termed diseasome, that is connecting them based on genetic (Goh et al., 2007) and clinical (Hidalgo et al., 2009; Zhou et al., 2014) commonalities. In Fig. 5, we have defined a network of diseases, the NRF2 diseasome, based on shared genes, symptom similarity, and comorbidities. NRF2 appears to connect diseases governed substantially by inflammatory processes, such as acute kidney injury, liver cirrhosis, and atherosclerosis. Furthermore, neurodegenerative diseases such as $\mathrm{AD}, \mathrm{PD}$, Huntington's disease, and ALS constitute a cluster consistent with recent studies implicating also NRF2 in neuroinflammatory processes (Rojo et al., 2010; Lastres-Becker et al., 2012, 2014; Jung et al., 2017; Wang et al., 2017b). The regulation of NRF2 by kinase-signaling cascades (Jung et al., 2017) could explain the well-connected cluster of cancers, particularly supporting the involvement of NRF2 in pathologic ROS

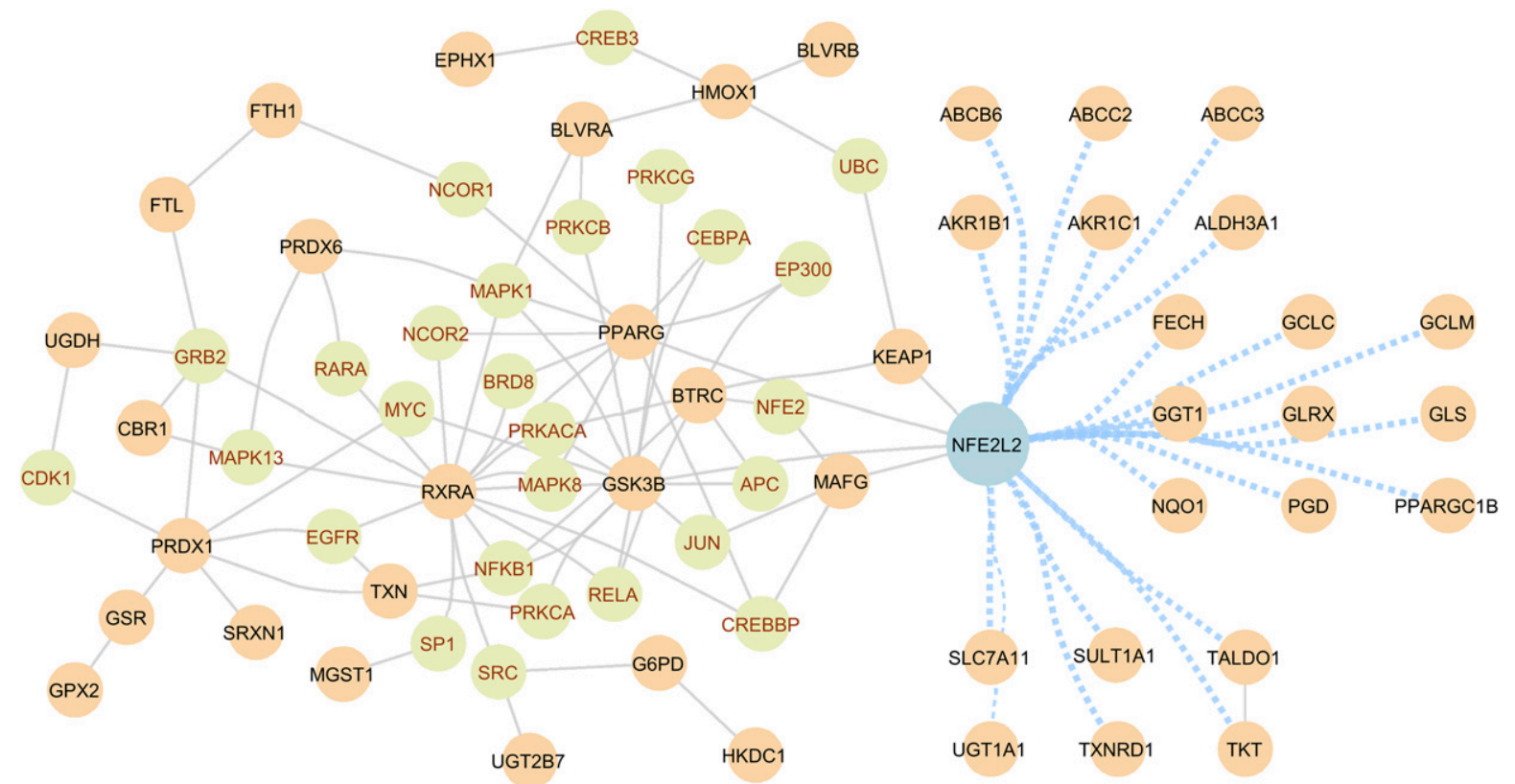

Fig. 3. Locating the NRF2 regulatory pathway in the human interactome. NRF2 plays a key role in pathologic ROS formation as well as inflammatory

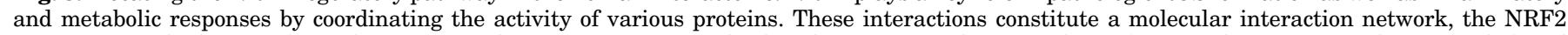

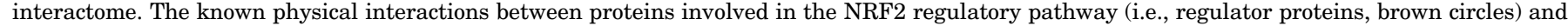

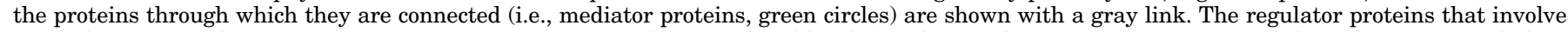

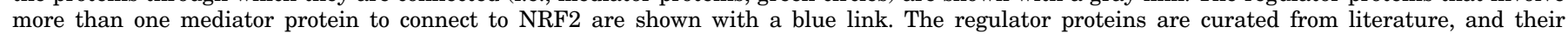

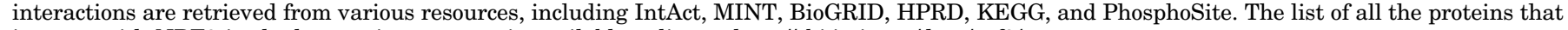
interact with NRF2 in the human interactome is available online at http://sbi.imim.es/data/nrf2/. 
TABLE 1

Cluster of diseases with evidence of NRF2 association

Disease phenotypes with evidence of genetic association with NRF2 were selected from the DisGeNet database. DisGeNet integrates diseasegene association information from various resources, such as UniProt, ClinVar, GWAS Catalog, and Comparative Toxicogenomics Database and scores disease-gene associations according to the number of resources and publications supporting these associations. The curation of the list was based on the following criteria: 1) only pathophenotypes with more than one citation in Pubmed were selected; 2) the score of reliability was set to a threshold of 0.001 ; and 3) disease entries with very similar names or overlapping terms were simplified to one single entry.

\begin{tabular}{lclc}
\hline \multicolumn{1}{c}{ Pathophenotype } & Reliability Score & \multicolumn{1}{c}{ Pathophenotype } \\
\hline Diabetic nephropathy & 0.2016 & Diabetic cardiomyopathy \\
Liver cirrhosis & 0.2005 & Middle cerebral artery infraction \\
Nonalcoholic steatohepatitis & 0.2005 & Breast neoplasms & 0.0803 \\
Acute kidney injury & 0.2000 & Vitiligo & 0.0800 \\
Pulmonary fibrosis & 0.2000 & Atherosclerosis & 0.0076 \\
Nonsmall cell lung carcinoma & 0.1252 & Asthma & 0.0067 \\
Squamous cell carcinoma & 0.1243 & Leukemia & 0.0043 \\
Liver neoplasms & 0.1238 & Colon neoplasm \\
Hyperglycemia & 0.1208 & Gastrointestinal diseases \\
Drug-induced liver injury & 0.1200 & Parkinson disease \\
Prostatic neoplasms & 0.1200 & Systemic lupus erythematous nephritis \\
Chronic obstructive pulmonary disease & 0.0899 & Glioma & 0.0038 \\
Colorectal neoplasms & 0.0847 & Amyotrophic lateral sclerosis \\
Alzheimer disease & 0.0837 & Ischemia & 0.0029 \\
Type 2 diabetes mellitus & 0.0814 & Pulmonary emphysema \\
Chronic kidney disease & 0.0808 & Pancreatic neoplasms \\
Diabetic retinopathy & 0.0805 & Vascular diseases \\
Huntington's disease & 0.0805 & Sepsis \\
\hline
\end{tabular}

formation underlining colon (Gonzalez-Donquiles et al., 2017) and breast (Lu et al., 2017) tumors.

\section{Target Validation of Nuclear Factor (Erythroid-Derived 2)-Like 2 in Human Disease States}

\section{A. Key Role of Nuclear Factor (Erythroid-Derived 2)-} Like 2 in Resolution of Inflammation

Persistent inflammation is a hallmark of all pathophenotypes found in the NRF2 diseasome. This is most likely because inflammation is associated with increased local and systemic pathologic formation of reactive oxygen species (ROS). In fact, ROS and reactive nitrogen species (RNS) stimulate and aggravate inflammatory responses that are mechanistically related to the activation of transcription factor, p65 subunit of nuclear factor $\kappa$-light-chain enhancer of activated B cells $(\mathrm{NF}-\kappa \mathrm{B})$ (Wenzel et al., 2017). Very simplified, in resting immune cells, $\mathrm{NF}-\kappa \mathrm{B}$ is retained in the cytosol through interaction with the nuclear $\kappa$-B inhibitor $(\mathrm{I} \kappa \mathrm{B} \alpha)$. Pathogen-associated molecular pattern molecules derived from microorganisms as well as damageassociated molecular pattern molecules released in

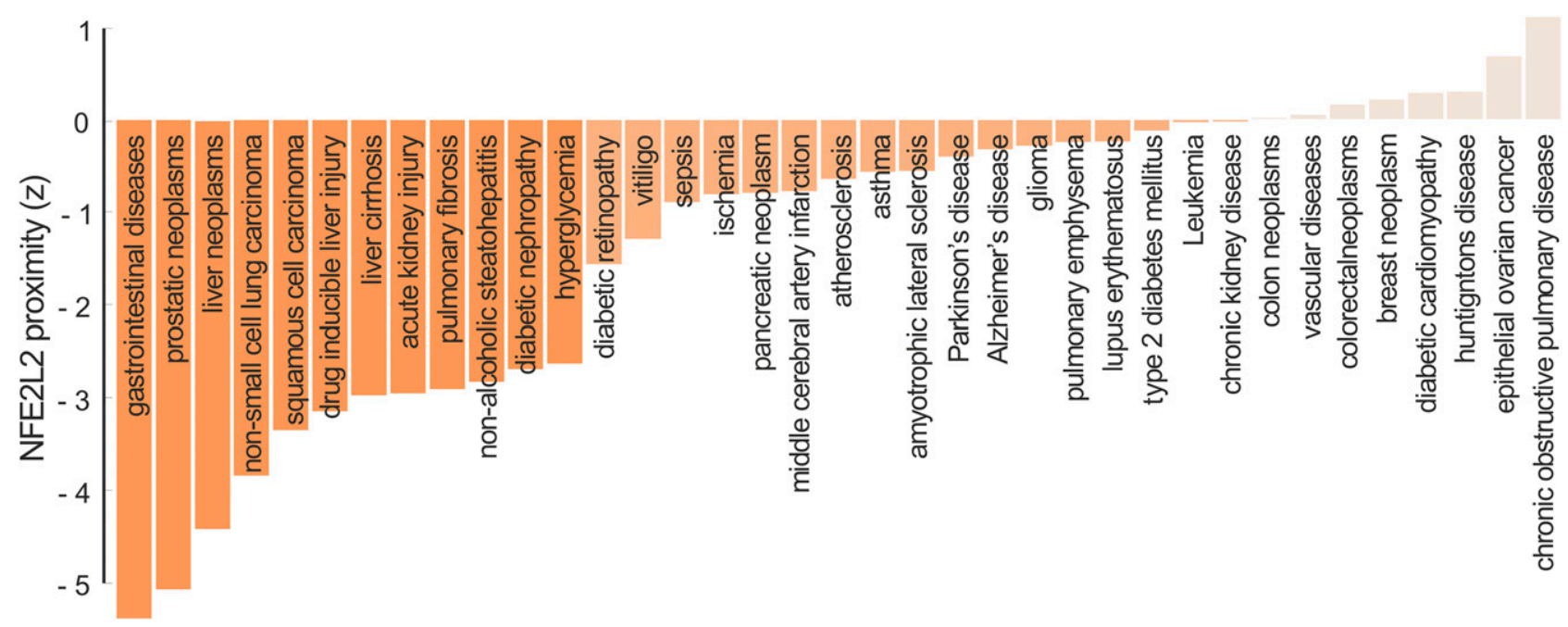

Fig. 4. Systems medicine view of NRF2 from the perspective of the human interactome. Diseases are triggered by mutations that perturb proteins and their interactions, affecting a certain neighborhood in the NRF2 interactome. Interactome-based proximity measures the distance of genes to those disease neighborhoods. The bars show the proximity of NRF2 gene (NFE2L2) to known disease genes that participate in NRF2-related pathophenotypes. These bars highlight the role of NRF2 in digestive system diseases and cancers. For a given disease, the proximity first calculates the distance from NRF2 to the closest known disease gene and then compares that distance to a random expectation that is estimated using average distances between randomly selected proteins in the interactome. The $z$-score reported by interactome-based proximity corresponds to the significance of the observed distance between NRF2 and the disease genes. A negative value indicates that the observed distance is lower than what would be expected by chance. The bars are colored in varying tones of orange based on the $z$-score: significantly proximal (dark orange), proximal (orange), not proximal (light orange), respectively. The known disease genes are taken from DisGeNet, OMIM, and GWAS Catalog. 


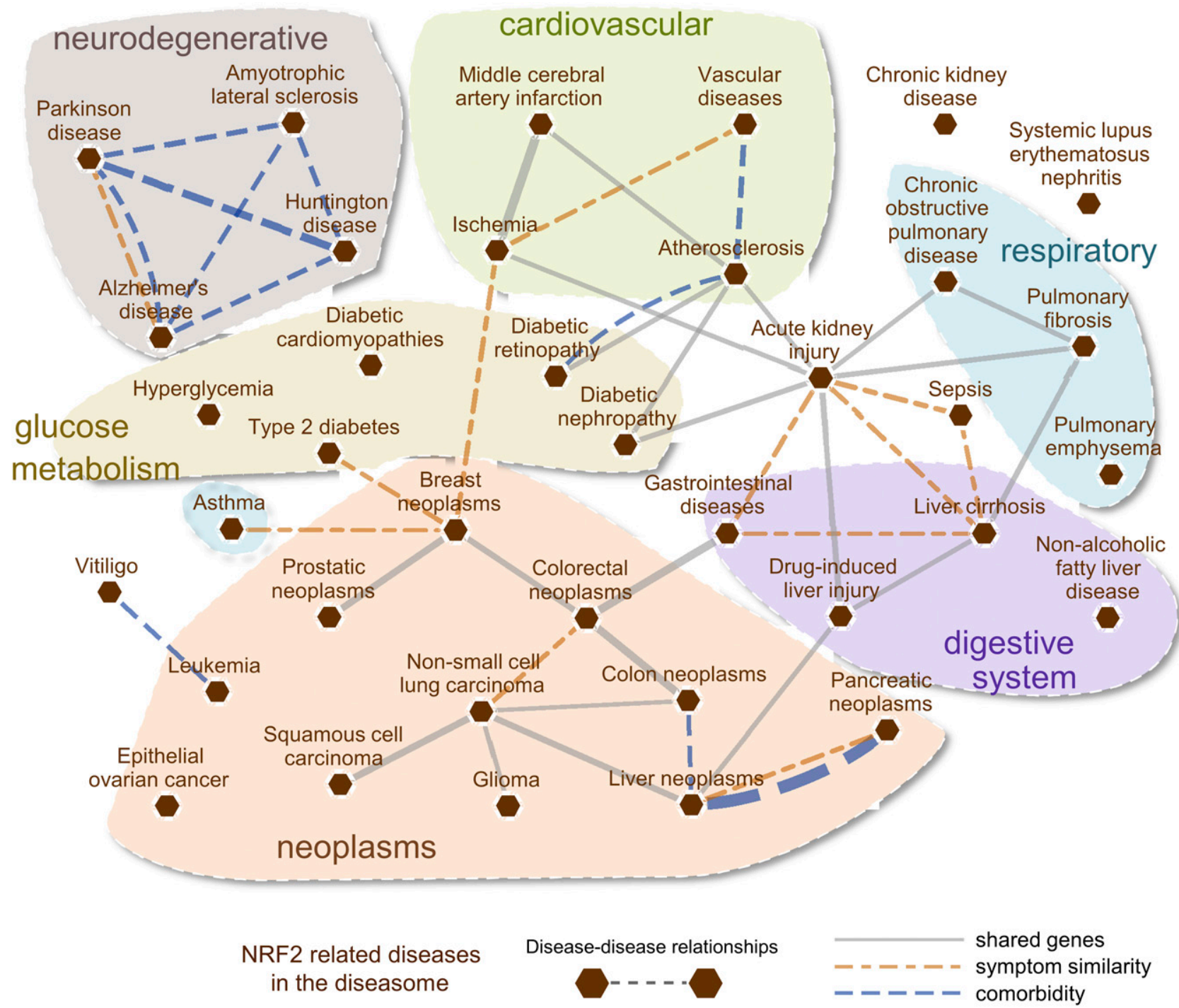

Fig. 5. Current status of the NRF2 diseasome. The relationships between diseases are represented as a network in which pathophenotypes are linked by common genetic and clinical descriptors. In the figure, nodes (red hexagons) represent diseases, and the edges are similarities among them based on shared genes, common symptoms, and comorbidities (gray, orange, and blue lines, respectively). The genes and symptoms associated with the diseases are used to identify disease pairs that have a significant genetic and symptomatic overlap calculated using the Jaccard index. Among significant disease-disease connections $(P<0.05$, assessed by Fisher's exact test based on the observed gene or symptom overlap), only the links that have an elevated overlap and comorbidity are shown to eliminate potentially spurious connections. Accordingly, the diseases that share at least $10 \%$ of the disease-associated genes and more than half of the associated symptoms are included in the figure. The comorbidity information is extracted from medical insurance claims, representing disease pairs that tend to occur together in the population (relative risk $>2$ ).

response to tissue damage stimulate cognate receptors expressed by immune cells that lead to activation of $\mathrm{I}_{\kappa} \mathrm{B}$ kinase (IKK) $\beta$. This kinase phosphorylates $\mathrm{I} \kappa \mathrm{B} \alpha$, targeting it for degradation and allowing nuclear translocation and activation of NF- $\kappa \mathrm{B}$ (Napetschnig and $\mathrm{Wu}$, 2013). These events are submitted to redox control through several modes of regulation of $\mathrm{I} \kappa \mathrm{B} \alpha$ (Bowie and O'Neill, 2000; Morgan and Liu, 2011; Siomek, 2012), but one that has been described recently involves the regulation of $\operatorname{IKK} \beta$ stability by KEAP1. Just like NRF2, IKK $\beta$ possesses an ETGE motif that enables its binding to KEAP for ubiquitination and proteasomal degradation. Therefore, under basal redox conditions, active KEAP1 targets $\operatorname{IKK} \beta$ for degradation and then $\mathrm{I} \kappa \mathrm{B} \alpha$ inhibits NF- $\kappa \mathrm{B}$. By contrast, in the presence of
ROS, KEAP1 is inhibited and $\operatorname{IKK} \beta$ is stabilized, phosphorylating $\mathrm{I} \kappa \mathrm{B} \alpha$ and leading to its degradation and therefore to upregulation of $\mathrm{NF}-\kappa \mathrm{B}$ (Lee et al., 2009).

Because NRF2 is a master regulator of redox homeostasis, it exerts an indirect control on NF- $\kappa \mathrm{B}$ activity. Lipopolysaccharide (LPS) activates simultaneously a fast, proinflammatory $\mathrm{NF}-\kappa \mathrm{B}$ response and a slow NRF2 response. The NF- $\kappa$ B response is subsequently inhibited when NRF2 is maximally active (Cuadrado et al., 2014). For instance, Ras-related C3 botulinum toxin substrate 1 , a small $\mathrm{G}$ protein of the Rho family, activated the NF- $\kappa \mathrm{B}$ pathway and NRF2 overexpression blocked, whereas NRF2 knockdown enhanced $\mathrm{NF}-\kappa \mathrm{B}-$ dependent transcription (Cuadrado et al., 
2014). Consistently, in NRF2-deficient $\left(\mathrm{Nrf2}^{-1-}\right)$ mice challenged with LPS or tumor necrosis factor (TNF)- $\alpha$, the activity of IKK was exacerbated and led to increased phosphorylation and degradation of $\mathrm{I} \kappa \mathrm{B}$ (Thimmulappa et al., 2006a).

NRF2 also induces an anti-inflammatory phenotype that modulates the functions of $\mathrm{CD} 8^{+} \mathrm{T}$ cells (Sha et al., 2015) as well as in macrophages and microglia ( Rojo et al., 2010, 2014a; Brune et al., 2013). This is because NRF2 increases cysteine and GSH levels in macrophages through regulation of the cystine/glutamate transporter and the GSH-synthesizing enzyme $\gamma$-glutamyl cysteine ligase modulator and catalytic subunits [ $\gamma$-glutamyl cysteine ligase modulator subunit (GCLM) and $\gamma$-glutamyl cysteine ligase catalytic subunit (GCLC)]. Conversely, GSH depletion sensitizes macrophages to NRF2 activation by LPS (Diotallevi et al., 2017). All of these studies point to NRF2 as an anti-inflammatory factor, crucial in controlling the intensity and duration of inflammatory responses (Fig. 6).

NRF2 and NF- $\kappa$ B crosstalk through feed forward and feedback mechanisms (Fig. 7). At the transcriptional level, NF- $\kappa \mathrm{B}$ activates NRF2 expression due to the existence of several functional binding sites in the promoter region of the NFE2L2 gene, thus inducing a negative feedback loop (Rushworth et al., 2012). Moreover, both NF- $\kappa \mathrm{B}$ and NRF2 transcription factors require the coactivator $\mathrm{CBP} / \mathrm{p} 300$, which is a histone acetyltransferase that acetylates and increases the
DNA-binding capacity. As such, NF- $\kappa \mathrm{B}$ overexpression hampers the availability of $\mathrm{CBP} / \mathrm{p} 300$ for NRF2, hence reducing its transcriptional capacity, whereas $\mathrm{NF}-\kappa \mathrm{B}$ knockdown shows the opposite effect (Liu et al., 2008). Additionally, $\mathrm{NF}-\kappa \mathrm{B}$ may promote interaction of histone deacetylase-3 with MAF proteins, therefore preventing their dimerization with NRF2 (Liu et al., 2008). NF- $\kappa$ B binds and translocates KEAP1 to the nucleus, thus favoring NRF2 ubiquitination and degradation in this cellular compartment ( $\mathrm{Yu}$ et al., 2011). The E3 ligase adapter $\beta$-TrCP tags both $\mathrm{I} \kappa \mathrm{B} \alpha$ (Winston et al., 1999) and NRF2 (Rada et al., 2011, 2012; Cuadrado, 2015) for proteasomal degradation, and therefore it can lead to increased NF- $\kappa$ B activity.

The anti-inflammatory activity of NRF2 was thought to rely only on modulation of redox metabolism or crosstalk with NF- $\kappa$ B. However, NRF2 can also directly block the transcription of the proinflammatory genes interleukin (IL)-6 and IL- $1 \beta$ in macrophages upon exposure to LPS (Kobayashi et al., 2016). LPS exposure or pharmacological activation of NRF2 leads to its binding to the proximal promoters of these proinflammatory genes and blocks the recruitment of RNA pol II. The mechanism appears to be independent of the binding of NRF2 to its well-established ARE enhancer. In other studies, NRF2 could directly regulate the expression of several other macrophage-specific genes, such as macrophage receptor with collagenous structure, a receptor required for bacterial phagocytosis, or CD36, a scavenger receptor for oxidized low-density

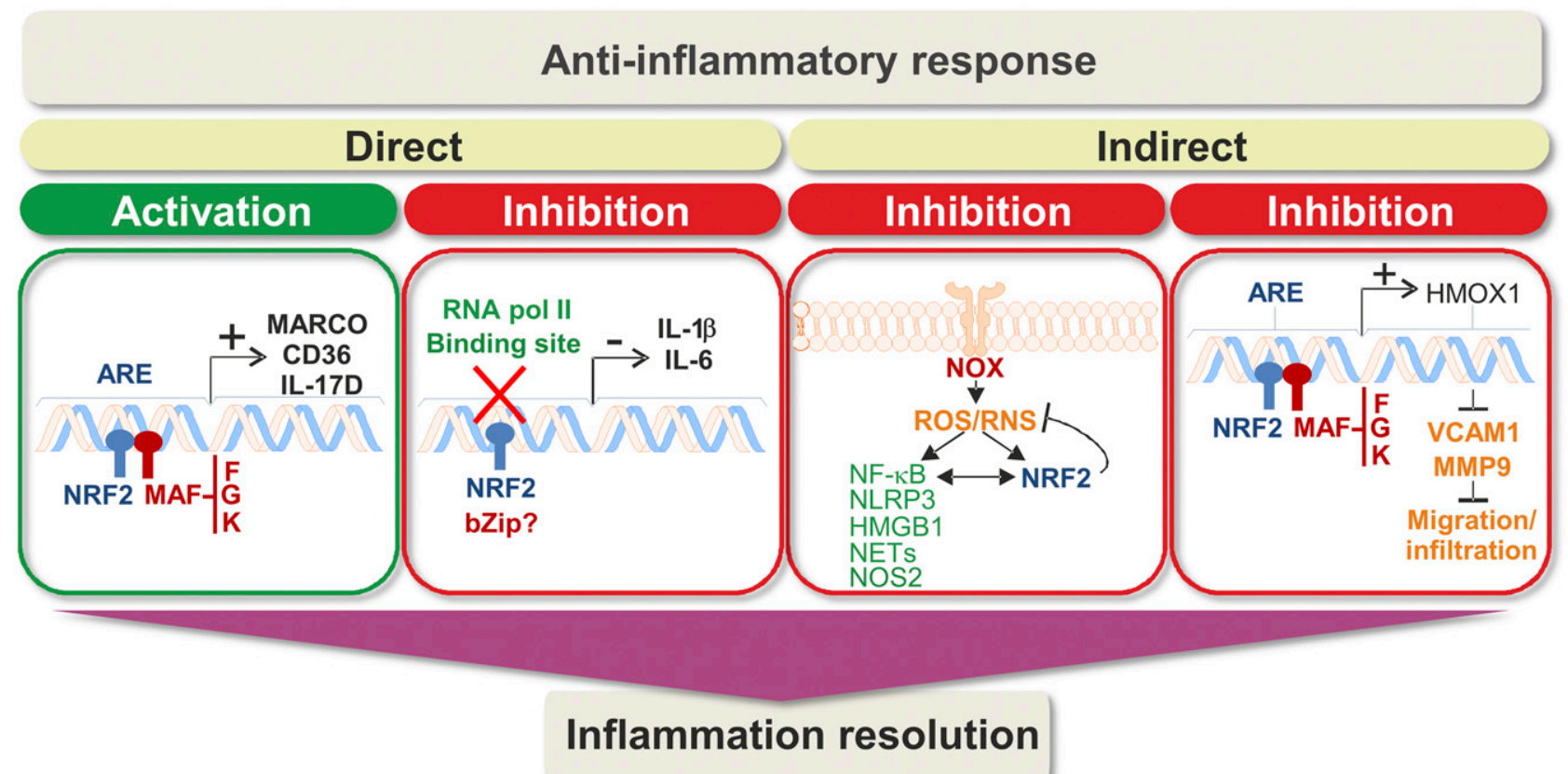

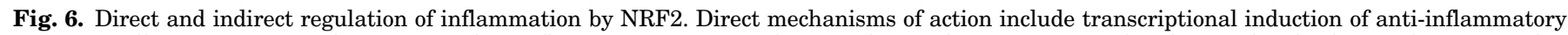

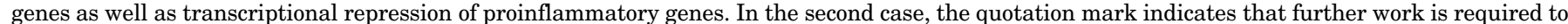

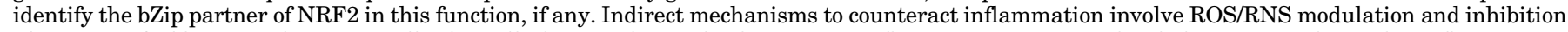

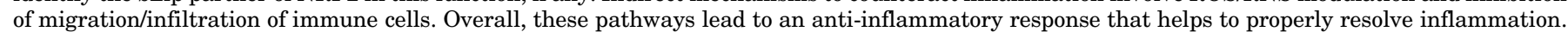

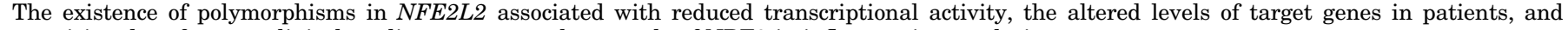
promising data from preclinical studies support a relevant role of NRF2 in inflammation resolution. 
A

NF-кB binding sites in NFE2L2 promoter region

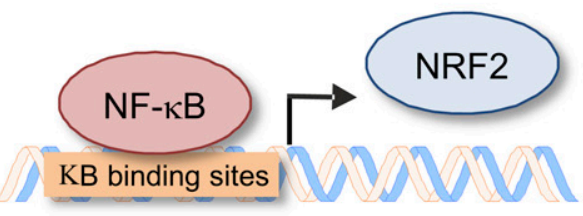

C

(1 KEAP1-dependent degradation of IKK $\beta$

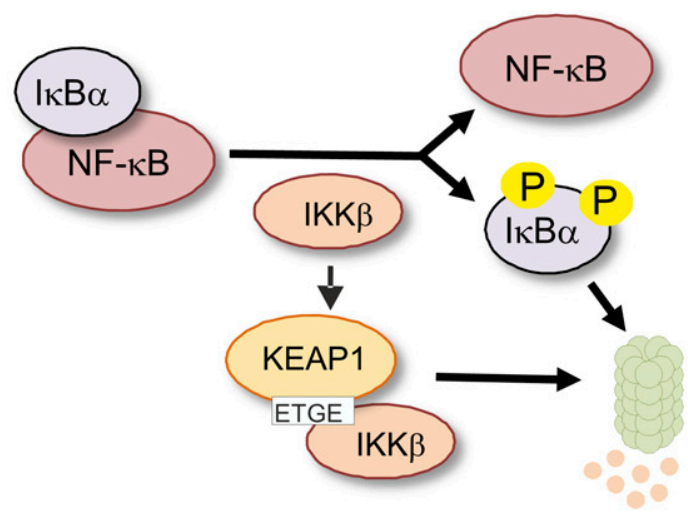

E

ROS modulation

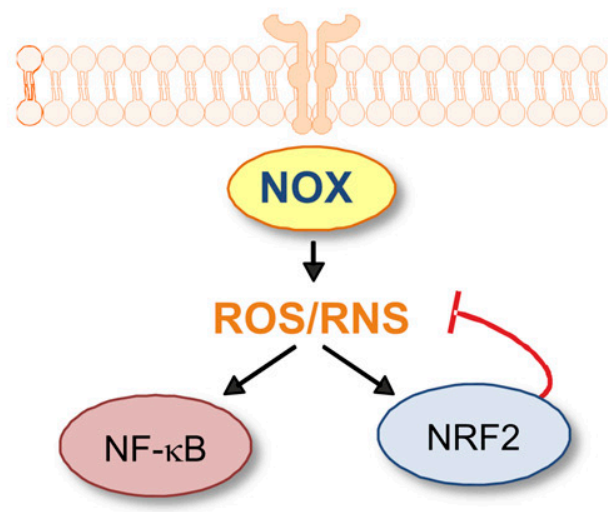

B

Competition for CBP/p300

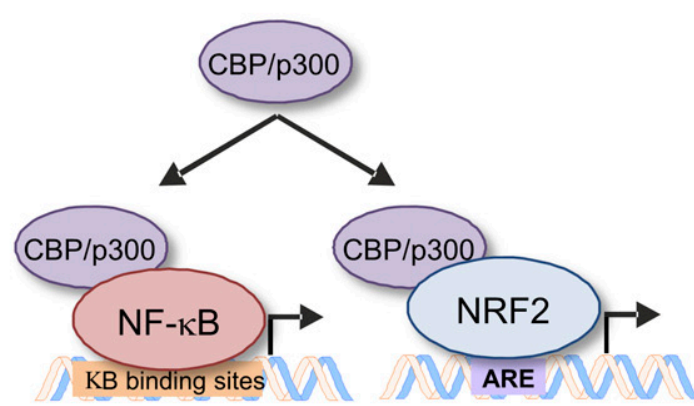

D

NFאB-dependent KEAP1

translocation into the nucleus

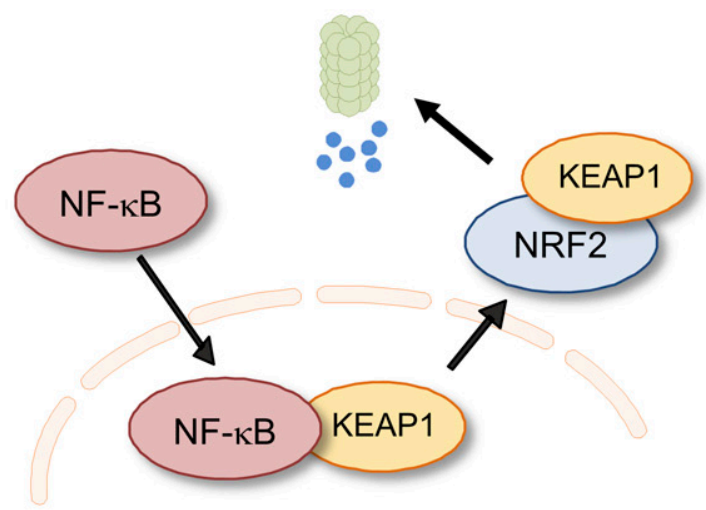

F Signalling pathways

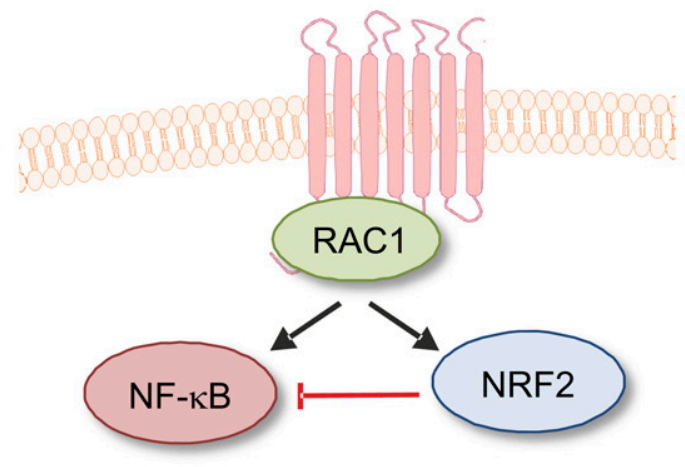

Fig. 7. Crosstalk between NF- $\kappa$ B and NRF2 occurs at different levels. (A) Responsive elements have been identified in the promoter region of NFE2L2. (B) Both NRF2 and NF- $\kappa$ B transcription factors compete for binding to the transcriptional coactivator CREB-binding protein (CBP/p300). (C) The $\mathrm{NF}-\kappa \mathrm{B}$ activating kinase IKK $\beta$ contains an ETGE motif allowing KEAP1 binding and subsequent ubiquitin-proteasome degradation. (D) NF- $\kappa \mathrm{B}$ was reported to bind and translocate KEAP1 to the nucleus, thereby promoting NRF2 degradation. (E) ROS produced during inflammation activate NF- $\kappa$ B and NRF2; finally, NRF2 attenuates ROS and consequently NF- $\kappa$ B activity. (F) Different proinflammatory signals activate the Rho GTPase RAC1, which leads to NF- $\kappa$ B and NRF2 activation. Then NRF2 inhibits RAC1-mediated activation of NF- $\kappa$ B.

lipoprotein (Harvey et al., 2011; Ishii and Mann, 2014). Similarly, the gene encoding the proinflammatory cytokine, IL-17D, contains AREs, and this NRF2-T helper (Th)17 axis seems to confer protection against tumorigenesis and viral infections (Saddawi-Konefka et al., 2016).
Chronic inflammatory processes involve adhesion of leukocytes to the vascular endothelium and infiltration into the damaged tissue. Both processes appear to be modulated by NRF2 together with at least one of its target genes HMOX1, coding heme oxygenase-1 (HO-1). The NRF2/HO-1 axis inhibits adhesion of inflammatory 
cells to the endothelium by modulating the expression of several cell adhesion molecules such as vascular cell adhesion molecule 1 (Banning and Brigelius-Flohe, 2005; Wenzel et al., 2015). Additionally, NRF2/HO-1 inhibits metalloproteinase- 9 in macrophages that are necessary for migration of immune cells within tissues (Bourdonnay et al., 2009).

Numerous preclinical studies have reported that activation of NRF2 by natural compounds (Satoh et al., 2013) or by disrupting its negative regulator KEAP1 leads to potent anti-inflammatory effects in myeloid leukocytes (Kong et al., 2011) and macrophages (Lin et al., 2008). In observational studies, a polymorphism in NFE2L2 was associated with reduced transcriptional activity correlating with increased risk of inflammatory bowel disease (Arisawa et al., 2008b) and chronic gastritis (Arisawa et al., 2007). One example of the immune modulatory action of NRF2 is provided in the central nervous system. Injured neurons release fractalkine, a chemokine that specifically activates the phosphatidylinositol 3 kinase/AKT (PI3K/AKT) pathway in microglia, resulting in inhibition of GSK-3 $\beta$ and upregulation of NRF2 (LastresBecker et al., 2014). In this study, necropsies from AD and progressive supranuclear palsy patients exhibited a compensatory increase in fractalkine levels together with upregulated NRF2 protein, suggesting that this pathway contributes to limiting the inflammatory response in the diseased brain.

\section{B. Nuclear Factor (Erythroid-Derived 2)-Like 2 in Autoimmune Diseases}

At the periphery of the NRF2 diseasome cluster, we found several autoimmune disease phenotypes, such as vitiligo, asthma, multiple sclerosis (MS), and systemic lupus erythematosus (SLE). Indeed, extensive work in animal models of experimental autoimmune encephalomyelitis (EAE) and rheumatoid arthritis (RA), as well as clinical evidence in MS and psoriasis further points to a role of NRF2 in autoimmune diseases. Oxidative tissue damage and apoptosis may increase the generation of autoantigens, leading to activation of $\mathrm{T}$ cells and production of autoantibodies by B cells, e.g., as observed for 3-nitrotyrosine-positive proteins (Thomson et al., 2012). In addition, loss of phase II detoxification enzymes, many of which are transcriptionally regulated by NRF2, results in increased production of reactive intermediates that contribute to formation of haptens or damaged macromolecules that sometimes become immunogenic, increasing hence the pool of autoantigens that trigger autoimmune reactions. Because NRF2regulated enzymes play a critical role in the detoxification of many chemicals, it is conceivable that NRF2 may be a protective mechanism against the environmental contribution to autoimmune pathogenesis (Ma, 2013). Potential mechanisms for NRF2-mediated regulation of autoimmunity also involve suppression of proinflammatory Th1 and Th17 responses and activation of immunosuppressive T regulatory (Treg) and Th2 ones. There is also increasing evidence that NRF2 may control the differentiation and function of dendritic cells (DCs) and macrophages involved in antigen presentation and regulation of adaptive immune responses. In fact, NRF2 deficiency was shown to alter the function and phenotype of DCs by increasing the expression of costimulatory molecules and consequently the antigenspecific $\mathrm{T}$ cell reactivity (Al-Huseini et al., 2013).

MS is a chronic inflammatory disease characterized by infiltration of autoreactive immune cells into the central nervous system. The absence of NRF2 exacerbates the development of EAE, which is a mouse model of MS (Johnson et al., 2010). Part of the effects associated with NRF2 deficiency may be related to the reduced levels of HO-1. Thus, mice with a myeloidspecific HO-1 deficiency exhibited higher incidence of lesions, accompanied by activation of antigenpresenting cells and infiltration of inflammatory Th17 and myelin-specific T cells (Tzima et al., 2009). Knockdown of KEAP1 (Kobayashi et al., 2016) or treatment with a wide range of small molecules that activate NRF2 (Buendia et al., 2016) inhibited the development and severity of disease. NRF2 is strongly upregulated in active MS lesions, and the expression of NRF2responsive genes is predominantly found in areas of initial myelin destruction (Licht-Mayer et al., 2015). In MS brains, NRF2 and its targets NADPH:quinone oxidoreductase (NQO1) and HO-1 are mainly expressed in infiltrating macrophages and to a lesser extent in astrocytes, most likely as a compensatory response against pathologic ROS formation. In contrast, there is a lack of NRF2 and antioxidant gene expression in oligodendrocytes, and this may underlie their damage and loss in MS (van Horssen et al., 2010). As a consequence of the altered immune and redox homeostasis, HO-1 expression is reduced in peripheral blood mononuclear cells of MS patients and is downregulated during exacerbation of the disease (Fagone et al., 2013). Of note, gene expression profiling in interferon- $\beta$-treated patients identified NRF2 as a potential mediator of longterm antioxidant response and neuronal preservation (Croze et al., 2013).

SLE is underlined by high oxidative environment, deregulated cell death, and defects in removal of dead cells, which leads to cell necrosis as source of autoantigens. Female mice deficient in NRF2 develop with age a multiorgan autoimmune disorder similar to SLE, characterized by increased DNA oxidation, lipid peroxidation, splenocyte apoptosis, presence of antibodies against double-strand DNA and the Smith antigen, along with important tissue damage (vasculitis, glomerulonephritis, hepatitis, and myocarditis) (Li et al., 2004). The fact that only female mice show progression to SLE suggests that female-specific factors may contribute to break immune tolerance to self-antigens 
(Li et al., 2004). NRF2 deficiency also results in enhanced proliferative responses of $\mathrm{CD}^{+} \mathrm{T}$ cells, altered $\mathrm{CD}^{+} / \mathrm{CD}^{+}$ratio, and promotion of proinflammatory Th17 in SLE (Ma et al., 2006; Zhao et al., 2016). In fact, NRF2 depletion has been associated with Th17 differentiation and function during development of lupus nephritis, which seems to be mediated by regulation of the suppressor of cytokine signaling 3/phosphorylated signal transducer and activator of transcription (STAT)3 pathway and IL- $1 \beta$ signaling (Zhao et al., 2016). In addition, the salivary glands of $N r f 2^{-/-}$mice show intense lymphocyte infiltration, reminiscent of the Sjögren syndrome, which is often associated with SLE (Ma et al., 2006). SLE patients exhibit alterations in repair mechanisms of oxidative DNA damage (Evans et al., 2000), high serum levels of oxidized proteins, apolipoprotein C3 (Morgan et al., 2007), oxidized phospholipids, and autoantibodies against oxidatively modified lipoproteins (Frostegard et al., 2005). NRF2 polymorphisms have not been associated with SLE susceptibility, although the SNP rs35652124 was related to increased risk of nephritis in childhood onset of Mexican females (Cordova et al., 2010).

Rheumatoid arthritis (RA) is a systemic inflammatory disease with a complex but still elusive autoimmune profile, in which neutrophils, macrophages, and lymphocytes are actively recruited and activated in the inflamed joints. This results in increased secretion of proinflammatory mediators such as ROS/RNS, eicosanoids, cytokines (IL-17, TNF- $\alpha$, interferon- $\gamma$, IL-6, and IL- $1 \beta$ ), and catabolic enzymes that trigger hyperproliferation of synovial fibroblasts, joint swelling, and progressive destruction of cartilage and bone (Roberts et al., 2015). Deletion of the NRF2 gene increases vulnerability to joint alterations in experimental RA models. For instance, in mice expressing the $\mathrm{T}$ cell receptor $\mathrm{KRN}$ and the major histocompatibility complex class II molecule $\mathrm{A}(\mathrm{g} 7)$ (the $\mathrm{K} / \mathrm{B} \times \mathrm{N}$ arthritis model), and in antibody-induced arthritis, NRF2 deficiency accelerates the incidence and aggravates the disease course (Maicas et al., 2011; Wu et al., 2016b). NRF2 deficiency dramatically upregulates migration of inflammatory cells, expression of cyclooxygenase- 2 and inducible nitric oxide synthase, production of ROS and RNS, and release of proinflammatory cytokines and chemokines. Moreover, NRF2 may be a protective factor for bone metabolism in arthritis (Maicas et al., 2011), and NRF2/HO-1 activation exerts anti-inflammatory and antioxidant effects in animal models of RA and in human synovial fibroblasts (Wu et al., 2016b). It is interesting that antirheumatic gold(I)-containing compounds that stimulate the antioxidant response through activation of NRF2 and upregulation of HO-1 and GCLC proved clinical efficacy in RA (Kobayashi et al., 2016). Moreover, NRF2/HO-1 activation mediates the induction of synovial cell apoptosis and inhibition of proinflammatory cytokine production by cilostazol (Park et al., 2010) as well as the anti-inflammatory effects of $\mathrm{H}_{2} \mathrm{~S}$ and related compounds, which are able to modify by sulfhydration the cysteine residues of KEAP1 (Wu et al., 2016b). Other drugs that induce NRF2 and HO-1 signaling, such as rebamipide, can divert the differentiation of human and murine $\mathrm{CD}^{+} \mathrm{T}$ cells toward an immunosuppressive Treg phenotype and inhibit the differentiation of $\mathrm{TCD}^{+}$cells toward inflammatory Th17 cells through specific inhibition of STAT3 (Moon et al., 2014). Excessive ROS generation within the inflamed synovium appears to contribute to the pathogenesis of RA because patients show a marked increase in ROS formation, lipid peroxidation, protein oxidation, DNA damage, and decrease in the activity of the antioxidant defense mechanisms, all of these contributing to tissue damage and disease progression (Datta et al., 2014). In response to pathologic ROS formation, the NRF2 pathway is activated in synovial cells of RA patients and in joints of antibody-induced arthritic mice, but this response is apparently insufficient to counteract the disease progression (Wu et al., 2016b).

Vitiligo is a skin inflammatory disorder characterized by the accumulation of ROS in the epidermis, which participates in the death of melanocytes. These molecules modify DNA and melanosomal proteins with formation of autoantigens and activation of an autoimmune response against melanocytes (Xie et al., 2016). Genetic studies have revealed associations of NRF2 promoter SNPs with susceptibility to develop vitiligo, such as the SNP at -650 position (Guan et al., 2008), whereas the $\mathrm{C}$ allele of rs35652124 was shown to be associated with protective effects in a Han Chinese population (Song et al., 2016). NRF2 and its downstream detoxification target genes NQO1, GCLC, and GCLM are upregulated in the epidermis of vitiligo patients, suggesting insufficient activation of this defensive mechanism (Natarajan et al., 2010).

\section{Nuclear Factor (Erythroid-Derived 2)-Like 2 in Chronic Respiratory Diseases}

The relevance of NRF2 in respiratory diseases was reviewed in 2010 (Cho and Kleeberger, 2010), and in this work we will highlight only the most relevant findings (Fig. 8). Cigarette smoke is a main risk factor for chronic obstructive pulmonary disease (COPD). COPD patients have dysfunctional alveolar macrophages that lead to uncontrolled ROS production, proinflammatory mediators, defective phagocytosis, and an array of metalloproteinases that participate in tissue damage. In fact, the emphysematous lung tissue shows a direct correlation between alveolar macrophage density in the parenchyma and severity of lung destruction (Finkelstein et al., 1995). Impaired phagocytic activity of alveolar macrophages is a major cause of recurrent bacterial and viral infections that cause acute 


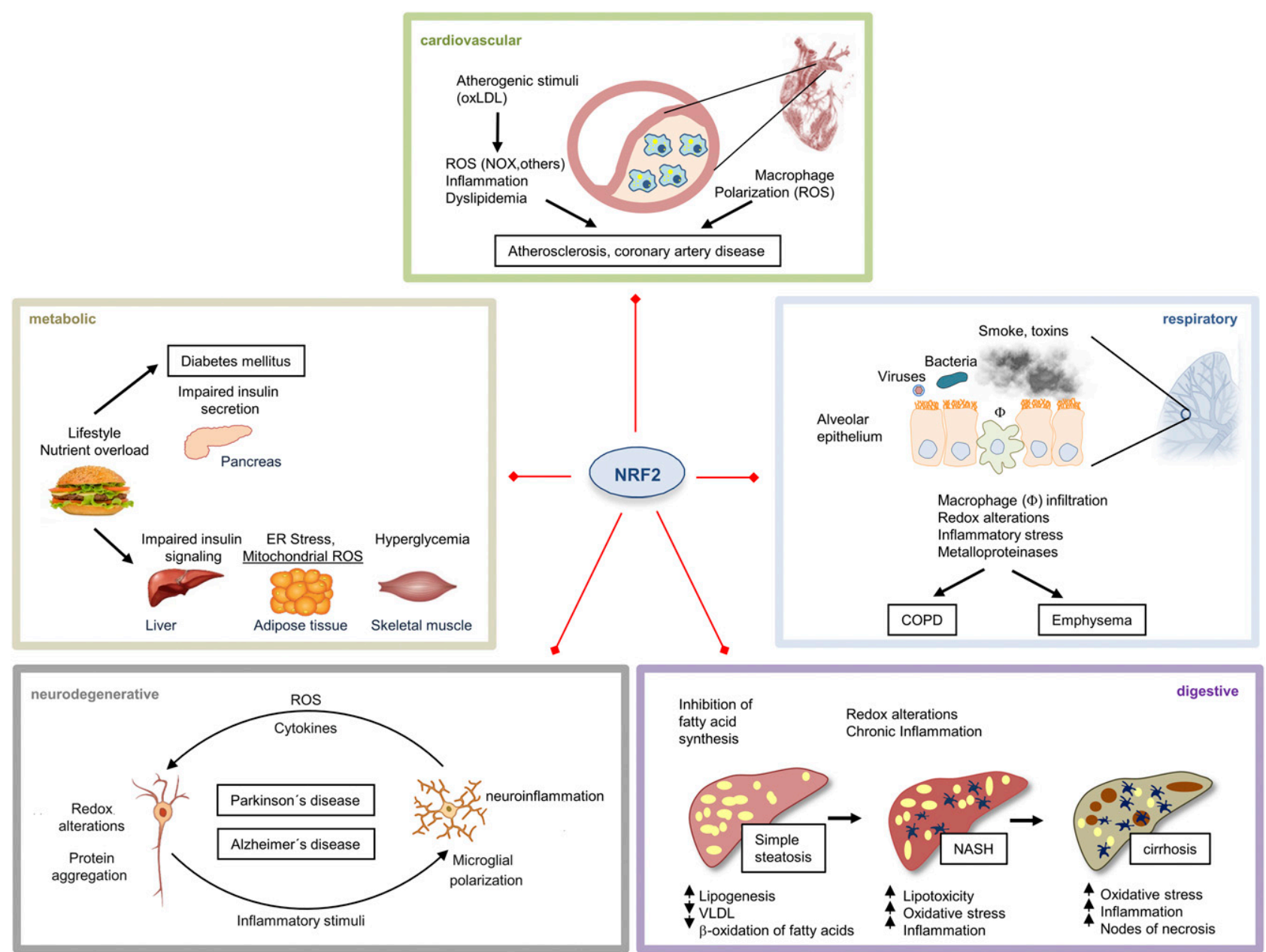

Fig. 8. Role of NRF2 in common mechanisms and pathophenotypes of chronic diseases. The picture provides some examples extracted from the NRF2 diseasome cluster of Fig. 5. Common pathomechanisms of these diseases include abnormally high ROS levels and low-grade chronic inflammation that participate in tissue damage. NRF2 provides a cytoprotective signature against these and other tissue-specific alterations by regulating the expression of numerous cytoprotective genes.

exacerbations of COPD and are a major source of morbidity and mortality. Nrf2 ${ }^{-1-}$ mice exhibit enhanced susceptibility to cigarette smoke-induced emphysema (Rangasamy et al., 2004). Importantly, activation of NRF2 with the isothiocyanate sulforaphane (SFN) restores bacteria recognition and phagocytosis, enhances pulmonary bacterial clearance by alveolar macrophages, and reduces inflammation in wild-type mice, but not in $N r f 2^{-1-}$ mice exposed to cigarette smoke (Harvey et al., 2011). In humans, the transcriptional signature of NRF2 is decreased in alveolar macrophages from patients with smokingrelated lung emphysema as compared with smoking and nonsmoking patients without emphysema (Goven et al., 2008). Decreased NRF2 expression is associated with increased macrophage expression of the lipid peroxidation product 4-hydroxynonenal. In the NFE2L2 promoter, a functional haplotype constituted by three SNPs and one triplet repeat, polymorphism that produces low to medium NRF2 expression (Yamamoto et al., 2004), was associated with increased risk to develop COPD (Hua et al., 2010). The low-expressing haplotypes were significant predictors for developing respiratory failure. Thus, the $-617 \mathrm{~A}$ allele of SNP rs6721961 had a significantly higher risk for developing acute lung injury (Marzec et al., 2007).

Pathologic ROS formation may play a role in the pathogenesis of chronic lung fibrosis. An early study demonstrated that pulmonary fibrosis induced by bleomycin is more severe in $N r f 2^{-/-}$than in wild-type mice (Cho et al., 2004). In fact, wild-type mice induced an antioxidant and anti-inflammatory response by upregulating NRF2, and this could not be achieved in the $N r f 2^{-1-}$ mice. Later, it was verified that patients with idiopathic pulmonary fibrosis or chronic sarcoidosis/hypersensitivity pneumonitis exhibit increased expression of NRF2 and augmented levels of low-mol. wt. antioxidants in bronchoalveolar lavage fluids, such as uric acid, ascorbic acid, retinol, and $\alpha$-tocopherol, suggesting an unsuccessful adaptive response to the ROS challenge (Markart et al., 2009). Mechanistically, NRF2 deficiency increases myofibroblast differentiation, whereas pharmacological induction of NRF2 with SFN results in lower number of myofibroblasts and 
attenuation of the profibrotic effects of transforming growth factor- $\beta$ (TGF- $\beta$ ) (Artaud-Macari et al., 2013).

\section{Nuclear Factor (Erythroid-Derived 2)-Like 2 in the Digestive System}

The prominent position of pathophenotypes of the digestive system in the NRF2 diseasome highlights the relevance of the transcriptional signature of NRF2 as a potent adaptive mechanism to chronic oxidative damage and inflammatory stress triggered by xenobiotics. In the gastrointestinal tract (GI), chronic exposure to xenobiotics triggers dysfunctional interactions between the microbiota of the intestinal lumen and the immune system (Aviello and Knaus, 2017). This can lead to chronic diseases of the GI tract, like the inflammatory bowel disease (IBD) phenotypes comprising Crohn's disease and ulcerative colitis, in which there is evidence of activation of a protective NRF2 response. For instance, in colonic tissues from IBD patients, colon epithelial cells responded to inflammatory signals through a NRF2-dependent adaptation that was associated with increased proteasome protein expression (Kruse et al., 2016). Monocyte-derived macrophages from IBD patients evidenced a specific NRF2dependent gene expression profile that was exacerbated in response to LPS, further suggesting an attempt to attenuate the inflammatory challenge (Baillie et al., 2017). At the genetic level, a particular genotype of the NFE2L2 gene (-686-684) was associated with the development of ulcerative colitis, especially in females, in a Japanese cohort (Arisawa et al., 2008a). In fact, pathologic processes in the GI are highly dependent on the genetic background of the host in relation with dysfunctional interaction between the microbiota of the intestinal lumen and the immune system (Aviello and Knaus, 2017).

One of the symbiotic effects of the microbiota of the GI is to release moderate amounts of ROS that elicit a cytoprotective response mediated by NRF2 in epithelial colonocytes and infiltrating immune cells (Jones et al., 2015). Moreover, cytoprotective molecules that are under the transcriptional control of NRF2 in eukaryotes can also be produced by commensal bacteria. For instance, the HO-1 homologs in the microbiota may greatly contribute to GI homeostasis, and this can be therapeutically exploited for local delivery of carbon monoxide to the intestine (Onyiah et al., 2014).

The proven involvement of NRF2 in maintaining GI homeostasis makes this transcription factor a promising therapeutic target in IBD. Thus, several chemical compounds and dietary supplements might exhibit beneficial effects, like melatonin, 3-(3-pyridylmethylidene)-2indolinone, butyrate, Lactobacillus casei, L-carnitine, 4-vinyl-2,6-dimethoxyphenol (canolol), lacto-wolfberry (formulated product of wolfberries in skimmed milk), etc. (Orena et al., 2015). Therefore, it is of utmost importance to define the involvement of NRF2 in chronic and acute diseases of the GI tract for better guidance on the therapeutic approach for modulating the NRF2 pathway.

The liver is also a first line of defense against food xenobiotics. Therefore, it is not surprising that the NRF2 diseasome highlights the relevance of this transcription factor in pathophenotypes associated with liver damage. Early work with the $\mathrm{Nrf2}^{-/-}$mouse model demonstrated its protective effect against acetaminopheninduced hepatocellular injury, benzo[a]pyrene-induced tumor formation, and Fas- and TNF- $\alpha$-mediated hepatocellular apoptosis (Aleksunes and Manautou, 2007). The higher sensitivity of $\mathrm{Nrf2}^{-/-}$mice to chemical toxicity correlated with reduced basal and inducible expression of detoxification enzymes. In humans, the functional haplotype of three NRF2 promoter SNPs that result in reduced NRF2 expression was significantly associated with development of gastric mucosal inflammation, either independently or by interacting with Helicobacter pylori infection (Arisawa et al., 2007). Analysis of the transcriptional signature of NRF2 in patients with primary biliary cholangitis indicated that these patients exhibit reduced NRF2 expression together with low levels of HO-1 and GCLC proteins, and these impairments are more advanced in patients with cirrhosis (Wasik et al., 2017).

Pathologic ROS formation is a key mechanism of hepatocellular injury and disease progression in patients with nonalcoholic steatohepatitis (NASH) (Fig. 8). This disease evolves in two phases, one of progressive accumulation of fatty acids in hepatocytes and a second that involves liver injury and inflammatory pathologic ROS formation (Wang et al., 2018). Accordingly, mice fed with a high-fat diet (HFD) developed a simple steatosis, characterized by increased hepatic fat deposition without inflammation or fibrosis, but $\mathrm{Nrf2}^{-/-}$ mice presented exacerbated hepatic steatosis and substantial inflammation, consistent with NASH (Reccia et al., 2017). It is interesting, however, that the hepatocyte-specific KEAP1 deletion, while reducing liver steatosis, did not alter inflammation during development of NASH, suggesting a compensatory mechanism (Ramadori et al., 2016). At least in the rat model of NASH, dietary NRF2 activators attenuate the progression of liver fibrosis (Shimozono et al., 2013). Markers of pathologic ROS formation were increased in liver biopsies of NASH patients, and the NRF2 signature was increased, suggesting an attempt to reduce the oxidant and inflammatory burden (Takahashi et al., 2014).

\section{E. Nuclear Factor (Erythroid-Derived 2)-Like 2 in the Cardiovascular System}

The NRF2 diseasome cluster points to the high susceptibility of the cardiovascular system to changes in the cellular redox balance and the development of well-known comorbidities like atherosclerosis, hypertension, and diabetes (Griendling and FitzGerald, 2003a,b; Harrison et al., 2003; Jay et al., 2006) 
(Fig. 8). A role of NRF2 in preventing these pathophenotypes has been demonstrated in $N r f 2^{-1-}$ mice, which exhibit impaired cardiac structure (more remodeling events) and function (less fractional shortening) in response to chronic endurance exercise (Shanmugam et al., 2017a). They are also more susceptible to develop heart failure after myocardial infarction (Strom and Chen, 2017). In contrast, constitutive activation of NRF2 creates a reductive state, characterized by increased cardiac GSH/glutathione disulfide ratio and decreased ROS formation and malondialdehyde levels (Shanmugam et al., 2017b). In humans, microarray analysis in Tako-Tsubo cardiomyopathy indicated an increase in pathologic ROS levels and a compensatory upregulation of NRF2 during the acute phase of this contractile dysfunction (Nef et al., 2008). Recently, systemic inflammation and pathologic ROS formation in hemodialysis patients were associated with downregulation of NRF2 (Pedruzzi et al., 2015), and two promoter polymorphisms (rs35652124 and rs6721961) were associated with increased risk of mortality in these patients (Shimoyama et al., 2014).

One of the most relevant targets of NRF2 in endothelial homeostasis is HO-1, which is usually paralleled by upregulation of ferritin, hence decreasing free iron levels and preventing Fenton-type reactions. Bilirubin, which is generated from the combined activity of HO-1 and biliverdin reductase, is one of the most powerful endogenous antioxidants that scavenges ROS/RNS (Jansen et al., 2010), and is highly efficient in preventing lipid peroxidation in vitro (Stocker et al., 1987). Hmox $1^{-1-}$ mice show increased pulmonary hypertension in response to chronic hypoxia (Christou et al., 2000), and pharmacological HO-1 induction improves diabetic complications (Kruger et al., 2006), as well as nitroglycerin-induced vascular dysfunction (nitrate tolerance) (Wenzel et al., 2007). Recently, Hmox $1^{-1-}$ mice were shown to display upregulated NADPH oxidase-2, vascular pathologic ROS formation, markers of inflammation, endothelial dysfunction, and higher blood pressure in response to angiotensin-II (Wenzel et al., 2015). In fact, high serum levels of bilirubin are inversely correlated with the incidence of coronary artery disease (Hopkins et al., 1996). Bilirubin prevents the activation of the vascular NADPH oxidase (Kwak et al., 1991), involved in the development of cardiovascular diseases (Griendling and FitzGerald, 2003a,b; Harrison et al., 2003; Jay et al., 2006). Patients suffering from peripheral artery disease, which is a common manifestation of atherosclerosis, present reduced levels of HO-1 (Signorelli et al., 2016).

\section{F. Nuclear Factor (Erythroid-Derived 2)-Like 2 in Metabolic Diseases}

Type 2 diabetes mellitus (T2DM) is one of the most common chronic metabolic diseases and is highly underlined in the NRF2 diseasome. Pathologic ROS formation in insulin-sensitive tissues, as well as in pancreas, has been found in T2DM patients, resulting in severe impairment of both insulin secretion by pancreatic $\beta$ cells and insulin action in peripheral tissues (Uruno et al., 2015) (Fig. 8). Likewise, pathologic ROS levels also contribute to the pathogenesis of diabetic complications due to nonenzymatic glycation of proteins. This has been evidenced in diabetic nephropathy, in which the glomeruli exhibit pathologic ROS levels and a compensatory elevation of NRF2 (Jiang et al., 2010). Since 2007, several studies have addressed the role of NRF2 in T2DM and its complications using animal models and cell lines. In vitro studies in human cells reported that NRF2 activation is achieved with acute exposure to high glucose, whereas longer incubation times or oscillating glucose concentration failed to activate NRF2 (Ungvari et al., 2011; Liu et al., 2014). Accordingly, these studies pointed out that NRF2 activation is dependent on glucose concentration and dynamics. In contrast, NRF2 is downregulated in peripheral blood mononuclear cells of prediabetic and diabetic patients, suggesting that NRF2 could be an important therapeutic target (Jimenez-Osorio et al., 2014).

The impact of NRF2 deficiency on hyperglycemia was first shown in $\mathrm{Nrf2}^{-/-}$mice, where oxidative and nitrosative alterations were enhanced and led to early-stage renal injury (Yoh et al., 2008). In a subsequent study, streptozotocin-induced diabetic $N r f 2^{-/-}$mice exhibited exacerbated glomerular injury, together with high ROS production and increased expression of the profibrotic markers TGF- $\beta$ and fibronectin (Jiang et al., 2010). In this diabetic model, NRF2 protected against dysfunction of the blood-retina barrier and the progression of diabetic retinopathy (Xu et al., 2014). Likewise, HFD-induced increase in vascular ROS levels was significantly exacerbated in $\mathrm{Nrf2}^{-1-}$ mice and was accompanied by a severe endothelial dysfunction, as shown by diminished acetylcholine-induced relaxation of aorta and increased expression of intercellular adhesion molecule-1 and TNF- $\alpha$ (Ungvari et al., 2011).

NRF2 plays a complex role in tissue-specific insulin resistance. Thus, HFD-fed $N r f 2^{-1-}$ mice displayed better insulin sensitivity due to enhanced insulin signaling in liver and skeletal muscle than their wildtype counterparts, but conversely, these mice developed a severe NASH due to excessive hepatic lipotoxicity linked to pathologic ROS formation (Meakin et al., 2014). Accordingly, this study dissociated hepatic insulin resistance from the development of NASH. In light of these data, a subsequent study demonstrated that the livers of HFD-fed $\mathrm{Nrf2}^{-1-}$ mice exhibited higher pathologic ROS formation by a significant depletion of GSH due to attenuated expression of the CYP2A5 enzyme (Cui et al., 2013). The knockdown of NRF2 in hepatocytes enhanced the apoptosis induced by palmitate, a fatty acid that is highly elevated in insulin-resistant 
obese patients. This effect was correlated with increased production of pathologic ROS, again reinforcing the key role of NRF2 in the progression of NASH (Pilar Valdecantos et al., 2015).

To further examine the role of NRF2 in the metabolic syndrome, NRF2 was ablated in leptin-deficient (ob/ob) mice, a model with an extremely positive energy balance (Xue et al., 2013). Interestingly, global ob/ob/Nrf2 ${ }^{-1-}$ mice or adipocyte-specific ob/ob/Nrf2 ${ }^{-/-}$mice displayed reduced white fat mass, revealing NRF2 as a key player in adipogenesis. These mice had an even more severe metabolic syndrome that was characterized by hyperlipidemia, aggravated insulin resistance, and hyperglycemia, suggesting a mechanistic linkage between the metabolic syndrome and pathologic ROS formation.

Another subset of studies has evaluated the effects of persistent induction of NRF2 in glucose metabolism. Genetic NRF2 induction making use of a hypomorphic allele of Keap1 (Keap1flox/- mutant) decreased blood glucose in the obese diabetic $\mathrm{db} / \mathrm{db}$ mice by suppressing hepatic glucose 6 phosphatase through the repression of cAMP-CREB signaling in hepatocytes, as well as other gluconeogenic genes, such as peroxisome proliferatoractivated receptor coactivator- $1 \alpha$ (Uruno et al., 2013). Additionally, enhancement of NRF2 activity in Keap11knocked down mice increased the phosphorylation of AMP-activated protein kinase (AMPK) in the liver, as well as insulin signaling in skeletal muscle, resulting in a substantial improvement of glucose tolerance $(\mathrm{Xu}$ et al., 2013). Due to the pleiotropic activities of NRF2 in the context of T2DM, the results of all these and other studies have evidenced the need to design multiple genetic and pharmacological strategies to elucidate the full array of NRF2 functions in tissues involved in the control of whole-body glucose homeostasis.

In addition to diabetic factors like age, body weight, and blood glucose, genetic factors that are linked to NRF2 have been poorly studied in humans. In a Chinese population, the SNP rs6721961 has been associated with pathologic ROS formation and risk of newly diagnosed T2DM and may also contribute to impaired insulin secretory capacity and increased insulin resistance (Wang et al., 2015). The same SNP was associated with diabetes in Mexican mestizo men (Jimenez-Osorio et al., 2017). In a case-control study performed with Han volunteers, a significant difference in genotypic and allelic frequencies of four SNPs of the NFE2L2 gene was found between T2DM patients with and without complications, including peripheral neuropathy, nephropathy, retinopathy, foot ulcers, and microangiopathy (Xu et al., 2016b).

\section{G. Nuclear Factor (Erythroid-Derived 2)-Like 2 in Neurodegenerative Diseases}

The NRF2 diseasome provides evidence of NRF2 involvement in several neurodegenerative diseases, including $\mathrm{AD}$ and $\mathrm{PD}$, which represent the most prevalent cognitive and motor disorders of the elderly. In neurodegenerative diseases, the connection between low-grade pathologic ROS formation and proteostasis is particularly relevant because most of these pathophenotypes are characterized by abnormal aggregation of specific proteins (Fig. 8). Evidence pointing to pathologic ROS formation in proteinopathy, as well as NRF2 as regulator of proteasome and autophagy was provided in cellular and animal models (Pajares et al., 2017). Initially, it was reported that the autophagy cargo protein sequestosome 1 (SQSTM1) competes with NRF2 for binding to KEAP1. SQSTM1 takes KEAP1 to the autophagosome degradative pathway, therefore upregulating NRF2 (Komatsu et al., 2010). More recently, it was found that NRF2 regulates the expression of autophagy genes involved in autophagy initiation, cargo recognition, elongation, and autolysosome clearance (Pajares et al., 2016). In this study, amyloidopathy and tauopathy induced by transgene overexpression of human mutant amyloid precursor protein and tau were aggravated in $\mathrm{Nrf2}^{-1-}$ mice. A connection between NRF2 deficiency and neurodegeneration is supported by a growing body of evidence in animal models (Johnson and Johnson, 2015). The general point of view is that damaged neurons try to activate NRF2-dependent transcription, presumably to increase their own survival. Additionally, upregulation of NRF2 in astrocytes participates in metabolic compensations, including increased supply of GSH for augmenting their proliferative capacity (Bolanos, 2016), whereas NRF2 upregulation in microglia returns this immune cell to a resting state (Rojo et al., 2014a).

Ramsey et al. (2007) evidenced the nuclear localization of NRF2 in dopaminergic neurons of patients with PD. Other studies found that amyloid precursor protein- and tau-injured neurons expressed increased levels of NRF2 and its target SQSTM1, probably as compensatory mechanism to clear these toxic proteins through autophagy (Lastres-Becker et al., 2014; Pajares et al., 2016). In agreement with these results, the levels of HO-1, NQO1, GCLM, and SQSTM1 are increased in $\mathrm{AD}$ and PD brains (van Muiswinkel et al., 2004; Cuadrado et al., 2009; Schipper et al., 2009; LastresBecker et al., 2016). However, there is some controversy in the field, as Ramsey's study described the accumulation of NRF2 in the cytosol of AD-injured neurons, suggesting an impaired capacity of these neurons to upregulate NRF2 transcriptional activity. In addition, the cytoprotective proteins associated with NRF2 expression, such as NQO1 and SQSTM1, were partly sequestered in Lewy bodies, suggesting impaired neuroprotective capacity of the NRF2 signature in PD patients (Lastres-Becker et al., 2016). One possible explanation for this discrepancy could be that the levels of NRF2 and its target genes might change during ageing and disease progression. 
Some SNP haplotypes of NFE2L2 were associated with decreased risk or delayed onset of ALS, AD, or PD. The onset of ALS was analyzed in two studies regarding three functional promoter SNPs that were previously linked to high gene expression. Interestingly, this haplotype was associated with a 4-year delay in onset of ALS (Bergstrom et al., 2014), but another study did not find a clear association (LoGerfo et al., 2014). Regarding $\mathrm{AD}$, one haplotype allele was associated with 2 -year earlier age onset of $\mathrm{AD}$, suggesting that variants of the NFE2L2 gene may affect AD progression (von Otter et al., 2010b). Genetic association of NFE2L2 with PD has been analyzed in more detail. Three SNPs in the NFE2L2 promoter (rs6721961, rs6706649, and rs35652124) were evidenced as protective haplotype in a case-control study (von Otter et al., 2010a). Such haplotype delayed the onset of disease in a Swedish cohort or even reduced the risk of PD in a Polish cohort. These results were supported by four new independent European case-control studies (von Otter et al., 2014), but were not replicated in a Taiwanese population (Chen et al., 2013), suggesting disparity in ethnicities and environmental factors. As an alternative approach, PD cells derived from olfactory mucosa were exposed to smoke extract or pesticide to assess gene-environment interaction, and several SNPs were identified that affect the susceptibility to these toxins (Todorovic et al., 2015). Altogether, it is possible that a slight activation of NRF2, such as that found for some functional haplotypes of the NFE2L2 gene, should be enough to trigger protective mechanisms in the brain.

\section{The Kelch-Like ECH-Associated Protein 1 Paradox in Cancer}

An apparent dichotomy appears to exist in the role of NRF2 in tumorigenesis and further tumor progression. On one hand, by activating biotransformation reactions, NRF2 protects against chemically induced carcinogenesis. Preclinical studies have demonstrated complete protection against aflatoxin $\mathrm{B}(1)$-induced liver cancer after pharmacological activation of NRF2 in rats (Johnson et al., 2014). In contrast, the protective responses elicited by NRF2 provide a growth advantage in established cancers, and this will be the focus of this section.

Constantly increased levels of ROS can sustain tumorigenesis through alteration of genomic stability, along with activation of specific redox signaling circuits and inflammatory processes that favor survival and proliferation of tumor cells (Reuter et al., 2010). Therefore, upregulation of NRF2 represents a mechanism of adaptation of cancer cells to tolerate high ROS levels that propel tumor progression (Schumacker, 2006) as well as to maintain cancer stem cells that are responsible for tumor relapse and formation of distant metastases (Ryoo et al., 2016). For instance, the NRF2 signature in cancer stem cells from human colorectal tumors pointed out protective mechanisms mediated by high levels of GCLC, glutathione peroxidase, and thioredoxin reductase- 1 that underlie the ability of these cells to counteract stressors and chemotherapeutics (Emmink et al., 2013). From this perspective, NRF2 behaves in cancer cells like an oncogene that by inducing chronic activation of ARE-mediated cytoprotective responses affords adaptation to their oxidative environment (Panieri and Santoro, 2016). Several mechanisms of malignant activation of NRF2 have been reported, including somatic mutations, epigenetics, and oncogenic signaling alterations.

Close to 600 somatic mutations have been reported in cancer along the coding sequence of NFE2L2 (Gao et al., 2017). In Fig. 9, we show the results from a dataset of 10,000 cancer patients (Zehir et al., 2017). In most cases, these mutations alter the interaction of the DLG and ETGE motifs of NRF2 with KEAP1, hence inducing hyperactivation of NRF2 in several solid tumors, including esophagus, skin, lung, and larynx carcinomas (Kim et al., 2010b; Taguchi and Yamamoto, 2017). For instance, in advanced esophageal squamous cancer, gain-of-function mutations of NRF2 were associated with tumor recurrence and poor prognosis due to increased proliferation, attachmentindependent survival, and resistance to chemo- and radiotherapy (Shibata et al., 2011). Loss-of-function mutations in the KEAP1 gene are also frequent in some solid tumors such as lung cancer (Singh et al., 2006). Based on the strong evidence that this pathway regulates $\beta$-TrCP/NRF2, it is strange that disrupting somatic mutations have not been found at the interface between NRF2 and $\beta$-TrCP. This fact suggests that such mutations are not viable for unknown reasons or that the increase in NRF2 levels that would result from the escape of $\beta$-TrCP is not sufficient to drive oncogenicity.

Nonetheless, somatic mutations account for chronic NRF2 activation only in a fraction of cancer patients. At the level of gene expression, it is interesting that an allele of the SNP rs6721961 ( $-617 \mathrm{C}>\mathrm{A})$ located at the ARE enhancer of the human NRF2 gene abolished selfinduction of NRF2, and this correlated with remarkable survival of these cancer patients (Okano et al., 2013). Epigenetic changes due to promoter hypermethylation of three CpG sites of KEAP1 have been described in lung tumors, resulting in consequent NRF2 activation that could be reversed by 5 -aza- 2 -deoxycitydine treatment (Wang et al., 2008). The role of miRNAs in the posttranscriptional regulation of NRF2 levels has been reviewed recently (Kurinna and Werner, 2015). Briefly, miR200a targets the KEAP1 mRNA in human breast cancer cells, leading to its degradation and consequent activation of NRF2 (Eades et al., 2011). In turn, miR28 facilitates the degradation of the NRF2 mRNA (Yang et al., 2011). 
A

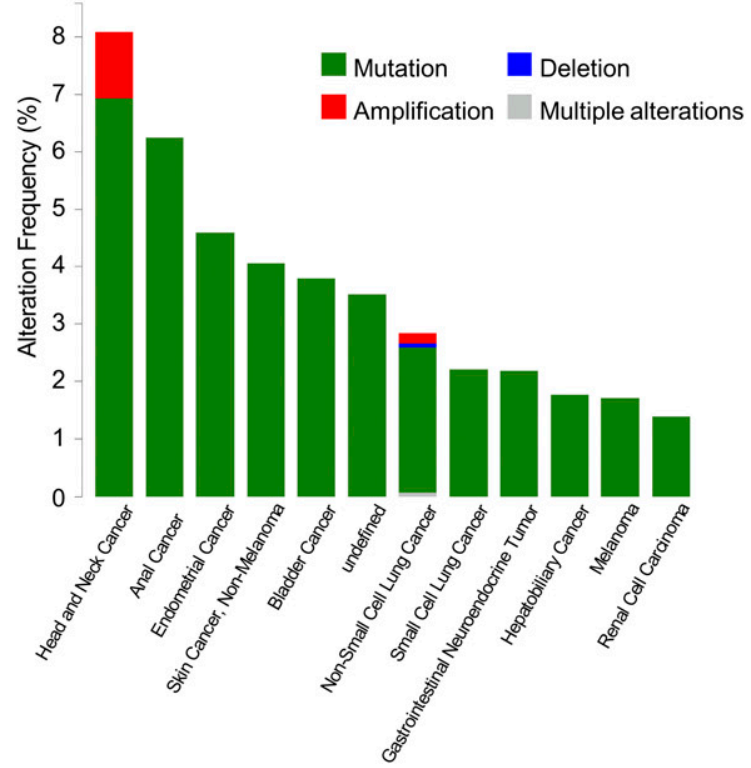

B

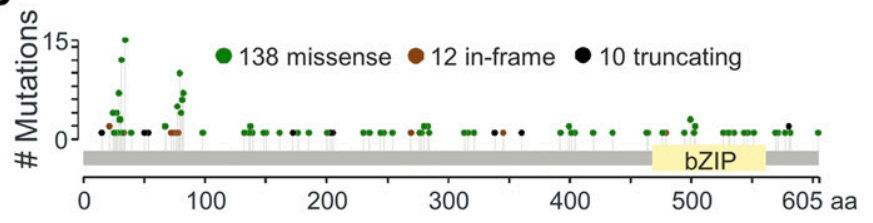

C

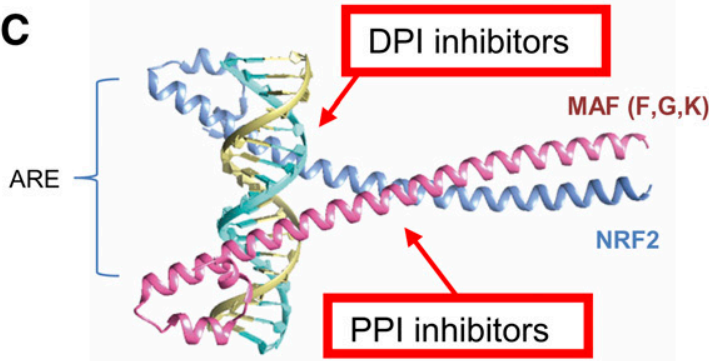

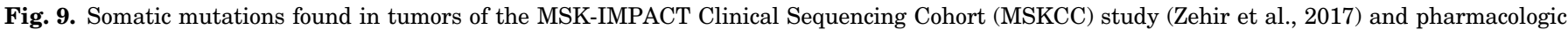

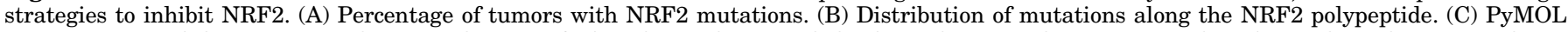

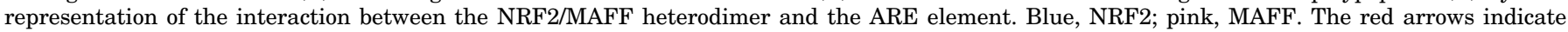

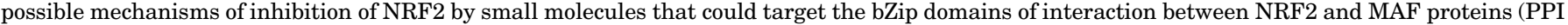
inhibitors) or the interface of interaction of the NRF2-MAF heterodimer with the ARE [DNA-protein interaction (DPI)].

Oncogenes or mutated tumor suppressors may enhance the activation of NRF2 in cancer. Endogenous oncogenic alleles of KRAS, BRAF, or c-MYC upregulate NRF2, presumably through oncogene-mediated ROS generation and consequent chronic inactivation of KEAP1 (DeNicola et al., 2011). The mutated form of the tumor suppressor p53, which sustains the growth of cancer cells by enhancing nutrient uptake and synthesis of building blocks, can also upregulate NRF2, possibly through the crosstalk with the Sp1 transcription factor that binds to the NRF2 promoter (Tung et al., 2015).

The phosphorylation of NRF2 (phospho-NRF2) by various protein kinases is a potential mechanism of activation in 107 hepatocellular carcinomas. Increased levels of phospho-NRF2 were associated with reduced KEAP1 expression and poor 5-year overall survival of patients exhibiting this distinctive phenotype (Chen et al., 2016). Additionally, mutations in the phosphatase and tensin homolog (PTEN) tumor suppressor sustain hyperactive and oncogenic phosphatidylinositol-3-kinase (PI3K)-AKT signaling and consequent increase in NRF2 activity due to the downregulation of the PTEN/GSK-3/ $\beta$-TrCP pathway for the proteasomal degradation of NRF2 (Rada et al., 2011, 2012; Cuadrado, 2015). Therapeutic interventions targeting the PTEN/GSK-3/ $\beta$-TrCP pathway should take into consideration that GSK-3 may act both as tumor suppressor and tumor promoter, and is also implicated in the generation of cancer stem cells (McCubrey et al., 2014).

Some stress-induced proteins interact with KEAP1 and thus compete with its NRF2 binding in cancer cells.
Consequently, NRF2 escapes KEAP1-mediated degradation. One of the NRF2 competitors for KEAP1 binding is the phosphorylated form of the autophagy-adaptor protein SQSTM1 that occurs during selective autophagy used by cancer cells for sustaining their own growth (Shimizu et al., 2016). The cyclin-dependent kinase inhibitor $\mathrm{p} 21$ that promotes cell cycle arrest in cancer stem cells was also demonstrated to inhibit the association of NRF2 with KEAP1 through the interaction of its KRR motif with DLG and ETGE motifs in NRF2 (Chen et al., 2009). Recently, it was shown that dipeptidyl-peptidase 3, which bears an ETGE motif, may compete with NRF2 for binding to KEAP1 (Hast et al., 2013). Overexpression of dipeptidyl-peptidase 3, possibly induced by chronic alteration of the redox status, correlates with increased expression of ARE genes and poor prognosis, particularly in estrogen receptor-positive breast cancer (Lu et al., 2017).

NRF2 induces metabolic changes that contribute to cancer progression. For instance, a multiplatform nontargeted metabolomics study identified patterns of metabolite changes in breast tumor samples (Tang et al., 2014). They found that GSH and 3-(4hydroxyphenyl)lactate were positively correlated with the involvement of BRCA1 in redox homeostasis through interaction with NRF2. Metabolomics studies also indicate that NRF2 can increase aerobic glycolysis in cancer cells to support their high-energy requirements. This occurs through NRF2-mediated induction of $\mathrm{Mn}$-superoxide dismutase expression, leading to elevated mitochondrial production of hydrogen peroxide 
and to activation of AMPK. The process is regulated by caveolin-1, which binds directly to both NRF2 and KEAP1, and impedes on NRF2 activation and hence on the glycolytic shift. This is apparently one explanation why glycolytic tumors, which are generally more aggressive, have a caveolin- $1^{\text {low}} / \mathrm{Mn}$-superoxide dismutase $^{\text {high }}$ phenotype (Hart et al., 2016). NRF2 can also drive glucose and glutamine toward anabolic pathways required for tumor cell proliferation (Mitsuishi et al., 2012). In the presence of active PI3K-AKT signaling and loss of KEAP1 activity, NRF2 was shown to induce the shift of glucose metabolism from glycolysis toward anabolic pathways (purine synthesis) in cancer (Mitsuishi et al., 2012; Xu et al., 2016a). This is underlined by NRF2-mediated transcription of genes involved in the pentose phosphate pathway and generation of NADPH (glucose 6 phosphate dehydrogenase; phosphogluconate dehydrogenase, malic enzyme 1 , isocitrate dehydrogenase 1 , transketolase, and transaldolase), along with genes involved in purine nucleotide synthesis (phosphoribosyl pyrophosphate amidotransferase, methylenetetrahydrofolate dehydrogenase 2 ).

The fact that activation of NRF2 confers a growth advantage to cancer cells might argue that its pharmacologic activation in chronic diseases presented in this work might imply a high risk of developing cancer. However, it must be considered that the oncogenic activity of NRF2 requires mutations in its gene or in $K E A P 1$, which results in very high and persistent induction of NRF2 signaling. This is not the case in pharmacological therapy, in which it is possible to modulate drug dosing and NRF2 activity. Moreover, empirical evidence indicates that subjects enrolled in clinical trials with NRF2 activators do not exhibit increased cancer risk. This is best exemplified in the case of patients with MS, who have been taking the NRF2 activator dimethyl fumarate for several years since it was approved by the regulatory agencies in 2013. Conversely, the use of NRF2 inhibitors in cancer patients might lead to manifestation of the pathophenotypes described in the NRF2 diseasome. This is a possibility that will need further investigation when NRF2 inhibitors reach the clinic.

\section{Nuclear Factor (Erythroid-Derived 2)- Like 2 Drugome}

This section attempts to develop a NRF2 drugome that might be useful for future clinical directions to target therapeutically NRF2 centered on the pathophenotypes of the NRF2 diseasome. As stated in Fig. 2B, the pharmacological activation of NRF2 is being pursued for increasing its stability by targeting KEAP1. These strategies are based on the discovery of either electrophile compounds that alter the KEAP1 structure or small molecules that prevent the docking of NRF2 to KEAP1. Although not yet demonstrated empirically, the GSK-3 inhibitors should prevent the recognition of NRF 2 by $\beta$-TrCP and some compounds could be discovered to prevent binding of NRF2 to $\beta$-TrCP. The inhibition of NRF2 is being analyzed with compounds that target the bZip dimerization domain to prevent formation of the active NRF2/MAF heterodimer. By comparison with other transcription factors, it might be possible to find small molecules that impede binding of the NRF2/MAF heterodimer to the ARE (Fig. 9C). This section summarizes the most important findings from a translational point of view in both de novo drug discovery and repurposing.

\section{A. Electrophilic Nuclear Factor (Erythroid-Derived 2)- Like 2 Inducers}

The majority of known physiologic or pharmacological NRF2 inducers are electrophilic molecules that covalently modify, by oxidation or alkylation, cysteine residues present in the thiol-rich KEAP1 protein (Hur and Gray, 2011; Satoh et al., 2013). KEAP1 is one of the best-suited proteins to act as electrophilic or redox sensor, as it contains 27 cysteine residues in humans and functions as an electrophile trap. The cysteines C151, C273, and C288 of KEAP1 appear to be the most prone to electrophile reaction (Fig. 2B), although there are some specificities (Yamamoto et al., 2008; Saito et al., 2015). Electrophile adducts inhibit KEAP1 in two different ways. One is induction of a conformational change in KEAP1 that will result in loss of its binding capacity to NRF2. The other is the blockade of the interaction between KEAP1 and CUL3/RBX1, resulting in sequestration of KEAP1 with NRF2 and further stabilization of newly synthetized NRF2 (Rachakonda et al., 2008; Baird and Dinkova-Kostova, 2013; Cleasby et al., 2014; Saito et al., 2015).

At least 30 recent patents for NRF2 modulators are indexed in the World International Property Organization. These patents are protecting chalcone derivatives, novel amide triterpenoid derivatives, deuteriumsubstituted fumarate derivatives, 3-alkylamino- $1 \mathrm{H}$ indolyl acrylate derivatives, withanolide, a benzyl derivative containing an activated vinyl group, andrographolide or $[\mathrm{S}]^{+}$apomorphine, and sesquiterpene lactone derivative (Sun et al., 2017). Although most of these compounds proved to be useful to some degree from a preclinical proof-of-concept perspective, their clinical value is to date generally very limited. Only a few of them have entered clinical trials, and regulatory bodies, such as Food and Drug Administration or European Medicines Agency, have approved even fewer. We in this study discuss the most developed NRF2 activators along the translational pipeline.

Fumaric acid esters are the most prominent example of a KEAP1 modifier, and dimethyl fumarate (DMF) is to date the only Food and Drug Administration- and European Medicines Agency-approved drug registered as NRF2 activator. The monoester form of DMF, 
monomethyl fumarate (MMF), was described as its active metabolite. DMF and MMF are Michael acceptors that directly react with cysteine residues present in KEAP1 (Lin et al., 2011).

DMF and other fumaric acid esters have been used for treating psoriasis for over 50 years, starting at a time when the function of NRF2 was still unknown. This compound was licensed in Europe under the commercial name of Fumaderm. Clinical trials showed a decrease in the psoriasis area and severity index to $50 \%-80 \%$ after 12-16 weeks of DMF therapy (Altmeyer et al., 1994; Mrowietz et al., 1998). More recently, DMF has demonstrated its efficacy in the treatment of adults with moderate to severe chronic plaque psoriasis in a phase III trial (BRIDGE) (Mrowietz et al., 2017). The mechanism of action underlying fumarates in remission of psoriatic lesions includes the decrease in the number of peripheral $\mathrm{T}$ cells along with a shift from a Th1 toward a Th2 immune response (Ghoreschi et al., 2011; Tahvili et al., 2015). In another autoimmune disease, SLE, fumaric acid esters have been used as systemic combination therapy in the treatment of severe, extensive, and refractory cutaneous manifestations (Saracino and Orteu, 2017).

DMF was approved in 2013 for the treatment of MS under the commercial name Tecfidera (Xu et al., 2015). The use of DMF in MS patients was propelled by positive results obtained in the MS mouse model of EAE. Significant therapeutic effects on the disease course and histology were associated with a markedly reduced macrophage-mediated inflammation in the spinal cord. Multiplex cytokine analysis in blood evidenced an increase of the anti-inflammatory cytokine IL-10 in DMF-treated animals (Schilling et al., 2006). Moreover, DMF also improved preservation of myelin, axons, and neurons in wild-type, but not in $\mathrm{Nrf2}^{-/-}$mice (Ellrichmann et al., 2011). In humans, DMF demonstrated a significant reduction of lesions and annualized relapse rate in MS (Schimrigk et al., 2006). Two phase III clinical trials, DEFINE and CONFIRM, substantiated these results (Fox et al., 2012; Gold et al., 2012). Therefore, DMF is currently used as the first line of treatment of relapsing-remitting MS that cannot be treated by traditional therapies. New formulations of DMF are being tested and patented to improve drug bioavailability and efficacy (Sun et al., 2017). For instance, MMF has been used to develop a second generation of NRF2 inducers as prodrugs (Zeidan et al., 2014). The lead compound ALKS-8700, a 2-(2,5dioxo-1-pyrrolidinyl)ethyl ester derivative of $\mathrm{MMF}$, is rapidly converted into $\mathrm{MMF}$ in the body, hence increasing its bioavailability and reducing gastrointestinal side effects. ALKS-8700 is currently under phase III clinical trial (EVOLVE MS).

DMF and MMF modulate the immune response. For example, they inhibit the maturation of DCs by reducing the release of inflammatory cytokines and hence the ability of DCs to process antigens. Moreover, DMF and MMF activate natural killer cells to lyse DCs and enhance apoptosis of both DCs and T cells (Ghoreschi et al., 2011; Al-Jaderi and Maghazachi, 2015). As such, DMF and MMF impede T cell-mediated autoreactivity. Some studies indicate that DMF also induces type II DCs by triggering GSH depletion, which results in enhanced HO-1 activity and suppression of STAT1 phosphorylation. These classic type II DCs suppress Th1- and Th17-mediated responses in favor of Th2 ones. Furthermore, the increased production of IL-10 by DCs favors the differentiation of $\mathrm{CD}^{+} \mathrm{T}$ cells toward a suppressive Treg phenotype (Ockenfels et al., 1998; Ghoreschi et al., 2011). DMF also inhibits the nuclear translocation of NF- $\kappa \mathrm{B}$ (Peng et al., 2012) and consequently the production of inflammatory mediators, such as TNF- $\alpha$, IL-1 $\beta$, IL-6, chemokines, adhesion molecules, and nitric oxide in microglia and astrocytes (Brennan et al., 2017), as well as in peripheral blood mononuclear cells (Eminel et al., 2017). In addition, DMF exerts antiangiogenic effects that are dependent on the downregulation of vascular endothelial growth factor receptor-2 expression in endothelial cells (Meissner et al., 2011). Recent findings indicated that DMF reduced the number of $\mathrm{CD}^{+}, \mathrm{CD}^{+}$, Th1, and Th17 cells, whereas the $\mathrm{CD} 4^{+} / \mathrm{CD} 8^{+}$ratio and the $\mathrm{Th} 2$ subset were increased in the blood of these patients. Interestingly, the inhibitory effects of DMF/MMF on $\mathrm{T}$ cell activation were confined mainly to memory $\mathrm{T}$ cells $(\mathrm{Wu}$ et al., 2017). These immunomodulatory activities of DMF or MMF are important for the protection of oligodendrocytes against ROS-induced cytotoxicity (Scannevin et al., 2012).

Additional mechanisms might explain the inhibition of NF $-\kappa \mathrm{B}$ independently of NRF2 activation. Thus, DMF may interact with cysteine residues in several proteins that regulate NF- $\kappa$ B signaling (Blewett et al., 2016). In addition, DMF inhibits ubiquitin-conjugating enzymes and thus prevents the degradation of the $\mathrm{I} \kappa \mathrm{B}$ repressor of NF- $\kappa \mathrm{B}$ in response to IL- $1 \beta$ or Toll-like receptor agonists (McGuire et al., 2016). Moreover, DMF binds directly to specific cysteine residues in protein kinase C- $\theta$, a key kinase involved in signaling by the $\mathrm{T}$ cell receptor (Blewett et al., 2016). In addition, MMF and DMF activate the hydroxycarboxylic acid receptor-2, resulting in inhibition of NF- $\kappa \mathrm{B}$ and downregulation of proinflammatory cytokines and adhesion molecules (Chen et al., 2014; Gillard et al., 2015) and leading to decreased neutrophil infiltration (Chen et al., 2014). Although these NRF2-independent effects would be relevant in the acute inflammatory phase of EAE, the neuroprotective efficacy of DMF during chronic autoimmune demyelination depends on NRF2 activation (Linker et al., 2011). The clinical benefit of DMF treatment in both $N r f 2^{-1-}$ and wild-type mice was associated with a reduction of inflammatory Th1 and Th17 cells, as well as with induction of 
anti-inflammatory M2 monocytes. At the same time, decreased expression of CD80 and CD86 costimulatory molecules was observed in wild-type, but not in $\mathrm{Nrf2}^{-/-}$ mice, indicating that at least these effects were NRF2dependent (Schulze-Topphoff et al., 2016).

The success of DMF for the treatment of autoimmune diseases indicates that other diseases that share common pathomechanisms underlined by chronic, lowgrade inflammation and pathologic ROS formation might benefit from the repositioning of this drug. In a mouse model of Huntington's disease, the survival rate, muscle function, and body weight were preserved with DMF treatment, and this was associated with an increased number of intact neurons (Ellrichmann et al., 2011). Also, in a recent preclinical study of PD, using the $\alpha$-synucleinopathy model of this disease, DMF was neuroprotective in wild-type, but not in $\mathrm{Nrf2}^{-1-}$ mice due to impaired autophagy induction (LastresBecker et al., 2016).

DMF was shown to prevent endothelial dysfunction and cardiovascular pathologic ROS formation and inflammation in diabetic mice (Sharma et al., 2017), and decreased atherosclerosis, kidney dysfunction, and other diabetic complications were reported in apolipoprotein E-deficient mice after streptozotocin injection (Tan et al., 2014). Additionally, several studies indicated that DMF might exert antitumor activity by inhibiting the NF- $\kappa \mathrm{B}$ pathway, hence adding therapeutic value in the treatment of aggressive cancers (Kastrati et al., 2016). DMF is a relevant example of the drug-repurposing concept within the network pharmacology approach.

Synthetic triterpenoids are derivatives of 2-cyano3,12-dioxo-oleana-1,9(11)-dien-28-oate (CDDO; bardoxolone, RTA401) that resemble the natural product oleanolic acid. They exhibit Michael acceptor activity through its $\alpha-\beta$ unsaturated scaffold and represent the most potent inducers of NRF2 (Sun et al., 2017). They interact with $\mathrm{C} 151$ of KEAP1 and impede its interaction with CUL3, hence leading to NRF2 activation (Cleasby et al., 2014). Proof-of-principle studies strongly support the use of synthetic triterpenoids for degenerative diseases and are being the focus of intensive research as antioxidant modulators of inflammation by Reata/ Abbott. For instance, CDDO-imidazole (CDDO-Im RTA403) induced in peritoneal neutrophils of wildtype but not $\mathrm{Nrf2}^{-1-}$ mice the expression of various antioxidant genes (Hmox1, Gclc, Gclm, and Nqo1) and attenuated LPS-induced ROS generation and production of proinflammatory cytokines, consequently decreasing mortality (Thimmulappa et al., 2006b). CDDO-ethyl amide (RTA405) and CDDO-CDDOtrifluoethyl amide (RTA 404) had significant effects across all endpoints measured in a toxin-induced PD model (1-methyl-4-phenyl-1,2,3,6-tetrahydropyridine) (Kaidery et al., 2013). In the EAE model of MS, CDDOCDDO-trifluoethyl amide suppressed inflammation, pathologic ROS formation, and myelin degeneration (Pareek et al., 2011).

CDDO-methyl ester (CDDO-Me, RTA 402) was the first CDDO that reached in clinical trials for the treatment of diabetic nephropathy (Pergola et al., 2011). Although the results of the phase II were very encouraging, CDDO-Me was later withdrawn at phase III (BEACON trial) due to cardiovascular safety issues (Zhang, 2013) that were not related to NRF2 but most likely to an off-target alteration of endothelin signaling (de Zeeuw et al., 2013; Chin et al., 2014). Currently, CDDO-Me is under clinical study as potential treatment of Alport syndrome and pulmonary hypertension (Table 2). In an effort to improve its safety profile, further studies have led to the development of CDDOdifluoropropionamide (RTA-408, omaveloxone), which is currently in phase II trial for the treatment of Friedreich's ataxia, ocular inflammation, and pain after ocular surgery.

Oltipraz is an organosulfur compound that is used as an antischistosomal agent and is currently in phase III trial for the treatment of nonalcoholic steatohepatitis. Advanced clinical trials for the treatment of Huntington's disease are under development with minocycline, an antibiotic that has demonstrated neuroprotective properties due to NRF2 activation (Kuang et al., 2009). Another NRF2 inducer in phase I clinical study for the treatment of acute kidney disease is CXA-10, a nitro fatty acid with anti-inflammatory properties through the activation of NRF2 (Batthyany and Lopez, 2015). Many other NRF2 inducers with the same mechanism of action have been described in the last years (Buendia et al., 2015a,b, 2016), and some are in preclinical studies, such as the compound VEDA-1209, a chalcone derivative with a good anti-inflammatory profile for the treatment of ulcerative colitis.

SFN is an isothiocyanate produced from enzymatic cleavage of the organosulfur compound glucoraphanin, which is present in sprouts of broccoli, cabbage, and other Brassicacea plants. The catalytic reaction is driven by the enzyme myrosinase that is found in plants and microbiota of the GI tract (Kensler et al., 2013). More recently, SFN has been obtained by chemical synthesis (Kim et al., 2015). Translation of SFN to the clinic has been achieved by administration of SFNcontaining broccoli sprout powder to patients with T2DM (Bahadoran et al., 2012). Broccoli powder decreased plasma malondialdehyde and oxidized lowdensity lipoprotein (LDL) and increased the total antioxidant capacity. Cardiovascular risk factors such as serum triglycerides, oxidized LDL/LDL ratio, and atherogenic index of plasma (log of triglycerides/highdensity lipoprotein ratio) were also reduced. Furthermore, proinflammatory markers such as C-reactive protein and IL-6 were decreased. In a more recent study, SFN administered as concentrated broccoli sprout extract suppressed glucose production from 
TABLE 2

Selected NRF2 inducers acting as electrophilic modifiers of KEAP1

The reference corresponds to the code in ClinicalTrials.gov.

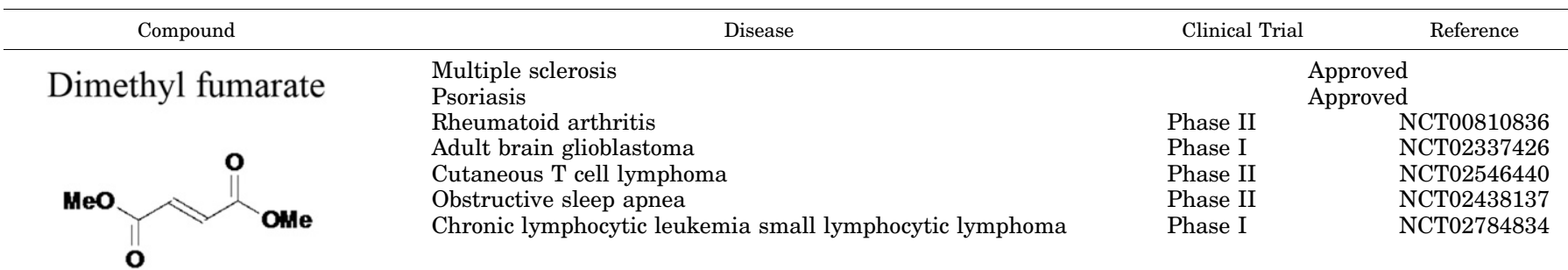

ALKS-8700

(MMF-derivate)<smiles>O=C(O)/C=C/C(=O)OCCN1C(=O)CCC1=O</smiles>

CDDO-Me (RTA402)

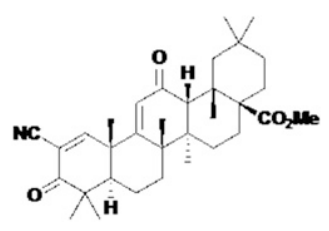

\section{CDDO-DFPA} (RTA-408)

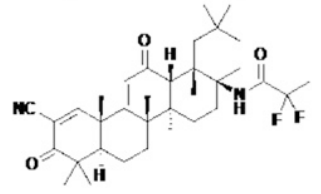<smiles></smiles><smiles>CC(C)C=CCCC(=O)O</smiles>

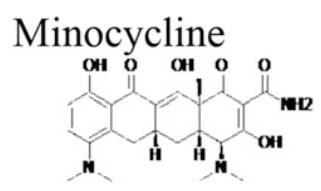

Oltipraz

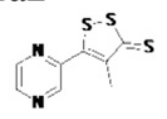

HD

Intracerebral hemorrhage

Retinitis pigmentosa

Intracerebral hemorrhage

NASH

Schistosomiasis

Lung cancer
Phase II

Phase III

Phase I/II

Phase I

Phase I

PhaseII/III

Phase III

Phase III

Phase II

Phase II

Phase II

Phase II

Phase II

Phase I/II

Phase II

Phase I

Phase I

NCT02248051

NCT02255422

NCT02255435

NCT02065375

NCT02128113

NCT02259231

NCT02142959

NCT02029729

Phase II/III

NCT00277355 NCT01805895

Phase I/II

Phase I/II

NCT02140164

NCT03040128

Phase III

Phase I
Approved

NCT02068339

NCT00006457 
TABLE 2-Continued

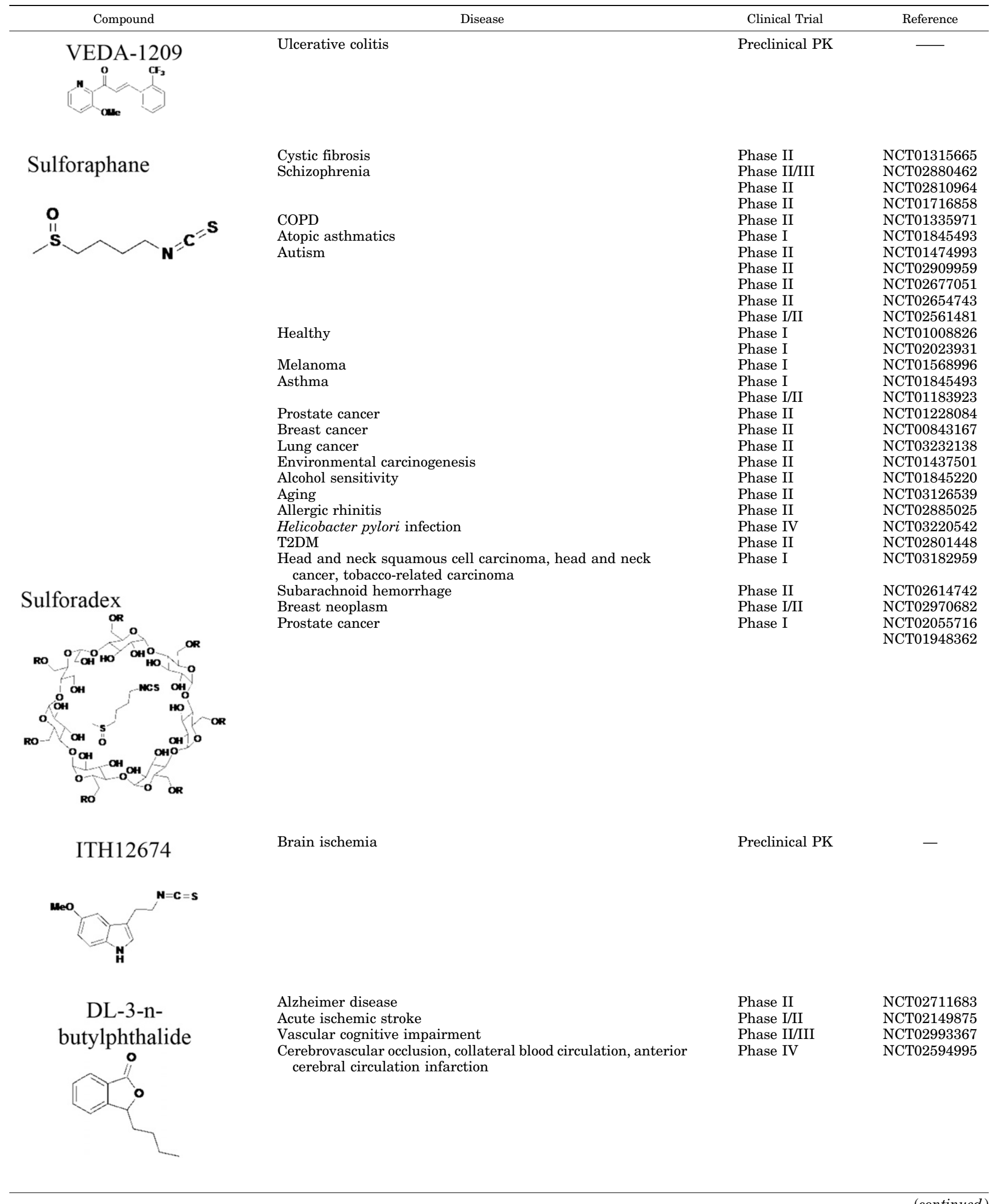


TABLE 2-Continued

\begin{tabular}{|c|c|c|c|}
\hline Compound & Disease & Clinical Trial & Reference \\
\hline \multirow{5}{*}{ Ursodiol } & Cholestasis & Phase II/III & NCT00846963 \\
\hline & $\mathrm{HD}$ & Phase I & NCT00514774 \\
\hline & Barrett esophagus, low-grade dysplasia & Phase II & NCT01097304 \\
\hline & Chronic hepatitis C & Phase III & NCT00200343 \\
\hline & T2DM & Phase II & NCT02033876 \\
\hline
\end{tabular}

T2DM

Colon cancer

COPD

Friedreich ataxia

NASH

Non-ischemic cardiomyopathy

Endometriosis

Chronic renal insufficiency

Metabolic syndrome X

Chronic subclinic inflammation

$\mathrm{AD}$

Colorectal cancer

HD

Curcumin

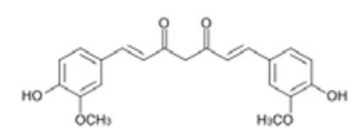

T2DM, cardiovascular risk

Schizophrenia, cognition, psychosis

Acute kidney injury, abdominal aortic aneurysm

Chronic kidney diseases, T2DM

$\mathrm{AD}$

Neoplasms

Crohn's disease

Chronic schizophrenia

Mild cognitive impairment

Prostate cancer

Major depression

\begin{tabular}{ll} 
Phase I & NCT01677611 \\
Phase I & NCT00256334 \\
Phase III & NCT02245932 \\
Phase I/II & NCT01339884 \\
Phase II/III & NCT02030977 \\
Phase III & NCT01914081 \\
Phase IV & NCT02475564 \\
Phase III & NCT02433925 \\
Phase II & NCT02114892 \\
Phase III & NCT01492114 \\
Phase II & NCT01504854 \\
Phase III & NCT00743743 \\
Phase I & NCT00433576 \\
Phase III & NCT02336633 \\
Phase IV & NCT01052025 \\
Phase I/II & NCT02104752 \\
Phase II/III & NCT01225094 \\
Phase II/III & NCT03262363 \\
Phase I/II & NCT00164749 \\
Phase II & NCT02944578 \\
Phase III & NCT02255370 \\
Phase IV & NCT02298985 \\
Phase II & NCT01811381 \\
Phase III & NCT02064673 \\
Phase IV & NCT01750359 \\
\hline
\end{tabular}

hepatocytes by nuclear translocation of NRF2 and decreased expression of key enzymes involved in gluconeogenesis. Moreover, SFN reduced fasting blood glucose and glycated hemoglobin in obese patients with T2DM (Axelsson et al., 2017). SFN-induced activation of NRF2 protected renal cells against lupus nephritis by reducing the ROS burden and by inhibiting the NF- $\kappa \mathrm{B}$ and TGF- $\beta 1$ signaling pathways (Jiang et al., 2014a).

In regard to neurodegenerative diseases, it has been shown that SFN crosses the blood brain barrier and provides sufficient cerebral bioavailability to activate the NRF2 signature and to reduce LPS-elicited neuroinflammation, as reflected in the reduction of proinflammatory markers (inducible nitric oxide synthase, IL-6, TNF- $\alpha$ ) and microgliosis in the hippocampus (Innamorato et al., 2008). SFN also safeguarded dopaminergic neurons against the parkinsonian toxin 1-methyl-4-phenyl-1,2,3,6-tetrahydropyridine and attenuated astrogliosis and microgliosis (Jazwa et al., 2011). In line with these findings, SFN reduced the levels of phosphorylated tau and increased Beclin-1 and LC3-II, suggesting that NRF2 activation might facilitate degradation of this toxic protein through autophagy in the brain (Jo et al., 2014). SFN-treated rats subjected to spinal cord injury had significantly decreased levels of inflammatory cytokines, reduced contusion volume, and improved coordination (Wang et al., 2012). This drug also ameliorated EAE by preserving the blood-brain barrier and by reducing pathologic ROS formation and the number of inflammatory cells ( $\mathrm{Li}$ et al., 2013). SFN has been used to date in at least 32 clinical studies addressing chronic diseases such as cancer, asthma, chronic kidney disease, T2DM, cystic fibrosis, autism, and schizophrenia (Duran et al., 2016; Houghton et al., 2016) (Table 2).

Altogether, these observations paved the way for the development of other SFN-derived compounds exhibiting an improved pharmacokinetic profile. SFN is an oily substance with low stability in hydrophilic media. Its physicochemical profile prompted Evgen Pharma (Wilmslow, Cheshire, England) to develop a cyclodextrin complex formulation, Sulforadex, which is under phase II clinical trial for the treatment of subarachnoid hemorrhage. SFN was also hybridized with melatonin to generate the ITH12674, a compound that was designed to have a dual drug-prodrug mechanism of action for treatment of brain ischemia (Egea et al., 2015).

Curcumin is the main curcuminoid found in turmeric and has been used for the treatment of obesity, metabolic syndrome, and prediabetes. A nontargeted 
metabolomics study to investigate the effects of curcumin on rat liver was conducted by means of gas chromatography with electron impact mass spectrometry. The intermittent intake of curcumin upregulated NRF2 and displayed antioxidant and anti-inflammatory roles in the protection against liver damage (Qiu et al., 2016). Oral consumption of curcumin is effective in lowering serum triglycerides, IL-1 $\beta$, IL-4, and vascular endothelial growth factor, and in increasing adiponectin levels in blood. In T2DM patients, curcumin decreases the levels of fasting blood glucose, glycated hemoglobin, serum free fatty acids, triglycerides, and uric acid, and increases the levels of lipoprotein lipase ( $\mathrm{Na}$ et al., 2013; Chuengsamarn et al., 2014).

Resveratrol is a polyphenol that protects plants against fungal infection and is found in the skin of grapes, red wine, berries, and many other plants. Resveratrol exerts antioxidant properties through activation of NRF2 signaling by downregulating KEAP1 expression and by activating the protein deacetylase sirtuin-1 (Ungvari et al., 2010). In healthy subjects, the dietary administration of resveratrol prevented the elevation in plasma of cholesterol, endotoxins, prooxidants, and inflammatory markers (p47phox, KEAP1, IL-1 $\beta$, and TNF- $\alpha$ ). These events correlated with the elevation of NRF2 activity as determined by enhanced expression of its targets NQO1 and glutathione S-transferase (Ghanim et al., 2011). In T2DM patients, insulin sensitivity was improved after 4 weeks of treatment, as determined by enhanced insulin signaling via $\mathrm{AKT}$, decreased pathologic ROS formation, and reduced levels of glycated hemoglobin (Brasnyo et al., 2011; Bhatt et al., 2012). Overall, resveratrol was reported to prevent major cardiovascular, inflammatory, oxidative, and metabolic complications in hypertension, hypercholesterolemia, atherosclerosis, ischemic heart disease, diabetes, and metabolic syndrome in animal models and patients (Xia et al., 2017).

A problem that is frequently overlooked is the lack of selectivity of electrophilic KEAP1 inhibitors. Electrophiles react with different nucleophiles present in the cell, thus exhibiting off-target and nondesired side effects. For instance, CDDO-Im can interact with more than 500 different targets (Yore et al., 2011). In general, several protein phosphatases contain redox-sensitive cysteines in their catalytic center, and some KEAP1 inhibitors may modify and inactivate these phosphatases, hence disturbing signaling networks. One of these phosphatases is PTEN (Lee et al., 2002; Kitagishi and Matsuda, 2013; Han et al., 2015). The catalytic $\mathrm{C} 124$ residue of PTEN can be modified through adduct formation with strong electrophiles such as CDDO-Im (Pitha-Rowe et al., 2009) and tertbutylhydroquinone (Rojo et al., 2014b). Then, the increased activation of the PI3K/AKT pathway involves inhibition of GSK-3 and subsequent stabilization of NRF2 (Fig. 2C) (Rada et al., 2011, 2012). Moreover,
KEAP1 interacts with other proteins that also contain the high-affinity binding motif ETGE (Hast et al., 2013), such as Bcl-2 and IKK $\beta$ (Kim et al., 2010a; Cazanave et al., 2014). Therefore, some results obtained from KEAP1-deficient cells may not necessarily be related to NRF2 activation.

\section{B. Protein-Protein Interaction Inhibitors for Nuclear Factor (Erythroid-Derived 2)-Like 2 Activation}

To overcome the pitfall of selectivity, a new class of NRF2 inducers that prevent the docking of NRF2 to KEAP1 has emerged (Richardson et al., 2015). The use of PPI inhibitors has been achieved by the prior elucidation of the X-ray crystal structure of KEAP1 (Padmanabhan et al., 2006) bound to a peptide containing the high-affinity binding ETGE motif of NRF2 (Lo et al., 2006). KEAP1 contains a six-bladed $\beta$-propeller with specific hydrophobic and hydrophilic residues that participate in the docking of the ETGE motif that adopts a $\beta$-hairpin structure. Docking is mainly favored by electrostatic interactions between several arginines of KEAP1 and the two glutamates in the ETGE motif (Lo et al., 2006; Padmanabhan et al., 2006). The docking to KEAP1 of the low-affinity DLG motif of NRF2 has also been characterized (Tong et al., 2007). Based on these interactions, peptidomimetic compounds were the first example of PPI inhibitors with significantly improved selectivity over electrophiles (Hu et al., 2013; Marcotte et al., 2013; Winkel et al., 2015). These inhibitors show weak activity in cells, and a new provocative strategy has now been reported based on the use of cyclic peptides. One of these peptides exhibited high-binding affinity for KEAP1 and activation of NRF2 and elicited anti-inflammatory effects in mouse macrophages ( $\mathrm{Lu}$ et al., 2018).

The discovery of new peptides and small-molecule inhibitors of the KEAP1/NRF2 interaction has been reviewed recently (Abed et al., 2015; Jiang et al., 2016). Briefly, a series of truncated NRF2 peptides was initially evaluated as direct inhibitors of PPI using surface plasmon resonance and fluorescence polarization assays ( $\mathrm{Hu}$ et al., 2013). The minimal peptide sequence with inhibitory capacity was the 9-mer sequence of LDE-ETGE-FL (Chen et al., 2011; Inoyama et al., 2012). In parallel, Wells and collaborators (Hancock et al., 2013) searched for new putative peptide ligands using a phage display library combined with high-throughput fluorescence polarization assay. They found that hybrid peptides based upon the ETGE motif of NRF2 and SQSTM1 have superior binding activity to KEAP1 compared with either native peptide alone. To facilitate cellular uptake, a peptide was designed with the ETGE motif fused to the cell transduction domain of the HIV-Tat protein and the cleavage sequence of calpain (DEETGE-Cal-Tat). This peptide showed neuroprotective and cognitive-preserving effects in a mouse model of cerebral ischemia (Tu et al., 2015). 
TABLE 3

Selected NRF2 inducers acting as NRF2-KEAP1 protein-protein interaction inhibitors

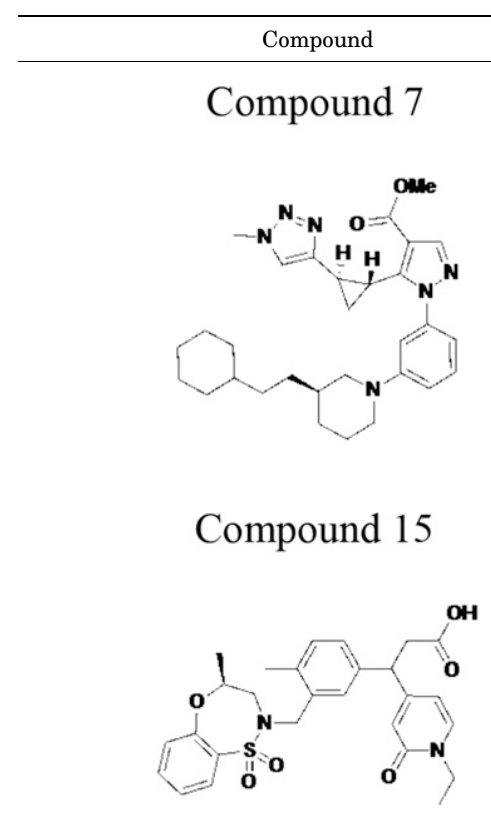

BM19

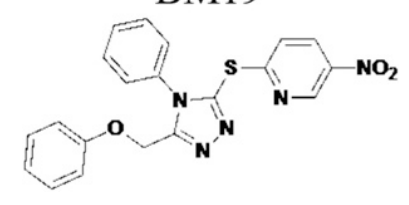

LH601
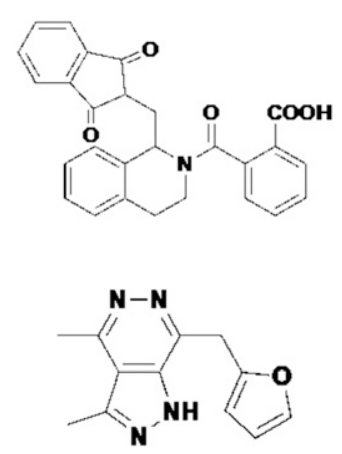

AN-465/144580

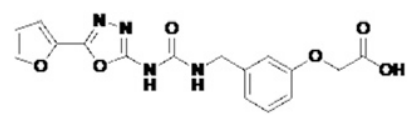

WO2016/202253 NRF2 regulators

WO2014/197818

WO2013/067036

WO2011/156889

JP2011/0167537
Small-molecule activators of NRF2 pathway
Applicant

Arylcyclohexyl pyrazoles as NRF2 regulators

GlaxoSmithKline Astex Therapeutics
GlaxoSmithKline Astex
Therapeutics, GlaxoSmithKline (China), R\&D

\section{General Hospital, Regents of the University of California}

Direct inhibitors of KEAP1-NRF2 interaction as antioxidant inflammation modulators

Rutgers, The State University of New Jersey, Broad Institute

Novel modulators of NRF2 and uses thereof
TRT Pharma Gerald Batist, Jian Hui Wu

$$
\begin{aligned}
& \text { KEAP1 protein-binding compound, } \\
& \text { crystal of complex between the } \\
& \text { same and KEAP1 protein, and }
\end{aligned}
$$
method for producing the same 
TABLE 3-Continued

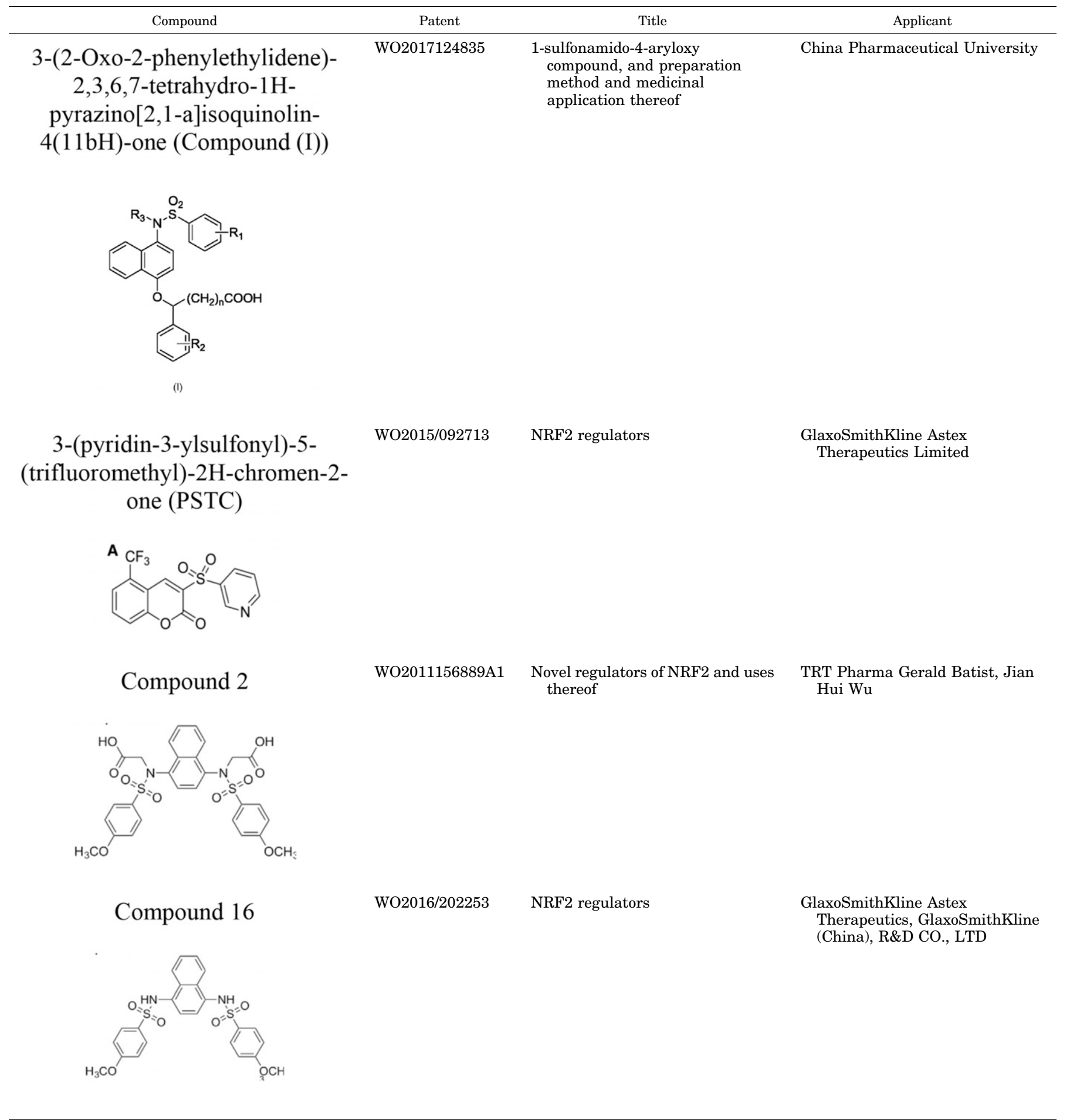

Five families of PPI inhibitors have been described: tetrahydroisoquinoline (Jnoff et al., 2014; Richardson et al., 2015), thiopyrimidine (Marcotte et al., 2013), naphthalene (Jiang et al., 2014b), carbazone (Ranjan et al., 2014), and urea derivatives (Sato et al., 2013). Table 3 compiles recent patents addressing these small molecules. Although these compounds are very promising, it is still needed to demonstrate that they are selective for the KEAP1/NRF2 interaction, because KEAP1 also targets at least Bcl2 and IKK (Kim et al., 2010a; Hast et al., 2013; Cazanave et al., 2014).

From the large number of compounds indexed in the available libraries, the compounds LH601, benzenesulfonylpyrimidone 2, N-phenyl-benzenesulfonamide, and a series 
of 1,4-diphenyl-1,2,3-triazoles might be very well-suited candidates to inhibit the PPI with KEAP1 (Hu et al., 2013; Jnoff et al., 2014; Bertrand et al., 2015; Wen et al., 2015; Nasiri et al., 2016). These studies described in detail the atomic interaction with KEAP1, the affinity, and the thermodynamics parameters of binding. The therapeutic efficacy of these compounds is to be analyzed in future work in which safety, potency, and blood brain barrier permeability should be addressed.

\section{Drug Targets Other Than Kelch-Like ECH-Associated Protein 1 for Nuclear Factor (Erythroid-Derived 2)-Like 2 Activation}

Protein kinase GSK-3 phosphorylates the two serine residues in the DSGIS sequence of NRF2 to generate a phosphorylation-dependent degradation motif or phosphodegron (Fig. 2). This phosphodegron is recognized by the E3 ligase adapter $\beta$-TrCP, leading to ubiquitindependent proteasomal degradation of NRF2. Therefore, GSK-3 inhibitors should stop NRF2 degradation by preventing the generation of this phosphodegron. GSK-3 is an important kinase in $\mathrm{AD}$ and other pathophenotypes. It phosphorylates the cytoskeletal protein tau, facilitating the formation of neurofibrillary tangles, which are pathologic intracellular aggregates that disturb axonal transport and lead to neuronal death (Silva et al., 2014). Therefore, it has been speculated that GSK-3 inhibition might have the double benefit of preventing neurofibrillary tangle formation and NRF2 degradation. Unfortunately, most pipelines for the development of GSK-3 inhibitors have been discontinued due to futility, although in most cases there was not good evidence of target modulation (Palomo and Martinez, 2017).

Conceptually, inhibitors of the $\beta$-TrCP-phosphoNRF2 interaction should also lead to NRF2 activation as they should disrupt this branch of NRF2 degradation (Fig. 2). The molecular interactions between the $\beta$-propeller of $\beta$-TrCP and a peptide containing the NRF2 phosphodegron have been resolved by NMR (Rada et al., 2012). As it happens for KEAP1/EGTE, the most relevant amino acids appear to be several arginine residues of $\beta$-TrCP that interact with the two phosphoserines of the DpSGIpS motif. However, the discovery of small molecules that could inhibit the $\beta$-TrCP-phosphoNRF2 interaction is still to come.

Additional strategies have been developed to inhibit the NRF2 repressor BACH1, a bZip protein that makes heterodimers with MAF proteins and blocks expression of ARE genes. Efficient inhibition of BACH1 by the HPP-4382 compound has been described in vitro (Attucks et al., 2014), but, prior to a full clinical trial, the safety and efficacy profile of HPP-4382 will have to be demonstrated in vivo. Considering that other pathways may also influence NRF2 activity, it is reasonable to speculate that a combinatorial approach will be the best way to activate this transcription factor.

\section{Nuclear Factor (Erythroid-Derived 2)-} Like 2 Inhibitors

NRF2 has a "dark side" related to its oncogenic activity when constitutively and highly overexpressed. Therefore, NRF2 inhibition has been proposed as a mechanism to sensitize cancer cells to chemotherapeutic drugs or radiotherapy (Milkovic et al., 2017). Two strategies can be envisioned to inhibit NRF2 with small molecules: PPI inhibitors that disrupt the bZip interaction between NRF2 and MAFs, and DNA-protein interaction inhibitors that block binding of NRF2-MAF to the ARE (Fig. 9C). Both strategies are hampered by the need by such drugs to overcome the large free energy of association between protein-protein and, to a lesser extent, protein-DNA interfaces. Nevertheless, such drugs have been found for other bZip transcription factors such as STAT3-STAT3, MYC-MAX, and JUNFOS (Yap et al., 2011), and new small molecules are being described for NRF2-MAF. For instance, malabaricone-A is a pro-oxidant compound that overcomes leukemia resistance by targeting NRF2 (Manna et al., 2015). Ascorbic acid (vitamin C), a well-known ROS scavenger, was found to sensitize imatinib-resistant cancer cells by decreasing the levels of the NRF2/ARE complex, reducing the expression of the GCLC gene and dropping GSH levels (Tarumoto et al., 2004). All-transretinoic acid is another example of NRF2 inhibitor that significantly decreases NRF2 activation by potent electrophilic NRF2 inducers in vitro and in vivo. It activates the retinoic acid receptor $\alpha$, which forms a complex with NRF2, hence impeding the binding of the transcription factor to ARE genes (Wang et al., 2007).

Natural products such as brusatol (Ren et al., 2011; Olayanju et al., 2015), ochratoxin A (Tarumoto et al., 2004; Limonciel and Jennings, 2014), and trigonelline (Arlt et al., 2013) have also been found to inhibit NRF2. However, their mechanism of action is not fully understood. In fact, a significant issue related to currently available compounds is the profound off-target effect that they might have. For instance, promising results with brusatol were recently discouraged by the finding that this drug exerts a general and unspecific inhibition of protein synthesis, resulting in the drop of NRF2 levels, but also of many other proteins with rapid turnover (Harder et al., 2017). Similarly, the antiprotozoal agent halofuginone, used in veterinary practice, enhances the chemosensitivity of cancer cells by suppressing NRF2 accumulation, but this effect appears to be indirect by inhibiting prolyl-transfer RNA synthesis that is strongly required for ribosomal translation of NRF2 as well as many other proline-containing proteins (Tsuchida et al., 2017).

A novel approach to identify selective NRF2 inhibitors has been reported recently by the use of quantitative highthroughput screen of small-molecule inhibitors (Singh et al., 2016). The authors identified a first-in class compound, termed ML385, which most likely prevented 
the binding of NRF2 to other bZip coactivators. This compound blocked NRF2 transcriptional activity and sensitized KEAP1-deficient cells to carboplatin and other chemotherapeutic drugs. Additional studies are needed to confirm whether ML385 is selective for NRF2 or if it also inhibits other bZip transcription factors.

In light of the highly favorable systemic effects of NRF2 in various tumor pathophenotypes, a specific targeting of NRF2 with small-molecule inhibitors seems to provide an excellent clinical approach. However, it is necessary to determine whether cancer treatment with NRF2 inhibitors increases the risk of other pathophenotypes of the NRF2 diseasome.

\section{E. Repurposing Instead of De Novo Drug Discovery and Development}

As previously discussed, numerous compounds are under development to provide a benefit for the pathophenotypes associated with the NRF2 diseasome. An alternative approach is to give drugs that are already in clinical use for a certain pathomechanism a new use for the treatment of other pathomechanisms that are connected to NRF2. This section provides the basis for repositioning some commonly used drugs based on their role in NRF2 regulation.

Metformin is the first-line monotherapy for the T2DM. According to Fig. 6, it provides therapeutic benefit to the NRF2 subcluster of pathophenotypes related to glucose metabolism. In fact, SFN reduces hepatic glucose production and improves glucose control in patients with T2DM (Axelsson et al., 2017). Interestingly, some evidence suggests that metformin may be effective in preventing other nonglycemic pathophenotypes of the NRF2 diseasome, including cardiovascular (Nesti and Natali, 2017), respiratory (Sato et al., 2016), digestive (Bauer and Duca, 2016), neurodegenerative (Markowicz-Piasecka et al., 2017), autoimmune (Schuiveling et al., 2017), and neoplastic (Heckman-Stoddard et al., 2017) disorders. The mechanism of action of metformin is not completely clear, but it involves inhibition of mitochondrial complex I, thus increasing the AMP/ATP ratio (El-Mir et al., 2000; Owen et al., 2000) and leading to activation of the energy sensor AMPK (Hardie, 2004; Rena et al., 2017). Importantly, AMPK activates NRF2 (Wang et al., 2017a; Zhao et al., 2017), and pharmacological targeting of this axis attenuates inflammation after stroke (Wang et al., 2017c) or endotoxin exposure (Ci et al., 2017; Lv et al., 2017). Indeed, metformin activates NRF2 in an AMPK-dependent manner, resulting in inhibition of inflammatory responses in preclinical rodent models of transient global cerebral ischemia (Ashabi et al., 2015; Kaisar et al., 2017). Glucose metabolism and inflammation may not be the only pathomechanisms affected by metformin/NRF2. In fact, other salutary effects have been described for redox (Kocer et al., 2014; Kelleni et al., 2015) and protein homeostasis (Tsai et al., 2017).
Statins prevent and reduce cardiovascular pathophenotypes. In addition to a lipid-lowering effect, statins appear to protect against pathomechanisms associated with the NRF2 network such as inflammatory (Pantan et al., 2016; Wu et al., 2016a; Hwang et al., 2017) and pathologic ROS formation (Abdanipour et al., 2014). They are competitive inhibitors of 3-hydroxy-3-methyl-glutaryl-CoA reductase, which catalyzes the rate-limiting reaction in cholesterol synthesis. Other pleiotropic effects include the upregulation of transcription factor Krüppel-like factor 2, which is induced early during progression of cirrhosis and lessens the development of hepatic vascular dysfunction (Marrone et al., 2015). Recent evidence indicates that at least some statins activate NRF2. In a proteomic study conducted in isolated hepatocytes, high concentrations of simvastatin activated NRF2, probably as a defensive mechanism (Cho et al., 2013). The pretreatment of neural stem cells with lovastatin activated the NRF2 pathway and elicited protection against hydrogen peroxide-induced cell death (Abdanipour et al., 2014). In liver cirrhosis, simvastatin activates an axis formed by Krüppel-like factor 2 and NRF2 to reduce the oxidative burden and inflammatory response of stellate cells, improving liver fibrosis, endothelial dysfunction, and portal hypertension. The mechanism of activation of NRF2 by simvastatin is not completely clear, but it appears to involve elements found in the NRF2 interactome, such as mitogenactivated protein kinase, PI3K/AKT pathways (Jang et al., 2016), and GSK-3 (Lin et al., 2016).

Other cases for drug repurposing can be inferred from the NRF2 interactome of Fig. 4, in particular with signaling kinases. As indicated in Fig. 2C, GSK-3 phosphorylates the Neh6 domain of NRF2, leading to the recognition by $\beta$-TrCP and further ubiquitindependent proteasomal degradation. GSK-3 is active in the absence of stimuli and inactive when signaling cascades that activate AKT and other kinases lead to phosphorylation of GSK-3 at its N-terminal pseudosubstrate domain. It follows that medications known to target signaling kinases may be used to upregulate (GSK-3 inhibitors) or downregulate (PI3K/AKT inhibitors) the NRF2 signature.

GSK-3 participates in at least some pathophenotypes found in the NRF2 diseasome such as diabetes and neurodegeneration (Beurel et al., 2015; Maqbool and Hoda, 2017). A broad spectrum of GSK-3 inhibitors has been discovered from natural and synthetic origins (Khan et al., 2017), but probably the best evidence for repurposing a GSK-3 inhibitor to increase NRF2 activity stems from the clinical use of lithium as mood stabilizer (Chiu et al., 2013). Although bipolar disorder and depression are not found at this time in the NRF2 diseasome, it is becoming evident that they exhibit neuroinflammatory and degenerative pathophenotypes that at least in mouse models imply deregulation of 
NRF2 (Martin-de-Saavedra et al., 2013; Freitas et al., 2016; Yao et al., 2016).

The NRF2 interactome also provides a justification for the inhibition of NRF2 by cancer drugs that block signaling kinases, thus activating GSK-3. For example, the epidermal growth factor receptor inhibitor erlotinib leads to NRF2 inhibition, participating in tumor cell sensation in nonsmall cell lung cancer (Xiaobo et al., 2016). The kinase cascade inhibitor sorafenib, used in therapy of hepatocellular carcinoma, also leads to inhibition of NRF2 and its downstream targets metallothionein-1 (Houessinon et al., 2016) and methylenetetrahydrofolate dehydrogenase 1 (Lee et al., 2017).

Finally, search for repurposing drugs that might impinge on NRF2 regulation has been done to date in two relevant studies. Using a fluorescence correlation spectroscopy-based screening system, two of 1633 drugs significantly increased NRF2 protein levels in HepG2 cells: chlorophyllin and bonaphton (Yoshizaki et al., 2017). In another study, the connectivity map database that comprises gene expression profiles for human cell lines treated with 1309 agents (Lamb et al., 2006; Iorio et al., 2010) was analyzed (Zhang et al., 2017) in search for potential redox regulators through activation of NRF2 (Xiong et al., 2014). This study found astemizole, a potent antihistamine drug, used in allergic conditions, as a novel NRF2 activator.

\section{Biomarkers as Nuclear Factor (Erythroid- Derived 2)-Like 2 Signature and for Monitoring Target Engagement}

The evaluation of the redox status in patients or population studies is hampered by the short half-life of ROS, in the range of milliseconds or nanoseconds (Ghezzi et al., 2017b). Therefore, biomarkers of pathologic ROS formation are based on measuring the traces left by ROS, which are normally terminal oxidation products of cellular molecules, many of them being nonspecific (Frijhoff et al., 2015). On the contrary, activation of NRF2 and subsequent expression of its target genes is an indirect but reliable estimation of the total exposure of the organism to pathologic ROS formation. Because NRF2 activation is a wellestablished cellular response to environmental stressors, it has been considered as biomarker of exposure to xenobiotics. In lung, a data mining of several transcription studies followed by Ingenuity pathway analysis reported that the NRF2 signature is upregulated in healthy smokers, therefore suggesting that NRF2regulated antioxidant genes play a central role in protection against toxic effects of tobacco smoke (Comandini et al., 2010). Similarly, the levels of NQO1, an enzyme regulated by NRF2, were 15-fold higher in liver tissue obtained from acetaminophenoverdosed patients (Aleksunes et al., 2006). The association between disease and nutrition is frequently based on unreliable self-reporting (Archer et al., 2015). Measuring biomarkers of response to nutrients, supposedly having beneficial effects by activating NRF2, could provide a reliable method to validate nutritional studies. However, this possibility is still unexplored.

The changes associated with NRF2 transcription could be useful as biomarker for monitoring the efficacy of drugs aimed at reducing pathologic ROS formation by inhibitors of xanthine oxidase and NADPH oxidase. Similarly, exposure to environmental chemicals could be detected and monitored by defining a global protein and gene expression profile (Ghezzi et al., 2017a). This approach is similar to the use of phase I drugmetabolizing enzymes, in which cytochrome P450, which is induced by various xenobiotics through the Ah receptor, can be used as indicator of marine pollution (Cajaraville et al., 2000). Daily oral administration of fumaric acid esters over 12 weeks was associated with the increased expression of NRF2 target genes in the skin of patients with psoriasis (Onderdijk et al., 2014). Similarly, a fivefold increase in the mRNA level of NQO1 has been reported in peripheral blood mononuclear cells obtained from cancer patients that received a daily dose of CDDO-Me for 3 weeks (Hong et al., 2012).

The use of the transcriptional signature of NRF2 as a biomarker requires a good knowledge of the mechanisms involved in activation of ARE genes, as most of the NRF2 targets are regulated by additional transcription factors. It is therefore important to analyze the expression of several ARE genes. For instance, a study using NRF2 as predictor for response to treatment in lung squamous cell carcinoma has proposed the use of 28 genes to define a NRF2 activation profile (Cescon et al., 2015).

\section{Conclusions}

Systems medicine together with network pharmacology highlights a cluster of chronic disease pathophenotypes in which NRF2 plays a fundamental role. These diseases share common mechanisms, including oxidative, inflammatory, and metabolic alterations. The NRF2 interactome, the NRF2 diseasome, and the NRF2 drugome presented in this work are still in an early stage of development, but they represent a first attempt to structure NRF2 as a common therapeutic and systems medicine approach. The forthcoming refinement of current databases and upcoming clinical outcome data will further improve the accuracy of this new approach to pharmacology and mechanism-based drug repurposing. This paper provides a road map for a comprehensive strategy for drug discovery to activate or inhibit NRF2 and highlights the need of translational efforts toward the development of de novo drugs or the 
repurposing of drugs that target NRF2 as a common element in chronic diseases.

\section{Authorship Contributions}

Participated in research design: Cuadrado, Schmidt.

Wrote or contributed to the writing of the manuscript: Manda, Oliva, Guney, Alcaraz, Barbas, Valverde, Daiber, Ghezzi, López, León, Pajares, Rojo, Robledinos-Antón, Hassan.

\section{References}

Abdanipour A, Tiraihi T, Noori-Zadeh A, Majdi A, and Gosaili R (2014) Evaluation of lovastatin effects on expression of anti-apoptotic Nrf2 and PGC-1 $\alpha$ genes in neural stem cells treated with hydrogen peroxide. Mol Neurobiol 49:1364-1372.

Abed DA, Goldstein M, Albanyan H, Jin H, and Hu L (2015) Discovery of direct inhibitors of Keap1-Nrf2 protein-protein interaction as potential therapeutic and preventive agents. Acta Pharm Sin B 5:285-299.

Aleksunes LM, Goedken M, and Manautou JE (2006) Up-regulation of NAD(P)H quinone oxidoreductase 1 during human liver injury. World $J$ Gastroenterol 12: $1937-1940$

Aleksunes LM and Manautou JE (2007) Emerging role of Nrf2 in protecting against hepatic and gastrointestinal disease. Toxicol Pathol 35:459-473.

Al-Huseini LM, Aw Yeang HX, Sethu S, Alhumeed N, Hamdam JM, Tingle Y, Djouhri L, Kitteringham N, Park BK, Goldring CE, et al. (2013) Nuclear factorerythroid 2 (NF-E2) p45-related factor-2 (Nrf2) modulates dendritic cell immune function through regulation of p38 MAPK-cAMP-responsive element binding protein/activating transcription factor 1 signaling. J Biol Chem 288:22281-22288.

Al-Jaderi $\mathrm{Z}$ and Maghazachi AA (2015) Vitamin $\mathrm{D}_{3}$ and monomethyl fumarate enhance natural killer cell lysis of dendritic cells and ameliorate the clinical score in mice suffering from experimental autoimmune encephalomyelitis. Toxins (Basel) 7: 4730-4744.

Altmeyer PJ, Matthes U, Pawlak F, Hoffmann K, Frosch PJ, Ruppert P, Wassilew SW, Horn T, Kreysel HW, Lutz G, et al. (1994) Antipsoriatic effect of fumaric acid derivatives: results of a multicenter double-blind study in 100 patients. J Am Acad Dermatol 30:977-981.

Archer E, Pavela G, and Lavie CJ (2015) The inadmissibility of what we eat in America and NHANES dietary data in nutrition and obesity research and the scientific formulation of national dietary guidelines. Mayo Clin Proc 90:911-926.

Arisawa T, Tahara T, Shibata T, Nagasaka M, Nakamura M, Kamiya Y, Fujita H, Hasegawa S, Takagi T, Wang FY, et al. (2007) The relationship between Helicobacter pylori infection and promoter polymorphism of the Nrf2 gene in chronic gastritis. Int $J$ Mol Med 19:143-148.

Arisawa T, Tahara T, Shibata T, Nagasaka M, Nakamura M, Kamiya Y, Fujita H, Yoshioka D, Okubo M, Hirata I, et al. (2008a) Nrf2 gene promoter polymorphism and gastric carcinogenesis. Hepatogastroenterology 55:750-754

Arisawa T, Tahara T, Shibata T, Nagasaka M, Nakamura M, Kamiya Y, Fujita H, Yoshioka D, Okubo M, Sakata M, et al. (2008b) Nrf2 gene promoter polymorphism is associated with ulcerative colitis in a Japanese population. Hepatogastroenterology 55:394-397.

Arlt A, Sebens S, Krebs S, Geismann C, Grossmann M, Kruse ML, Schreiber S, and Schäfer H (2013) Inhibition of the Nrf2 transcription factor by the alkaloid trigonelline renders pancreatic cancer cells more susceptible to apoptosis through decreased proteasomal gene expression and proteasome activity. Oncogene 32: $4825-4835$.

Artaud-Macari E, Goven D, Brayer S, Hamimi A, Besnard V, Marchal-Somme J, Ali ZE, Crestani B, Kerdine-Römer S, Boutten A, et al. (2013) Nuclear factor erythroid 2 -related factor 2 nuclear translocation induces myofibroblastic dedifferentiation in idiopathic pulmonary fibrosis. Antioxid Redox Signal 18:66-79.

Ashabi G, Khalaj L, Khodagholi F, Goudarzvand M, and Sarkaki A (2015) Pretreatment with metformin activates Nrf2 antioxidant pathways and inhibits inflammatory responses through induction of AMPK after transient global cerebral ischemia. Metab Brain Dis 30:747-754.

Attucks OC, Jasmer KJ, Hannink M, Kassis J, Zhong Z, Gupta S, Victory SF, Guzel M, Polisetti DR, Andrews R, et al. (2014) Induction of heme oxygenase I (HMOX1) by HPP-4382: a novel modulator of Bach1 activity. PLoS One 9:e101044.

Aviello G and Knaus UG (2017) ROS in gastrointestinal inflammation: rescue or sabotage? Br J Pharmacol 174:1704-1718.

Axelsson AS, Tubbs E, Mecham B, Chacko S, Nenonen HA, Tang Y, Fahey JW, Derry JMJ, Wollheim CB, Wierup N, et al. (2017) Sulforaphane reduces hepatic glucose production and improves glucose control in patients with type 2 diabetes. Sci Transl Med 9:1-12.

Bahadoran Z, Mirmiran P, Hosseinpanah F, Rajab A, Asghari G, and Azizi F (2012) Broccoli sprouts powder could improve serum triglyceride and oxidized LDL/LDLcholesterol ratio in type 2 diabetic patients: a randomized double-blind placebocontrolled clinical trial. Diabetes Res Clin Pract 96:348-354.

Baillie JK, Arner E, Daub C, De Hoon M, Itoh M, Kawaji H, Lassmann T, Carninci P, Forrest AR, Hayashizaki Y, et al.; FANTOM Consortium (2017) Analysis of the human monocyte-derived macrophage transcriptome and response to lipopolysaccharide provides new insights into genetic aetiology of inflammatory bowel disease. PLoS Genet 13:e1006641.

Baird L and Dinkova-Kostova AT (2013) Diffusion dynamics of the Keap1-Cullin3 interaction in single live cells. Biochem Biophys Res Commun 433:58-65.

Banning A and Brigelius-Flohé R (2005) NF-kappaB, Nrf2, and HO-1 interplay in redox-regulated VCAM-1 expression. Antioxid Redox Signal 7:889-899.

Barabási AL, Gulbahce N, and Loscalzo J (2011) Network medicine: a network-based approach to human disease. Nat Rev Genet 12:56-68.
Batthyany CI and Lopez GV (2015) Nitroalkene Tocopherols and Analogs Thereof for Use in the Treatment and Prevention of Inflammation Related Conditions, Complexa, Radnor, PA.

Bauer PV and Duca FA (2016) Targeting the gastrointestinal tract to treat type 2 diabetes. J Endocrinol 230:R95-R113.

Bergström P, von Otter M, Nilsson S, Nilsson AC, Nilsson M, Andersen PM, Hammarsten O, and Zetterberg H (2014) Association of NFE2L2 and KEAP1 haplotypes with amyotrophic lateral sclerosis. Amyotroph Lateral Scler Frontotemporal Degener 15:130-137.

Bertrand HC, Schaap M, Baird L, Georgakopoulos ND, Fowkes A, Thiollier C, Kachi H, Dinkova-Kostova AT, and Wells G (2015) Design, synthesis, and evaluation of triazole derivatives that induce Nrf2 dependent gene products and inhibit the Keap1-Nrf2 protein-protein interaction. J Med Chem 58:7186-7194.

Beurel E, Grieco SF, and Jope RS (2015) Glycogen synthase kinase-3 (GSK3): regulation, actions, and diseases. Pharmacol Ther 148:114-131.

Bhatt JK, Thomas S, and Nanjan MJ (2012) Resveratrol supplementation improves glycemic control in type 2 diabetes mellitus. Nutr Res 32:537-541.

Blewett MM, Xie J, Zaro BW, Backus KM, Altman A, Teijaro JR, and Cravatt BF (2016) Chemical proteomic map of dimethyl fumarate-sensitive cysteines in primary human T cells. Sci Signal 9:rs10.

Bolaños JP (2016) Bioenergetics and redox adaptations of astrocytes to neuronal activity. J Neurochem 139 (Suppl 2):115-125.

Bourdonnay E, Morzadec C, Fardel O, and Vernhet L (2009) Redox-sensitive regulation of gene expression in human primary macrophages exposed to inorganic arsenic. J Cell Biochem 107:537-547.

Bowie A and O'Neill LA (2000) Oxidative stress and nuclear factor-kappaB activation: a reassessment of the evidence in the light of recent discoveries. Biochem Pharmacol 59:13-23.

Brasnyó P, Molnár GA, Mohás M, Markó L, Laczy B, Cseh J, Mikolás E, Szijártó IA Mérei A, Halmai R, et al. (2011) Resveratrol improves insulin sensitivity, reduces oxidative stress and activates the Akt pathway in type 2 diabetic patients. $\mathrm{Br} J$ Nutr 106:383-389.

Brennan MS, Matos MF, Richter KE, Li B, and Scannevin RH (2017) The NRF2 transcriptional target, OSGIN1, contributes to monomethyl fumarate-mediated cytoprotection in human astrocytes. Sci Rep 7:42054.

Brüne B, Dehne N, Grossmann N, Jung M, Namgaladze D, Schmid T, von Knethen A, and Weigert A (2013) Redox control of inflammation in macrophages. Antioxid Redox Signal 19:595-637.

Buendia I, Gómez-Rangel V, González-Lafuente L, Parada E, León R, Gameiro I Michalska P, Laudon M, Egea J, and López MG (2015a) Neuroprotective mechanism of the novel melatonin derivative Neu-P11 in brain ischemia related models. Neuropharmacology 99:187-195.

Buendia I, Michalska P, Navarro E, Gameiro I, Egea J, and León R (2016) Nrf2-ARE pathway: an emerging target against oxidative stress and neuroinflammation in neurodegenerative diseases. Pharmacol Ther 157:84-104.

Buendia I, Navarro E, Michalska P, Gameiro I, Egea J, Abril S, López A, GonzálezLafuente L, López MG, and León R (2015b) New melatonin-cinnamate hybrids as multi-target drugs for neurodegenerative diseases: Nrf2-induction, antioxidant effect and neuroprotection. Future Med Chem 7:1961-1969.

Cajaraville MP, Bebianno MJ, Blasco J, Porte C, Sarasquete C, and Viarengo A (2000) The use of biomarkers to assess the impact of pollution in coastal environments of the Iberian Peninsula: a practical approach. Sci Total Environ 247: 295-311.

Cazanave SC, Wang X, Zhou H, Rahmani M, Grant S, Durrant DE, Klaassen CD, Yamamoto M, and Sanyal AJ (2014) Degradation of Keap1 activates BH3-only proteins Bim and PUMA during hepatocyte lipoapoptosis. Cell Death Differ 21: 1303-1312.

Cescon DW, She D, Sakashita S, Zhu CQ, Pintilie M, Shepherd FA, and Tsao MS (2015) NRF2 pathway activation and adjuvant chemotherapy benefit in lung squamous cell carcinoma. Clin Cancer Res 21:2499-2505.

Chen H, Assmann JC, Krenz A, Rahman M, Grimm M, Karsten CM, Köhl J, Offermanns S, Wettschureck N, and Schwaninger M (2014) Hydroxycarboxylic acid receptor 2 mediates dimethyl fumarate's protective effect in EAE. J Clin Invest 124:2188-2192.

Chen J, Yu Y, Ji T, Ma R, Chen M, Li G, Li F, Ding Q, Kang Q, Huang D, et al. (2016) Clinical implication of Keap1 and phosphorylated Nrf2 expression in hepatocellular carcinoma. Cancer Med 5:2678-2687.

Chen W, Sun Z, Wang XJ, Jiang T, Huang Z, Fang D, and Zhang DD (2009) Direct interaction between Nrf2 and p21(Cip1/WAF1) upregulates the Nrf2-mediated antioxidant response. $\mathrm{Mol}$ Cell 34:663-673.

Chen Y, Inoyama D, Kong AN, Beamer LJ, and Hu L (2011) Kinetic analyses of Keap1-Nrf2 interaction and determination of the minimal Nrf2 peptide sequence required for Keap1 binding using surface plasmon resonance. Chem Biol Drug Des 78:1014-1021.

Chen YC, Wu YR, Wu YC, Lee-Chen GJ, and Chen CM (2013) Genetic analysis of NFE2L2 promoter variation in Taiwanese Parkinson's disease. Parkinsonism Relat Disord 19:247-250.

Chin MP, Reisman SA, Bakris GL, O'Grady M, Linde PG, McCullough PA, Packham D, Vaziri ND, Ward KW, Warnock DG, et al. (2014) Mechanisms contributing to adverse cardiovascular events in patients with type 2 diabetes mellitus and stage 4 chronic kidney disease treated with bardoxolone methyl. Am J Nephrol 39: 499-508.

Chiu CT, Wang Z, Hunsberger JG, and Chuang DM (2013) Therapeutic potential of mood stabilizers lithium and valproic acid: beyond bipolar disorder. Pharmacol Rev 65:105-142.

Cho HY and Kleeberger SR (2010) Nrf2 protects against airway disorders. Toxicol Appl Pharmacol 244:43-56.

Cho HY, Marzec J, and Kleeberger SR (2015) Functional polymorphisms in Nrf2: implications for human disease. Free Radic Biol Med 88 (Pt B):362-372. 
Cho HY, Reddy SP, Yamamoto M, and Kleeberger SR (2004) The transcription factor NRF2 protects against pulmonary fibrosis. FASEB $J$ 18:1258-1260.

Cho YE, Moon PG, Lee JE, Singh TS, Kang W, Lee HC, Lee MH, Kim SH, and Baek MC (2013) Integrative analysis of proteomic and transcriptomic data for identification of pathways related to simvastatin-induced hepatotoxicity. Proteomics 13 $1257-1275$.

Chowdhry S, Zhang Y, McMahon M, Sutherland C, Cuadrado A, and Hayes JD (2013) Nrf2 is controlled by two distinct $\beta$-TrCP recognition motifs in its Neh6 domain, one of which can be modulated by GSK-3 activity. Oncogene 32:3765-3781.

Christou H, Morita T, Hsieh CM, Koike H, Arkonac B, Perrella MA, and Kourembanas S (2000) Prevention of hypoxia-induced pulmonary hypertension by enhancement of endogenous heme oxygenase-1 in the rat. Circ Res 86: 1224-1229.

Chuengsamarn S, Rattanamongkolgul S, Phonrat B, Tungtrongchitr R, and Jirawatnotai S (2014) Reduction of atherogenic risk in patients with type 2 diabetes by curcuminoid extract: a randomized controlled trial. J Nutr Biochem 25:144-150.

Ci X, Zhou J, Lv H, Yu Q, Peng L, and Hua S (2017) Betulin exhibits antiinflammatory activity in LPS-stimulated macrophages and endotoxin-shocked mice through an AMPK/AKT/Nrf2-dependent mechanism. Cell Death Dis 8:e2798.

Cleasby A, Yon J, Day PJ, Richardson C, Tickle IJ, Williams PA, Callahan JF, Carr R, Concha N, Kerns JK, et al. (2014) Structure of the BTB domain of Keap1 and its interaction with the triterpenoid antagonist CDDO. PLoS One 9:e98896.

Comandini A, Marzano V, Curradi G, Federici G, Urbani A, and Saltini C (2010) Markers of anti-oxidant response in tobacco smoke exposed subjects: a data-mining review. Pulm Pharmacol Ther 23:482-492.

Córdova EJ, Velázquez-Cruz R, Centeno F, Baca V, and Orozco L (2010) The NRF2 gene variant, -653G/A, is associated with nephritis in childhood-onset systemic lupus erythematosus. Lupus 19:1237-1242.

Croze E, Yamaguchi KD, Knappertz V, Reder AT, and Salamon H (2013) Interferonbeta-1b-induced short- and long-term signatures of treatment activity in multiple sclerosis. Pharmacogenomics J 13:443-451.

Cuadrado A (2015) Structural and functional characterization of Nrf2 degradation by glycogen synthase kinase 3/ $\beta-T r C P$. Free Radic Biol Med 88 (Pt B):147-157.

Cuadrado A, Martín-Moldes Z, Ye J, and Lastres-Becker I (2014) Transcription factors NRF2 and NF-кB are coordinated effectors of the Rho family, GTP-binding protein RAC1 during inflammation. J Biol Chem 289:15244-15258.

Cuadrado A, Moreno-Murciano P, and Pedraza-Chaverri J (2009) The transcription factor Nrf2 as a new therapeutic target in Parkinson's disease. Expert Opin Ther Targets 13:319-329.

Cui Y, Wang Q, Li X, and Zhang X (2013) Experimental nonalcoholic fatty liver disease in mice leads to cytochrome p450 2a5 upregulation through nuclear factor erythroid 2-like 2 translocation. Redox Biol 1:433-440.

Datta S, Kundu S, Ghosh P, De S, Ghosh A, and Chatterjee M (2014) Correlation of oxidant status with oxidative tissue damage in patients with rheumatoid arthritis. Clin Rheumatol 33:1557-1564.

de la Vega MR, Dodson M, Gross C, Manzour H, Lantz RC, Chapman E, Wang T, Black SM, Garcia JG, and Zhang DD (2016) Role of Nrf2 and autophagy in acute lung injury. Curr Pharmacol Rep 2:91-101.

DeNicola GM, Karreth FA, Humpton TJ, Gopinathan A, Wei C, Frese K, Mangal D, Yu KH, Yeo CJ, Calhoun ES, et al. (2011) Oncogene-induced Nrf2 transcription promotes ROS detoxification and tumorigenesis. Nature 475:106-109.

de Zeeuw D, Akizawa T, Audhya P, Bakris GL, Chin M, Christ-Schmidt H, Goldsberry A, Houser M, Krauth M, Lambers Heerspink HJ, et al.; BEACON Trial Investigators (2013) Bardoxolone methyl in type 2 diabetes and stage 4 chronic kidney disease. $N$ Engl J Med 369:2492-2503.

Diotallevi M, Checconi P, Palamara AT, Celestino I, Coppo L, Holmgren A, Abbas K, Peyrot F, Mengozzi M, and Ghezzi P (2017) Glutathione fine-tunes the innate immune response toward antiviral pathways in a macrophage cell line independently of its antioxidant properties. Front Immunol 8:1239.

Duran CG, Burbank AJ, Mills KH, Duckworth HR, Aleman MM, Kesic MJ, Peden DB, Pan Y, Zhou H, and Hernandez ML (2016) A proof-of-concept clinical study examining the NRF2 activator sulforaphane against neutrophilic airway inflammation. Respir Res 17:89.

Eades G, Yang M, Yao Y, Zhang Y, and Zhou Q (2011) miR-200a regulates Nrf2 activation by targeting Keap1 mRNA in breast cancer cells. J Biol Chem 286: 40725-40733.

Egea J, Buendia I, Parada E, Navarro E, Rada P, Cuadrado A, López MG, García AG, and León R (2015) Melatonin-sulforaphane hybrid ITH12674 induces neuroprotection in oxidative stress conditions by a 'drug-prodrug' mechanism of action. Br J Pharmacol 172:1807-1821.

Ellrichmann G, Petrasch-Parwez E, Lee DH, Reick C, Arning L, Saft C, Gold R, and Linker RA (2011) Efficacy of fumaric acid esters in the R6/2 and YAC128 models of Huntington's disease. PLoS One 6:e16172.

El-Mir MY, Nogueira V, Fontaine E, Avéret N, Rigoulet M, and Leverve X (2000) Dimethylbiguanide inhibits cell respiration via an indirect effect targeted on the respiratory chain complex I. J Biol Chem 275:223-228.

Eminel S, Jin N, Rostami M, Dibbert S, Mrowietz U, and Suhrkamp I (2017) Dimethyl- and monomethylfumarate regulate indoleamine 2,3-dioxygenase (IDO) activity in human immune cells. Exp Dermatol 26:685-690.

Emmink BL, Verheem A, Van Houdt WJ, Steller EJ, Govaert KM, Pham TV, Piersma SR, Borel Rinkes IH, Jimenez CR, and Kranenburg O (2013) The secretome of colon cancer stem cells contains drug-metabolizing enzymes. J Proteomics 91:84-96.

Evans MD, Cooke MS, Akil M, Samanta A, and Lunec J (2000) Aberrant processing of oxidative DNA damage in systemic lupus erythematosus. Biochem Biophys Res Commun 273:894-898.

Fagone P, Patti F, Mangano K, Mammana S, Coco M, Touil-Boukoffa C, Chikovani T, Di Marco R, and Nicoletti F (2013) Heme oxygenase-1 expression in peripheral blood mononuclear cells correlates with disease activity in multiple sclerosis. $J$ Neuroimmunol 261:82-86.
Finkelstein R, Fraser RS, Ghezzo H, and Cosio MG (1995) Alveolar inflammation and its relation to emphysema in smokers. Am $J$ Respir Crit Care Med 152:1666-1672. Fox RJ, Miller DH, Phillips JT, Hutchinson M, Havrdova E, Kita M, Yang M, Raghupathi K, Novas M, Sweetser MT, et al.; CONFIRM Study Investigators (2012) Placebo-controlled phase 3 study of oral BG-12 or glatiramer in multiple sclerosis. N Engl J Med 367:1087-1097.

Freitas AE, Egea J, Buendia I, Gómez-Rangel V, Parada E, Navarro E, Casas AI, Wojnicz A, Ortiz JA, Cuadrado A, et al. (2016) Agmatine, by improving neuroplasticity markers and inducing Nrf2, prevents corticosterone-induced depressivelike behavior in mice. Mol Neurobiol 53:3030-3045.

Frijhoff J, Winyard PG, Zarkovic N, Davies SS, Stocker R, Cheng D, Knight AR Taylor EL, Oettrich J, Ruskovska T, et al. (2015) Clinical relevance of biomarkers of oxidative stress. Antioxid Redox Signal 23:1144-1170.

Frostegård J, Svenungsson E, Wu R, Gunnarsson I, Lundberg IE, Klareskog L, Hörkkö S, and Witztum JL (2005) Lipid peroxidation is enhanced in patients with systemic lupus erythematosus and is associated with arterial and renal disease manifestations. Arthritis Rheum 52:192-200.

Gao J, Chang MT, Johnsen HC, Gao SP, Sylvester BE, Sumer SO, Zhang H, Solit DB, Taylor BS, Schultz N, et al. (2017) 3D clusters of somatic mutations in cancer reveal numerous rare mutations as functional targets. Genome Med 9:4.

Ghanim H, Sia CL, Korzeniewski K, Lohano T, Abuaysheh S, Marumganti A, Chaudhuri A, and Dandona P (2011) A resveratrol and polyphenol preparation suppresses oxidative and inflammatory stress response to a high-fat, high carbohydrate meal. J Clin Endocrinol Metab 96:1409-1414.

Ghezzi P, Floridi L, Boraschi D, Cuadrado A, Manda G, Levic S, D'Acquisto F, Hamilton A, Athersuch TJ, and Selley L (2017a) Oxidative stress and inflammation induced by environmental and psychological stressors: a biomarker perspective. Antioxid Redox Signal [published ahead of print].

Ghezzi P, Jaquet V, Marcucci F, and Schmidt HHHW (2017b) The oxidative stress theory of disease: levels of evidence and epistemological aspects. $\mathrm{Br} J$ Pharmacol 174:1784-1796.

Ghoreschi K, Brück J, Kellerer C, Deng C, Peng H, Rothfuss O, Hussain RZ, Gocke AR, Respa A, Glocova I, et al. (2011) Fumarates improve psoriasis and multiple sclerosis by inducing type II dendritic cells. J Exp Med 208:2291-2303.

Gillard GO, Collette B, Anderson J, Chao J, Scannevin RH, Huss DJ, and Fontenot JD (2015) DMF, but not other fumarates, inhibits NF-kB activity in vitro in an Nrf2-independent manner. J Neuroimmunol 283:74-85.

Goh KI, Cusick ME, Valle D, Childs B, Vidal M, and Barabási AL (2007) The human disease network. Proc Natl Acad Sci USA 104:8685-8690.

Gold R, Kappos L, Arnold DL, Bar-Or A, Giovannoni G, Selmaj K, Tornatore C, Sweetser MT, Yang M, Sheikh SI, et al.; DEFINE Study Investigators (2012) Placebo-controlled phase 3 study of oral BG-12 for relapsing multiple sclerosis. $N$ Engl J Med 367:1098-1107.

Gonzalez-Donquiles C, Alonso-Molero J, Fernandez-Villa T, Vilorio-Marqués L, Molina AJ, and Martín V (2017) The NRF2 transcription factor plays a dual role in colorectal cancer: a systematic review. PLoS One 12:e0177549.

Goven D, Boutten A, Leçon-Malas V, Marchal-Sommé J, Amara N, Crestani B, Fournier M, Lesèche G, Soler P, Boczkowski J, et al. (2008) Altered Nrf2/Keap1 Bach1 equilibrium in pulmonary emphysema. Thorax 63:916-924.

Griendling KK and FitzGerald GA (2003a) Oxidative stress and cardiovascular injury: part I: basic mechanisms and in vivo monitoring of ROS. Circulation 108: 1912-1916.

Griendling KK and FitzGerald GA (2003b) Oxidative stress and cardiovascular injury: part II: animal and human studies. Circulation 108:2034-2040.

Guan CP, Zhou MN, Xu AE, Kang KF, Liu JF, Wei XD, Li YW, Zhao DK, and Hong WS (2008) The susceptibility to vitiligo is associated with NF-E2-related factor2 (Nrf2) gene polymorphisms: a study on Chinese Han population. Exp Dermatol 17: 1059-1062.

Guney E, Menche J, Vidal M, and Barábasi AL (2016) Network-based in silico drug efficacy screening. Nat Commun 7:10331.

Guney E and Oliva B (2014) Analysis of the robustness of network-based diseasegene prioritization methods reveals redundancy in the human interactome and functional diversity of disease-genes. PLoS One 9:e94686.

Han SJ, Ahn Y, Park I, Zhang Y, Kim I, Kim HW, Ku CS, Chay KO, Yang SY, Ahn BW, et al. (2015) Assay of the redox state of the tumor suppressor PTEN by mobility shift. Methods 77-78:58-62.

Hancock R, Schaap M, Pfister H, and Wells G (2013) Peptide inhibitors of the Keap1Nrf2 protein-protein interaction with improved binding and cellular activity. Org Biomol Chem 11:3553-3557.

Harder B, Tian W, La Clair JJ, Tan AC, Ooi A, Chapman E, and Zhang DD (2017) Brusatol overcomes chemoresistance through inhibition of protein translation. $M o l$ Carcinog 56:1493-1500.

Hardie DG (2004) The AMP-activated protein kinase pathway-new players upstream and downstream. J Cell Sci 117:5479-5487.

Harrison D, Griendling KK, Landmesser U, Hornig B, and Drexler H (2003) Role of oxidative stress in atherosclerosis. Am J Cardiol 91:7A-11A.

Hart PC, Ratti BA, Mao M, Ansenberger-Fricano K, Shajahan-Haq AN, Tyner AL, Minshall RD, and Bonini MG (2016) Caveolin-1 regulates cancer cell metabolism via scavenging Nrf2 and suppressing MnSOD-driven glycolysis. Oncotarget 7: 308-322.

Harvey CJ, Thimmulappa RK, Sethi S, Kong X, Yarmus L, Brown RH, Feller-Kopman D, Wise R, and Biswal S (2011) Targeting Nrf2 signaling improves bacterial clearance by alveolar macrophages in patients with COPD and in a mouse model. Sci Transl Med 3:78ra32.

Hast BE, Goldfarb D, Mulvaney KM, Hast MA, Siesser PF, Yan F, Hayes DN, and Major MB (2013) Proteomic analysis of ubiquitin ligase KEAP1 reveals associated proteins that inhibit NRF2 ubiquitination. Cancer Res 73:2199-2210.

Hayes JD and Dinkova-Kostova AT (2014) The Nrf2 regulatory network provides an interface between redox and intermediary metabolism. Trends Biochem Sci 39: 199-218. 
Heckman-Stoddard BM, DeCensi A, Sahasrabuddhe VV, and Ford LG (2017) Repurposing metformin for the prevention of cancer and cancer recurrence. Diabetologia 60:1639-1647.

Hidalgo CA, Blumm N, Barabási AL, and Christakis NA (2009) A dynamic network approach for the study of human phenotypes. PLOS Comput Biol 5:e1000353.

Hong DS, Kurzrock R, Supko JG, He X, Naing A, Wheler J, Lawrence D, Eder JP, Meyer CJ, Ferguson DA, et al. (2012) A phase I first-in-human trial of bardoxolone methyl in patients with advanced solid tumors and lymphomas. Clin Cancer Res 18:3396-3406

Hopkins PN, Wu LL, Hunt SC, James BC, Vincent GM, and Williams RR (1996) Higher serum bilirubin is associated with decreased risk for early familial coronary artery disease. Arterioscler Thromb Vasc Biol 16:250-255.

Houessinon A, François C, Sauzay C, Louandre C, Mongelard G, Godin C, Bodeau S, Takahashi S, Saidak Z, Gutierrez L, et al. (2016) Metallothionein-1 as a biomarker of altered redox metabolism in hepatocellular carcinoma cells exposed to sorafenib. Mol Cancer 15:38.

Houghton CA, Fassett RG, and Coombes JS (2016) Sulforaphane and other nutrigenomic Nrf2 activators: can the clinician's expectation be matched by the reality? Oxid Med Cell Longev 2016:7857186.

Hu L, Magesh S, Chen L, Wang L, Lewis TA, Chen Y, Khodier C, Inoyama D, Beamer LJ, Emge TJ, et al. (2013) Discovery of a small-molecule inhibitor and cellular probe of Keap1-Nrf2 protein-protein interaction. Bioorg Med Chem Lett 23: 3039-3043.

Hua CC, Chang LC, Tseng JC, Chu CM, Liu YC, and Shieh WB (2010) Functional haplotypes in the promoter region of transcription factor Nrf2 in chronic obstructive pulmonary disease. Dis Markers 28:185-193.

Hur W and Gray NS (2011) Small molecule modulators of antioxidant response pathway. Curr Opin Chem Biol 15:162-173.

Hwang AR, Han JH, Lim JH, Kang YJ, and Woo CH (2017) Fluvastatin inhibits AGE-induced cell proliferation and migration via an ERK5-dependent Nrf2 pathway in vascular smooth muscle cells. PLoS One 12:e0178278.

Innamorato NG, Rojo AI, García-Yagüe AJ, Yamamoto M, de Ceballos ML, and Cuadrado A (2008) The transcription factor Nrf2 is a therapeutic target against brain inflammation. $J$ Immunol 181:680-689.

Inoyama D, Chen Y, Huang X, Beamer LJ, Kong AN, and Hu L (2012) Optimization of fluorescently labeled Nrf2 peptide probes and the development of a fluorescence polarization assay for the discovery of inhibitors of Keap1-Nrf2 interaction. $J$ Biomol Screen 17:435-447.

Iorio F, Isacchi A, di Bernardo D, and Brunetti-Pierri N (2010) Identification of small molecules enhancing autophagic function from drug network analysis. Autophagy 6:1204-1205

Ishii T and Mann GE (2014) Redox status in mammalian cells and stem cells during culture in vitro: critical roles of Nrf2 and cystine transporter activity in the maintenance of redox balance. Redox Biol 2:786-794

Jang HJ, Hong EM, Kim M, Kim JH, Jang J, Park SW, Byun HW, Koh DH, Choi MH, Kae SH, et al. (2016) Simvastatin induces heme oxygenase-1 via NF-E2-related factor 2 (Nrf2) activation through ERK and PI3K/Akt pathway in colon cancer. Oncotarget 7:46219-46229.

Jansen T, Hortmann M, Oelze M, Opitz B, Steven S, Schell R, Knorr M, Karbach S, Schuhmacher S, Wenzel P, et al. (2010) Conversion of biliverdin to bilirubin by biliverdin reductase contributes to endothelial cell protection by heme oxygenase1-evidence for direct and indirect antioxidant actions of bilirubin. $\mathrm{J} \mathrm{Mol} \mathrm{Cell}$ Cardiol 49:186-195.

Jay D, Hitomi H, and Griendling KK (2006) Oxidative stress and diabetic cardiovascular complications. Free Radic Biol Med 40:183-192.

Jazwa A, Rojo AI, Innamorato NG, Hesse M, Fernández-Ruiz J, and Cuadrado A (2011) Pharmacological targeting of the transcription factor Nrf2 at the basal ganglia provides disease modifying therapy for experimental parkinsonism. Antioxid Redox Signal 14:2347-2360.

Jiang T, Huang Z, Lin Y, Zhang Z, Fang D, and Zhang DD (2010) The protective role of Nrf2 in streptozotocin-induced diabetic nephropathy. Diabetes 59:850-860.

Jiang T, Tian F, Zheng H, Whitman SA, Lin Y, Zhang Z, Zhang N, and Zhang DD (2014a) Nrf2 suppresses lupus nephritis through inhibition of oxidative injury and the NF-кB-mediated inflammatory response. Kidney Int 85:333-343.

Jiang ZY, Lu MC, Xu LL, Yang TT, Xi MY, Xu XL, Guo XK, Zhang XJ, You QD, and Sun HP (2014b) Discovery of potent Keap1-Nrf2 protein-protein interaction inhibitor based on molecular binding determinants analysis [published correction appears in J Med Chem (2014) 57:4406]. J Med Chem 57: 2736-2745.

Jiang ZY, Lu MC, and You QD (2016) Discovery and development of Kelch-like ECHassociated protein 1: Nuclear factor erythroid 2-related factor 2 (KEAP1:NRF2) protein-protein interaction inhibitors: achievements, challenges, and future directions. J Med Chem 59:10837-10858.

Jiménez-Osorio AS, González-Reyes S, García-Niño WR, Moreno-Macías H, Rodríguez-Arellano ME, Vargas-Alarcón G, Zúñiga J, Barquera R, Pedraza-Chaverri J, Meza-Espinoza JP, et al. (2017) Corrigendum to "association of nuclear factorerythroid 2-related factor 2, thioredoxin interacting protein, and heme oxygenase- 1 gene polymorphisms with diabetes and obesity in Mexican patients." Oxid Med Cell Longev 2017:7543194.

Jiménez-Osorio AS, Picazo A, González-Reyes S, Barrera-Oviedo D, Rodríguez-Arellano ME, and Pedraza-Chaverri J (2014) Nrf2 and redox status in prediabetic and diabetic patients. Int J Mol Sci 15:20290-20305.

Jnoff E, Albrecht C, Barker JJ, Barker O, Beaumont E, Bromidge S, Brookfield F, Brooks M, Bubert C, Ceska T, et al. (2014) Binding mode and structure-activity relationships around direct inhibitors of the Nrf2-Keap1 complex. ChemMedChem 9:699-705.

Jo C, Gundemir S, Pritchard S, Jin YN, Rahman I, and Johnson GV (2014) Nrf2 reduces levels of phosphorylated tau protein by inducing autophagy adaptor protein NDP52. Nat Commun 5:3496.
Johnson DA, Amirahmadi S, Ward C, Fabry Z, and Johnson JA (2010) The absence of the pro-antioxidant transcription factor Nrf2 exacerbates experimental autoimmune encephalomyelitis. Toxicol Sci 114:237-246.

Johnson DA and Johnson JA (2015) Nrf2-a therapeutic target for the treatment of neurodegenerative diseases. Free Radic Biol Med 88 (Pt B):253-267.

Johnson NM, Egner PA, Baxter VK, Sporn MB, Wible RS, Sutter TR, Groopman JD, Kensler TW, and Roebuck BD (2014) Complete protection against aflatoxin B(1) induced liver cancer with a triterpenoid: DNA adduct dosimetry, molecular signature, and genotoxicity threshold. Cancer Prev Res (Phila) 7:658-665.

Jones RM, Desai C, Darby TM, Luo L, Wolfarth AA, Scharer CD, Ardita CS, Reedy AR, Keebaugh ES, and Neish AS (2015) Lactobacilli modulate epithelial cytoprotection through the Nrf2 pathway. Cell Reports 12:1217-1225.

Jung KA, Lee S, and Kwak MK (2017) NFE2L2/NRF2 activity is linked to mitochondria and AMP-activated protein kinase signaling in cancers through miR181c/mitochondria-encoded cytochrome c oxidase regulation. Antioxid Redox Signal 27:945-961.

Kaidery NA, Banerjee R, Yang L, Smirnova NA, Hushpulian DM, Liby KT, Williams CR, Yamamoto M, Kensler TW, Ratan RR, et al. (2013) Targeting Nrf2-mediated gene transcription by extremely potent synthetic triterpenoids attenuates dopaminergic neurotoxicity in the MPTP mouse model of Parkinson's disease. Antioxid Redox Signal 18:139-157.

Kaisar MA, Villalba H, Prasad S, Liles T, Sifat AE, Sajja RK, Abbruscato TJ, and Cucullo L (2017) Offsetting the impact of smoking and e-cigarette vaping on the cerebrovascular system and stroke injury: is Metformin a viable countermeasure? Redox Biol 13:353-362.

Kastrati I, Siklos MI, Calderon-Gierszal EL, El-Shennawy L, Georgieva G, Thayer EN, Thatcher GR, and Frasor J (2016) Dimethyl fumarate inhibits the nuclear factor $\kappa \mathrm{B}$ pathway in breast cancer cells by covalent modification of p65 protein. $J$ Biol Chem 291:3639-3647.

Kelleni MT, Amin EF, and Abdelrahman AM (2015) Effect of metformin and sitagliptin on doxorubicin-induced cardiotoxicity in rats: impact of oxidative stress, inflammation, and apoptosis. J Toxicol 2015:424813.

Kensler TW, Egner PA, Agyeman AS, Visvanathan K, Groopman JD, Chen JG, Chen TY, Fahey JW, and Talalay P (2013) Keap1-nrf2 signaling: a target for cancer prevention by sulforaphane. Top Curr Chem 329:163-177.

Khan I, Tantray MA, Alam MS, and Hamid H (2017) Natural and synthetic bioactive inhibitors of glycogen synthase kinase. Eur J Med Chem 125:464-477.

Kim JE, You DJ, Lee C, Ahn C, Seong JY, and Hwang JI (2010a) Suppression of NF-kappaB signaling by KEAP1 regulation of IKKbeta activity through autophagic degradation and inhibition of phosphorylation. Cell Signal 22:1645-1654.

Kim T, Kim YJ, Han IH, Lee D, Ham J, Kang KS, and Lee JW (2015) The synthesis of sulforaphane analogues and their protection effect against cisplatin induced cytotoxicity in kidney cells. Bioorg Med Chem Lett 25:62-66.

Kim YR, Oh JE, Kim MS, Kang MR, Park SW, Han JY, Eom HS, Yoo NJ, and Lee SH (2010b) Oncogenic NRF2 mutations in squamous cell carcinomas of oesophagus and skin. J Pathol 220:446-451.

Kitagishi Y and Matsuda S (2013) Redox regulation of tumor suppressor PTEN in cancer and aging (Review). Int $J \mathrm{Mol}$ Med 31:511-515.

Kitsak M, Sharma A, Menche J, Guney E, Ghiassian SD, Loscalzo J, and Barabási AL (2016) Tissue specificity of human disease module. Sci Rep 6:35241.

Kobayashi EH, Suzuki T, Funayama R, Nagashima T, Hayashi M, Sekine H, Tanaka N, Moriguchi T, Motohashi H, Nakayama K, et al. (2016) Nrf2 suppresses macrophage inflammatory response by blocking proinflammatory cytokine transcription. Nat Commun 7:11624

Kocer D, Bayram F, and Diri H (2014) The effects of metformin on endothelial dysfunction, lipid metabolism and oxidative stress in women with polycystic ovary syndrome. Gynecol Endocrinol 30:367-371.

Komatsu M, Kurokawa H, Waguri S, Taguchi K, Kobayashi A, Ichimura Y, Sou YS, Ueno I, Sakamoto A, Tong KI, et al. (2010) The selective autophagy substrate p62 activates the stress responsive transcription factor $\mathrm{Nrf2}$ through inactivation of Keap1. Nat Cell Biol 12:213-223.

Kong X, Thimmulappa R, Craciun F, Harvey C, Singh A, Kombairaju P, Reddy SP, Remick D, and Biswal S (2011) Enhancing Nrf2 pathway by disruption of Keap1 in myeloid leukocytes protects against sepsis. Am J Respir Crit Care Med 184: 928-938.

Kruger AL, Peterson SJ, Schwartzman ML, Fusco H, McClung JA, Weiss M, Shenouda S, Goodman AI, Goligorsky MS, Kappas A, et al. (2006) Up-regulation of heme oxygenase provides vascular protection in an animal model of diabetes through its antioxidant and antiapoptotic effects. J Pharmacol Exp Ther 319: 1144-1152.

Kruse ML, Friedrich M, Arlt A, Röcken C, Egberts JH, Sebens S, and Schäfer H (2016) Colonic lamina propria inflammatory cells from patients with IBD induce the nuclear factor-E2 related factor-2 thereby leading to greater proteasome activity and apoptosis protection in human colonocytes. Inflamm Bowel Dis 22: $2593-2606$

Kuang X, Scofield VL, Yan M, Stoica G, Liu N, and Wong PK (2009) Attenuation of oxidative stress, inflammation and apoptosis by minocycline prevents retrovirusinduced neurodegeneration in mice. Brain Res 1286:174-184.

Kurinna S and Werner S (2015) NRF2 and microRNAs: new but awaited relations. Biochem Soc Trans 43:595-601.

Kwak JY, Takeshige K, Cheung BS, and Minakami S (1991) Bilirubin inhibits the activation of superoxide-producing NADPH oxidase in a neutrophil cell-free system. Biochim Biophys Acta 1076:369-373.

Lamb J, Crawford ED, Peck D, Modell JW, Blat IC, Wrobel MJ, Lerner J, Brunet JP, Subramanian A, Ross KN, et al. (2006) The connectivity map: using geneexpression signatures to connect small molecules, genes, and disease. Science $\mathbf{3 1 3}$ 1929-1935

Lastres-Becker I, García-Yagüe AJ, Scannevin RH, Casarejos MJ, Kügler S, Rábano A, and Cuadrado A (2016) Repurposing the NRF2 activator dimethyl fumarate as 
therapy against synucleinopathy in Parkinson's disease. Antioxid Redox Signal 25: $61-77$.

Lastres-Becker I, Innamorato NG, Jaworski T, Rábano A, Kügler S, Van Leuven F, and Cuadrado A (2014) Fractalkine activates NRF2/NFE2L2 and heme oxygenase 1 to restrain tauopathy-induced microgliosis. Brain 137:78-91.

Lastres-Becker I, Ulusoy A, Innamorato NG, Sahin G, Rábano A, Kirik D, and Cuadrado A (2012) $\alpha$-Synuclein expression and Nrf2 deficiency cooperate to aggravate protein aggregation, neuronal death and inflammation in early-stage Parkinson's disease. Hum Mol Genet 21:3173-3192.

Lee D, Xu IM, Chiu DK, Lai RK, Tse AP, Lan Li L, Law CT, Tsang FH, Wei LL, Chan CY, et al. (2017) Folate cycle enzyme MTHFD1L confers metabolic advantages in hepatocellular carcinoma. J Clin Invest 127:1856-1872.

Lee DF, Kuo HP, Liu M, Chou CK, Xia W, Du Y, Shen J, Chen CT, Huo L, Hsu MC, et al. (2009) KEAP1 E3 ligase-mediated downregulation of NF-kappaB signaling by targeting IKKbeta. Mol Cell 36:131-140.

Lee SR, Yang KS, Kwon J, Lee C, Jeong W, and Rhee SG (2002) Reversible inactivation of the tumor suppressor PTEN by H2O2. J Biol Chem 277:20336-20342.

Li B, Cui W, Liu J, Li R, Liu Q, Xie XH, Ge XL, Zhang J, Song XJ, Wang Y, et al. (2013) Sulforaphane ameliorates the development of experimental autoimmune encephalomyelitis by antagonizing oxidative stress and Th17-related inflammation in mice. Exp Neurol 250:239-249.

Li J, Stein TD, and Johnson JA (2004) Genetic dissection of systemic autoimmune disease in Nrf2-deficient mice. Physiol Genomics 18:261-272.

Licht-Mayer S, Wimmer I, Traffehn S, Metz I, Brück W, Bauer J, Bradl M, and Lassmann H (2015) Cell type-specific Nrf2 expression in multiple sclerosis lesions. Acta Neuropathol 130:263-277.

Limonciel A and Jennings P (2014) A review of the evidence that ochratoxin A is an Nrf2 inhibitor: implications for nephrotoxicity and renal carcinogenicity. Toxins (Basel) 6:371-379.

Lin CH, Lin HI, Chen ML, Lai TT, Cao LP, Farrer MJ, Wu RM, and Chien CT (2016) Lovastatin protects neurite degeneration in LRRK2-G2019S parkinsonism through activating the Akt/Nrf pathway and inhibiting GSK3 $\beta$ activity. Hum Mol Genet 25 $1965-1978$

Lin SX, Lisi L, Dello Russo C, Polak PE, Sharp A, Weinberg G, Kalinin S, and Feinstein DL (2011) The anti-inflammatory effects of dimethyl fumarate in astrocytes involve glutathione and haem oxygenase-1. ASN Neuro 3:75-84.

Lin W, Wu RT, Wu T, Khor TO, Wang H, and Kong AN (2008) Sulforaphane suppressed LPS-induced inflammation in mouse peritoneal macrophages through Nrf2 dependent pathway. Biochem Pharmacol 76:967-973.

Linker RA, Lee DH, Ryan S, van Dam AM, Conrad R, Bista P, Zeng W, Hronowsky X, Buko A, Chollate S, et al. (2011) Fumaric acid esters exert neuroprotective effects in neuroinflammation via activation of the Nrf2 antioxidant pathway. Brain 134 $678-692$.

Liu GH, Qu J, and Shen X (2008) NF-kappaB/p65 antagonizes Nrf2-ARE pathway by depriving CBP from Nrf2 and facilitating recruitment of HDAC3 to MafK. Biochim Biophys Acta 1783:713-727.

Liu TS, Pei YH, Peng YP, Chen J, Jiang SS, and Gong JB (2014) Oscillating high glucose enhances oxidative stress and apoptosis in human coronary artery endothelial cells. J Endocrinol Invest 37:645-651.

Lo SC, Li X, Henzl MT, Beamer LJ, and Hannink M (2006) Structure of the Keap1: Nrf2 interface provides mechanistic insight into Nrf2 signaling. $E M B O J \mathbf{2 5}$ 3605-3617.

LoGerfo A, Chico L, Borgia L, Petrozzi L, Rocchi A, D’Amelio A, Carlesi C, Caldarazzo Ienco E, Mancuso M, and Siciliano G (2014) Lack of association between nuclear factor erythroid-derived 2-like 2 promoter gene polymorphisms and oxidative stress biomarkers in amyotrophic lateral sclerosis patients. Oxid Med Cell Longev 2014:432626

Lu K, Alcivar AL, Ma J, Foo TK, Zywea S, Mahdi A, Huo Y, Kensler TW, Gatza ML, and Xia B (2017) NRF2 induction supporting breast cancer cell survival is enabled by oxidative stress-induced DPP3-KEAP1 interaction. Cancer Res $\mathbf{7 7}$ 2881-2892.

Lu MC, Jiao Q, Liu T, Tan SJ, Zhou HS, You QD, and Jiang ZY (2018) Discovery of a head-to-tail cyclic peptide as the Keap1-Nrf2 protein-protein interaction inhibitor with high cell potency. Eur J Med Chem 143:1578-1589.

Lv H, Liu Q, Wen Z, Feng H, Deng X, and Ci X (2017) Xanthohumol ameliorates lipopolysaccharide (LPS)-induced acute lung injury via induction of AMPK/GSK3BNrf2 signal axis. Redox Biol 12:311-324.

Ma Q (2013) Role of nrf2 in oxidative stress and toxicity. Annu Rev Pharmacol Toxicol 53:401-426.

Ma Q, Battelli L, and Hubbs AF (2006) Multiorgan autoimmune inflammation, enhanced lymphoproliferation, and impaired homeostasis of reactive oxygen species in mice lacking the antioxidant-activated transcription factor Nrf2. Am J Pathol 168:1960-1974

Maicas N, Ferrándiz ML, Brines R, Ibáñez L, Cuadrado A, Koenders MI, van den Berg WB, and Alcaraz MJ (2011) Deficiency of Nrf2 accelerates the effector phase of arthritis and aggravates joint disease. Antioxid Redox Signal 15:889-901.

Manna A, De Sarkar S, De S, Bauri AK, Chattopadhyay S, and Chatterjee M (2015) The variable chemotherapeutic response of malabaricone-A in leukemic and solid tumor cell lines depends on the degree of redox imbalance. Phytomedicine 22: $713-723$.

Maqbool M and Hoda N (2017) GSK3 inhibitors in the therapeutic development of diabetes, cancer and neurodegeneration: past, present and future. Curr Pharm Des 23:4332-4350

Marcotte D, Zeng W, Hus JC, McKenzie A, Hession C, Jin P, Bergeron C, Lugovskoy A, Enyedy I, Cuervo H, et al. (2013) Small molecules inhibit the interaction of Nrf2 and the Keap1 Kelch domain through a non-covalent mechanism. Bioorg Med Chem 21:4011-4019.

Markart P, Luboeinski T, Korfei M, Schmidt R, Wygrecka M, Mahavadi P, Mayer K, Wilhelm J, Seeger W, Guenther A, et al. (2009) Alveolar oxidative stress is associated with elevated levels of nonenzymatic low-molecular-weight antioxidants in patients with different forms of chronic fibrosing interstitial lung diseases. Antioxid Redox Signal 11:227-240.

Markowicz-Piasecka M, Sikora J, Szydłowska A, Skupień A, Mikiciuk-Olasik E, and Huttunen KM (2017) Metformin - a future therapy for neurodegenerative diseases: theme: drug discovery, development and delivery in Alzheimer's disease: guest editor: Davide Brambilla. Pharm Res 34:2614-2627.

Marrone G, Maeso-Díaz R, García-Cardena G, Abraldes JG, García-Pagán JC, Bosch J, and Gracia-Sancho J (2015) KLF2 exerts antifibrotic and vasoprotective effects in cirrhotic rat livers: behind the molecular mechanisms of statins. Gut 64: 1434-1443.

Martín-de-Saavedra MD, Budni J, Cunha MP, Gómez-Rangel V, Lorrio S, Del Barrio L, Lastres-Becker I, Parada E, Tordera RM, Rodrigues AL, et al. (2013) Nrf2 participates in depressive disorders through an anti-inflammatory mechanism. Psychoneuroendocrinology 38:2010-2022.

Marzec JM, Christie JD, Reddy SP, Jedlicka AE, Vuong H, Lanken PN, Aplenc R, Yamamoto T, Yamamoto M, Cho HY, et al. (2007) Functional polymorphisms in the transcription factor NRF2 in humans increase the risk of acute lung injury. FASEB $J$ 21:2237-2246.

McCubrey JA, Steelman LS, Bertrand FE, Davis NM, Sokolosky M, Abrams SL, Montalto G, D'Assoro AB, Libra M, Nicoletti F, et al. (2014) GSK-3 as potential target for therapeutic intervention in cancer. Oncotarget 5:2881-2911.

McGuire VA, Ruiz-Zorrilla Diez T, Emmerich CH, Strickson S, Ritorto MS, Sutavani RV, Wei $\beta$ A, Houslay KF, Knebel A, Meakin PJ, et al. (2016) Dimethyl fumarate blocks pro-inflammatory cytokine production via inhibition of TLR induced M1 and K63 ubiquitin chain formation. Sci Rep 6:31159.

Meakin PJ, Chowdhry S, Sharma RS, Ashford FB, Walsh SV, McCrimmon RJ, Dinkova-Kostova AT, Dillon JF, Hayes JD, and Ashford ML (2014) Susceptibility of Nrf2-null mice to steatohepatitis and cirrhosis upon consumption of a high-fat diet is associated with oxidative stress, perturbation of the unfolded protein response, and disturbance in the expression of metabolic enzymes but not with insulin resistance. Mol Cell Biol 34:3305-3320.

Meissner M, Doll M, Hrgovic I, Reichenbach G, König V, Hailemariam-Jahn T, Gille J, and Kaufmann R (2011) Suppression of VEGFR2 expression in human endothelial cells by dimethylfumarate treatment: evidence for anti-angiogenic action. $J$ Invest Dermatol 131:1356-1364.

Menche J, Sharma A, Kitsak M, Ghiassian SD, Vidal M, Loscalzo J, and Barabási AL (2015) Disease networks: uncovering disease-disease relationships through the incomplete interactome. Science 347:1257601.

Milkovic L, Zarkovic N, and Saso L (2017) Controversy about pharmacological modulation of Nrf2 for cancer therapy. Redox Biol 12:727-732.

Mitsuishi Y, Taguchi K, Kawatani Y, Shibata T, Nukiwa T, Aburatani H, Yamamoto M, and Motohashi H (2012) Nrf2 redirects glucose and glutamine into anabolic pathways in metabolic reprogramming. Cancer Cell 22:66-79.

Moon SJ, Park JS, Woo YJ, Lim MA, Kim SM, Lee SY, Kim EK, Lee HJ, Lee WS, Park SH, et al. (2014) Rebamipide suppresses collagen-induced arthritis through reciprocal regulation of th17/treg cell differentiation and heme oxygenase 1 induction. Arthritis Rheumatol 66:874-885.

Morgan MJ and Liu ZG (2011) Crosstalk of reactive oxygen species and NF-кB signaling. Cell Res 21:103-115.

Morgan PE, Sturgess AD, Hennessy A, and Davies MJ (2007) Serum protein oxidation and apolipoprotein CIII levels in people with systemic lupus erythematosus with and without nephritis. Free Radic Res 41:1301-1312.

Mrowietz U, Christophers E, and Altmeyer P (1998) Treatment of psoriasis with fumaric acid esters: results of a prospective multicentre study: German Multicentre study. Br J Dermatol 138:456-460.

Mrowietz U, Szepietowski JC, Loewe R, van de Kerkhof P, Lamarca R, Ocker WG Tebbs VM, and Pau-Charles I (2017) Efficacy and safety of LAS41008 (dimethyl fumarate) in adults with moderate-to-severe chronic plaque psoriasis: a randomized, double-blind, Fumaderm®- and placebo-controlled trial (BRIDGE). $\mathrm{Br}$ Dermatol 176:615-623.

Na LX, Li Y, Pan HZ, Zhou XL, Sun DJ, Meng M, Li XX, and Sun CH (2013) Curcuminoids exert glucose-lowering effect in type 2 diabetes by decreasing serum free fatty acids: a double-blind, placebo-controlled trial. Mol Nutr Food Res 57: 1569-1577.

Napetschnig J and Wu H (2013) Molecular basis of NF-кB signaling. Annu Rev Biophys 42:443-468.

Nasiri HR, Linge S, and Ullmann D (2016) Thermodynamic profiling of inhibitors of Nrf2:Keap1 interactions. Bioorg Med Chem Lett 26:526-529.

Natarajan VT, Singh A, Kumar AA, Sharma P, Kar HK, Marrot L, Meunier JR, Natarajan K, Rani R, and Gokhale RS (2010) Transcriptional upregulation of Nrf2dependent phase II detoxification genes in the involved epidermis of vitiligo vulgaris. J Invest Dermatol 130:2781-2789.

Nef HM, Möllmann H, Troidl C, Kostin S, Böttger T, Voss S, Hilpert P, Krause N, Weber M, Rolf A, et al. (2008) Expression profiling of cardiac genes in Tako-Tsubo cardiomyopathy: insight into a new cardiac entity. $J$ Mol Cell Cardiol 44:395-404.

Nesti L and Natali A (2017) Metformin effects on the heart and the cardiovascular system: a review of experimental and clinical data. Nutr Metab Cardiovasc Dis $\mathbf{2 7}$ $657-669$.

Ockenfels HM, Schultewolter T, Ockenfels G, Funk R, and Goos M (1998) The antipsoriatic agent dimethylfumarate immunomodulates T-cell cytokine secretion and inhibits cytokines of the psoriatic cytokine network. $\mathrm{Br} J$ Dermatol 139: 390-395

Okano Y, Nezu U, Enokida Y, Lee MT, Kinoshita H, Lezhava A, Hayashizaki Y, Morita S, Taguri M, Ichikawa Y, et al. (2013) SNP (-617C >A) in ARE-like loci of the NRF2 gene: a new biomarker for prognosis of lung adenocarcinoma in Japanese non-smoking women. PLoS One 8:e73794

Olayanju A, Copple IM, Bryan HK, Edge GT, Sison RL, Wong MW, Lai ZQ, Lin ZX, Dunn K, Sanderson CM, et al. (2015) Brusatol provokes a rapid and transient inhibition of Nrf2 signaling and sensitizes mammalian cells to chemical toxicity: implications for therapeutic targeting of Nrf2. Free Radic Biol Med 78:202-212. 
Onderdijk AJ, Balak DM, Baerveldt EM, Florencia EF, Kant M, Laman JD, van IJcken WF, Racz E, de Ridder D, Thio HB, et al. (2014) Regulated genes in psoriatic skin during treatment with fumaric acid esters. $\mathrm{Br} J$ Dermatol 171:732-741.

Onyiah JC, Sheikh SZ, Maharshak N, Otterbein LE, and Plevy SE (2014) Heme oxygenase-1 and carbon monoxide regulate intestinal homeostasis and mucosal immune responses to the enteric microbiota. Gut Microbes 5:220-224.

Orena S, Owen J, Jin F, Fabian M, Gillitt ND, and Zeisel SH (2015) Extracts of fruits and vegetables activate the antioxidant response element in IMR-32 cells. J Nutr 145:2006-2011.

Owen MR, Doran E, and Halestrap AP (2000) Evidence that metformin exerts its anti-diabetic effects through inhibition of complex 1 of the mitochondrial respiratory chain. Biochem $J$ 348:607-614.

Padmanabhan B, Tong KI, Ohta T, Nakamura Y, Scharlock M, Ohtsuji M, Kang MI, Kobayashi A, Yokoyama S, and Yamamoto M (2006) Structural basis for defects of Keap1 activity provoked by its point mutations in lung cancer. Mol Cell 21: 689-700.

Pajares M, Cuadrado A, and Rojo AI (2017) Modulation of proteostasis by transcription factor NRF2 and impact in neurodegenerative diseases. Redox Biol 11: 543-553.

Pajares M, Jiménez-Moreno N, Dias IH, Debelec B, Vucetic M, Fladmark KE, Basaga H, Ribaric S, Milisav I, and Cuadrado A (2015) Redox control of protein degradation. Redox Biol 6:409-420.

Pajares M, Jiménez-Moreno N, García-Yagüe AJ, Escoll M, de Ceballos ML, Van Leuven F, Rábano A, Yamamoto M, Rojo AI, and Cuadrado A (2016) Transcription factor NFE2L2/NRF2 is a regulator of macroautophagy genes. Autophagy 12 1902-1916

Palomo V and Martinez A (2017) Glycogen synthase kinase 3 (GSK-3) inhibitors: a patent update (2014-2015). Expert Opin Ther Pat 27:657-666.

Panieri E and Santoro MM (2016) ROS homeostasis and metabolism: a dangerous liason in cancer cells. Cell Death Dis 7:e2253.

Pantan R, Tocharus J, Suksamrarn A, and Tocharus C (2016) Synergistic effect of atorvastatin and cyanidin-3-glucoside on angiotensin II-induced inflammation in vascular smooth muscle cells. Exp Cell Res 342:104-112.

Pareek TK, Belkadi A, Kesavapany S, Zaremba A, Loh SL, Bai L, Cohen ML, Meyer C, Liby KT, Miller RH, et al. (2011) Triterpenoid modulation of IL-17 and Nrf-2 expression ameliorates neuroinflammation and promotes remyelination in autoimmune encephalomyelitis. Sci Rep 1:201.

Park SY, Lee SW, Shin HK, Chung WT, Lee WS, Rhim BY, Hong KW, and Kim CD (2010) Cilostazol enhances apoptosis of synovial cells from rheumatoid arthritis patients with inhibition of cytokine formation via Nrf2-linked heme oxygenase 1 induction. Arthritis Rheum 62:732-741.

Pedruzzi LM, Cardozo LF, Daleprane JB, Stockler-Pinto MB, Monteiro EB, Leite M Jr, Vaziri ND, and Mafra D (2015) Systemic inflammation and oxidative stress in hemodialysis patients are associated with down-regulation of Nrf2. J Nephrol 28: 495-501.

Peng H, Guerau-de-Arellano M, Mehta VB, Yang Y, Huss DJ, Papenfuss TL, LovettRacke AE, and Racke MK (2012) Dimethyl fumarate inhibits dendritic cell maturation via nuclear factor $\mathrm{\kappa B}(\mathrm{NF}-\mathrm{\kappa B})$ and extracellular signal-regulated kinase 1 and $2(\mathrm{ERK} 1 / 2)$ and mitogen stress-activated kinase 1 (MSK1) signaling. J Biol Chem 287:28017-28026.

Pergola PE, Raskin P, Toto RD, Meyer CJ, Huff JW, Grossman EB, Krauth M, Ruiz S, Audhya P, Christ-Schmidt H, et al.; BEAM Study Investigators (2011) Bardoxolone methyl and kidney function in CKD with type 2 diabetes. $N$ Engl J Med 365:327-336.

Pilar Valdecantos M, Prieto-Hontoria PL, Pardo V, Módol T, Santamaría B, Weber M, Herrero L, Serra D, Muntané J, Cuadrado A, et al. (2015) Essential role of Nrf2 in the protective effect of lipoic acid against lipoapoptosis in hepatocytes. Free Radic Biol Med 84:263-278.

Piñero J, Bravo À, Queralt-Rosinach N, Gutiérrez-Sacristán A, Deu-Pons J, Centeno E, García-García J, Sanz F, and Furlong LI (2017) DisGeNET: a comprehensive platform integrating information on human disease-associated genes and variants. Nucleic Acids Res 45:D833-D839.

Pitha-Rowe I, Liby K, Royce D, and Sporn M (2009) Synthetic triterpenoids attenuate cytotoxic retinal injury: cross-talk between Nrf2 and PI3K/AKT signaling through inhibition of the lipid phosphatase PTEN. Invest Ophthalmol Vis Sci 50: $5339-5347$.

Qiu P, Man S, Li J, Liu J, Zhang L, Yu P, and Gao W (2016) Overdose intake of curcumin initiates the unbalanced state of bodies. J Agric Food Chem 64 $2765-2771$.

Rachakonda G, Xiong Y, Sekhar KR, Stamer SL, Liebler DC, and Freeman ML (2008) Covalent modification at Cys151 dissociates the electrophile sensor Keap1 from the ubiquitin ligase CUL3. Chem Res Toxicol 21:705-710.

Rada P, Rojo AI, Chowdhry S, McMahon M, Hayes JD, and Cuadrado A (2011) SCF/ beta-TrCP promotes glycogen synthase kinase 3-dependent degradation of the Nrf2 transcription factor in a Keap1-independent manner. Mol Cell Biol 31:1121-1133.

Rada P, Rojo AI, Evrard-Todeschi N, Innamorato NG, Cotte A, Jaworski T, TobónVelasco JC, Devijver H, García-Mayoral MF, Van Leuven F, et al. (2012) Structural and functional characterization of $\mathrm{Nrf2}$ degradation by the glycogen synthase kinase 3/B-TrCP axis. Mol Cell Biol 32:3486-3499.

Ramadori P, Drescher H, Erschfeld S, Schumacher F, Berger C, Fragoulis A, Schenkel J, Kensler TW, Wruck CJ, Trautwein C, et al. (2016) Hepatocyte-specific Keap1 deletion reduces liver steatosis but not inflammation during non-alcoholic steatohepatitis development. Free Radic Biol Med 91:114-126.

Ramsey CP, Glass CA, Montgomery MB, Lindl KA, Ritson GP, Chia LA, Hamilton $\mathrm{RL}$, Chu CT, and Jordan-Sciutto KL (2007) Expression of Nrf2 in neurodegenerative diseases. J Neuropathol Exp Neurol 66:75-85.

Rangasamy T, Cho CY, Thimmulappa RK, Zhen L, Srisuma SS, Kensler TW, Yamamoto M, Petrache I, Tuder RM, and Biswal S (2004) Genetic ablation of Nrf? enhances susceptibility to cigarette smoke-induced emphysema in mice. J Clin Invest 114:1248-1259.
Ranjan N, Fulcrand G, King A, Brown J, Jiang X, Leng F, and Arya DP (2014) Selective inhibition of bacterial topoisomerase I by alkynyl-bisbenzimidazoles. MedChemComm 5:816-825.

Reccia I, Kumar J, Akladios C, Virdis F, Pai M, Habib N, and Spalding D (2017) Nonalcoholic fatty liver disease: a sign of systemic disease. Metabolism 72:94-108.

Ren D, Villeneuve NF, Jiang T, Wu T, Lau A, Toppin HA, and Zhang DD (2011) Brusatol enhances the efficacy of chemotherapy by inhibiting the Nrf2-mediated defense mechanism. Proc Natl Acad Sci USA 108:1433-1438.

Rena G, Hardie DG, and Pearson ER (2017) The mechanisms of action of metformin. Diabetologia 60:1577-1585. Reuter S, Gupta SC, Chaturvedi MM, and Aggarwal BB (2010) Oxidative stress, inflammation, and cancer: how are they linked? Free Radic Biol Med 49:1603-1616.

Richardson BG, Jain AD, Speltz TE, and Moore TW (2015) Non-electrophilic modulators of the canonical Keap1/Nrf2 pathway. Bioorg Med Chem Lett 25:2261-2268.

Roberts CA, Dickinson AK, and Taams LS (2015) The interplay between monocytes/ macrophages and CD4(+) T cell subsets in rheumatoid arthritis. Front Immunol 6 : 571.

Rojo AI, Innamorato NG, Martín-Moreno AM, De Ceballos ML, Yamamoto M, and Cuadrado A (2010) Nrf2 regulates microglial dynamics and neuroinflammation in experimental Parkinson's disease. Glia 58:588-598.

Rojo AI, McBean G, Cindric M, Egea J, López MG, Rada P, Zarkovic N, and Cuadrado A (2014a) Redox control of microglial function: molecular mechanisms and functional significance. Antioxid Redox Signal 21:1766-1801.

Rojo AI, Rada P, Mendiola M, Ortega-Molina A, Wojdyla K, Rogowska-Wrzesinska A Hardisson D, Serrano M, and Cuadrado A (2014b) The PTEN/NRF2 axis promotes human carcinogenesis. Antioxid Redox Signal 21:2498-2514.

Rushworth SA, Zaitseva L, Murray MY, Shah NM, Bowles KM, and MacEwan DJ (2012) The high Nrf2 expression in human acute myeloid leukemia is driven by $\mathrm{NF}-\mathrm{kB}$ and underlies its chemo-resistance. Blood 120:5188-5198.

Ryoo IG, Lee SH, and Kwak MK (2016) Redox modulating NRF2: a potential mediator of cancer stem cell resistance. Oxid Med Cell Longev 2016:2428153.

Saddawi-Konefka R, Seelige R, Gross ET, Levy E, Searles SC, Washington A Jr, Santosa EK, Liu B, O'Sullivan TE, Harismendy O, et al. (2016) Nrf2 induces IL-17D to mediate tumor and virus surveillance. Cell Reports 16:2348-2358.

Saito R, Suzuki T, Hiramoto K, Asami S, Naganuma E, Suda H, Iso T, Yamamoto H, Morita M, Baird L, et al. (2015) Characterizations of three major cysteine sensors of Keap1 in stress response. Mol Cell Biol 36:271-284.

Saracino AM and Orteu CH (2017) Severe recalcitrant cutaneous manifestations in systemic lupus erythematosus successfully treated with fumaric acid esters. $\mathrm{Br} J$ Dermatol 176:472-480.

Sato M, Aoki T, Inoue H, Tanaka T, and Kunishima N (2013) Keap1 Protein Binding Compound, Cristal of Complex Between the Same and Keap1 Protein, and Method for Producing the Same, Toray Industries, Tokyo.

Sato N, Takasaka N, Yoshida M, Tsubouchi K, Minagawa S, Araya J, Saito N, Fujita Y, Kurita Y, Kobayashi K, et al. (2016) Metformin attenuates lung fibrosis development via NOX4 suppression. Respir Res 17:107.

Satoh T, McKercher SR, and Lipton SA (2013) Nrf2/ARE-mediated antioxidant actions of pro-electrophilic drugs. Free Radic Biol Med 65:645-657.

Scannevin RH, Chollate S, Jung MY, Shackett M, Patel H, Bista P, Zeng W, Ryan S, Yamamoto M, Lukashev M, et al. (2012) Fumarates promote cytoprotection of central nervous system cells against oxidative stress via the nuclear factor (erythroid-derived 2)-like 2 pathway. J Pharmacol Exp Ther 341:274-284.

Schilling S, Goelz S, Linker R, Luehder F, and Gold R (2006) Fumaric acid esters are effective in chronic experimental autoimmune encephalomyelitis and suppress macrophage infiltration. Clin Exp Immunol 145:101-107.

Schimrigk S, Brune N, Hellwig K, Lukas C, Bellenberg B, Rieks M, Hoffmann V, Pohlau D, and Przuntek H (2006) Oral fumaric acid esters for the treatment of active multiple sclerosis: an open-label, baseline-controlled pilot study. Eur $J$ Neurol 13:604-610.

Schipper HM, Song W, Zukor H, Hascalovici JR, and Zeligman D (2009) Heme oxygenase-1 and neurodegeneration: expanding frontiers of engagement. $J \mathrm{Neu}$ rochem 110:469-485.

Schuiveling M, Vazirpanah N, Radstake TRDJ, Zimmermann M, and Broen JCA (2017) Metformin, a new era for an old drug in the treatment of immune mediated disease? Curr Drug Targets [published ahead of print].

Schulze-Topphoff U, Varrin-Doyer M, Pekarek K, Spencer CM, Shetty A, Sagan SA Cree BA, Sobel RA, Wipke BT, Steinman L, et al. (2016) Dimethyl fumarate treatment induces adaptive and innate immune modulation independent of Nrf2. Proc Natl Acad Sci USA 113:4777-4782.

Schumacker PT (2006) Reactive oxygen species in cancer cells: live by the sword, die by the sword. Cancer Cell 10:175-176.

Sha LK, Sha W, Kuchler L, Daiber A, Giegerich AK, Weigert A, Knape T, Snodgrass R, Schröder K, Brandes RP, et al. (2015) Loss of Nrf2 in bone marrow-derived macrophages impairs antigen-driven CD8(+) T cell function by limiting GSH and Cys availability. Free Radic Biol Med 83:77-88.

Shanmugam G, Narasimhan M, Conley RL, Sairam T, Kumar A, Mason RP, Sankaran R, Hoidal JR, and Rajasekaran NS (2017a) Chronic endurance exercise impairs cardiac structure and function in middle-aged mice with impaired Nrf2 signaling. Front Physiol 8:268.

Shanmugam G, Narasimhan M, Tamowski S, Darley-Usmar V, and Rajasekaran NS (2017b) Constitutive activation of Nrf2 induces a stable reductive state in the mouse myocardium. Redox Biol 12:937-945.

Sharma A, Rizky L, Stefanovic N, Tate M, Ritchie RH, Ward KW, and de Haan JB (2017) The nuclear factor (erythroid-derived 2)-like 2 (Nrf2) activator dh404 protects against diabetes-induced endothelial dysfunction. Cardiovasc Diabetol 16:33.

Shibata T, Kokubu A, Saito S, Narisawa-Saito M, Sasaki H, Aoyagi K, Yoshimatsu Y, Tachimori Y, Kushima R, Kiyono T, et al. (2011) NRF2 mutation confers malignant potential and resistance to chemoradiation therapy in advanced esophageal squamous cancer. Neoplasia 13:864-873. 
Shimizu T, Inoue K, Hachiya H, Shibuya N, Aoki T, and Kubota K (2016) Accumulation of phosphorylated p62 is associated with NF-E2-related factor 2 activation in hepatocellular carcinoma. J Hepatobiliary Pancreat Sci 23:467-471.

Shimoyama Y, Mitsuda Y, Tsuruta Y, Hamajima N, and Niwa T (2014) Polymorphism of Nrf2, an antioxidative gene, is associated with blood pressure and cardiovascular mortality in hemodialysis patients. Int J Med Sci 11:726-731.

Shimozono R, Asaoka Y, Yoshizawa Y, Aoki T, Noda H, Yamada M, Kaino M, and Mochizuki H (2013) Nrf2 activators attenuate the progression of nonalcoholic steatohepatitis-related fibrosis in a dietary rat model. Mol Pharmacol 84:62-70.

Signorelli SS, Li Volsi G, Fiore V, Mangiafico M, Barbagallo I, Parenti R, Rizzo M, and Li Volti G (2016) Plasma heme oxygenase-1 is decreased in peripheral artery disease patients. Mol Med Rep 14:3459-3463.

Silva T, Reis J, Teixeira J, and Borges F (2014) Alzheimer's disease, enzyme targets and drug discovery struggles: from natural products to drug prototypes. Ageing Res Rev 15:116-145.

Singh A, Misra V, Thimmulappa RK, Lee H, Ames S, Hoque MO, Herman JG, Baylin SB, Sidransky D, Gabrielson E, et al. (2006) Dysfunctional KEAP1-NRF2 interaction in non-small-cell lung cancer. PLoS Med 3:e420.

Singh A, Venkannagari S, Oh KH, Zhang YQ, Rohde JM, Liu L, Nimmagadda S, Sudini K, Brimacombe KR, Gajghate S, et al. (2016) Small molecule inhibitor of NRF2 selectively intervenes therapeutic resistance in KEAP1-deficient NSCLC tumors. ACS Chem Biol 11:3214-3225.

Siomek A (2012) NF-кB signaling pathway and free radical impact. Acta Biochim Pol 59:323-331.

Song P, Li K, Liu L, Wang X, Jian Z, Zhang W, Wang G, Li C, and Gao T (2016) Genetic polymorphism of the Nrf2 promoter region is associated with vitiligo risk in Han Chinese populations. J Cell Mol Med 20:1840-1850.

Stelzer G, Rosen N, Plaschkes I, Zimmerman S, Twik M, Fishilevich S, Stein TI, Nudel R, Lieder I, Mazor Y, et al. (2016) The GeneCards suite: from gene data mining to disease genome sequence analyses. Curr Protoc Bioinformatics 54: 1.30.1-1.30.33

Stocker R, Yamamoto Y, McDonagh AF, Glazer AN, and Ames BN (1987) Bilirubin is an antioxidant of possible physiological importance. Science 235:1043-1046.

Strom J and Chen QM (2017) Loss of Nrf2 promotes rapid progression to heart failure following myocardial infarction. Toxicol Appl Pharmacol 327:52-58.

Sun H, Zhu J, Lin H, Gu K, and Feng F (2017) Recent progress in the development of small molecule Nrf2 modulators: a patent review (2012-2016). Expert Opin Ther Pat 27:763-785.

Taguchi K and Yamamoto M (2017) The KEAP1-NRF2 system in cancer. Front Oncol 7:85

Tahvili S, Zandieh B, and Amirghofran Z (2015) The effect of dimethyl fumarate on gene expression and the level of cytokines related to different $\mathrm{T}$ helper cell subsets in peripheral blood mononuclear cells of patients with psoriasis. Int J Dermatol 54: e254-e260.

Takahashi Y, Kobayashi Y, Kawata K, Kawamura K, Sumiyoshi S, Noritake H, Watanabe S, Chida T, Souda K, Sakaguchi T, et al. (2014) Does hepatic oxidative stress enhance activation of nuclear factor-E2-related factor in patients with nonalcoholic steatohepatitis? Antioxid Redox Signal 20:538-543.

Tan SM, Sharma A, Stefanovic N, Yuen DY, Karagiannis TC, Meyer C, Ward KW, Cooper ME, and de Haan JB (2014) Derivative of bardoxolone methyl, dh404, in an inverse dose-dependent manner lessens diabetes-associated atherosclerosis and improves diabetic kidney disease. Diabetes 63:3091-3103.

Tang X, Lin CC, Spasojevic I, Iversen ES, Chi JT, and Marks JR (2014) A joint analysis of metabolomics and genetics of breast cancer. Breast Cancer Res 16:415.

Tarumoto T, Nagai T, Ohmine K, Miyoshi T, Nakamura M, Kondo T, Mitsugi K, Nakano S, Muroi K, Komatsu N, et al. (2004) Ascorbic acid restores sensitivity to imatinib via suppression of Nrf2-dependent gene expression in the imatinibresistant cell line. Exp Hematol 32:375-381.

Thimmulappa RK, Lee H, Rangasamy T, Reddy SP, Yamamoto M, Kensler TW, and Biswal S (2006a) Nrf2 is a critical regulator of the innate immune response and survival during experimental sepsis. J Clin Invest 116:984-995.

Thimmulappa RK, Scollick C, Traore K, Yates M, Trush MA, Liby KT, Sporn MB, Yamamoto M, Kensler TW, and Biswal S (2006b) Nrf2-dependent protection from LPS induced inflammatory response and mortality by CDDO-Imidazolide. Biochem Biophys Res Commun 351:883-889.

Thomson L, Tenopoulou M, Lightfoot R, Tsika E, Parastatidis I, Martinez M, Greco TM, Doulias PT, Wu Y, Tang WH, et al. (2012) Immunoglobulins against tyrosinenitrated epitopes in coronary artery disease. Circulation 126:2392-2401.

Todorovic M, Newman JR, Shan J, Bentley S, Wood SA, Silburn PA, and Mellick GD (2015) Comprehensive assessment of genetic sequence variants in the antioxidant 'master regulator' NRF2 in idiopathic Parkinson's disease. PLoS One 10:e0128030.

Tong KI, Padmanabhan B, Kobayashi A, Shang C, Hirotsu Y, Yokoyama S, and Yamamoto M (2007) Different electrostatic potentials define ETGE and DLG motifs as hinge and latch in oxidative stress response. Mol Cell Biol 27:7511-7521.

Tsai HH, Lai HY, Chen YC, Li CF, Huang HS, Liu HS, Tsai YS, and Wang JM (2017) Metformin promotes apoptosis in hepatocellular carcinoma through the CEBPDinduced autophagy pathway. Oncotarget 8:13832-13845.

Tsuchida K, Tsujita T, Hayashi M, Ojima A, Keleku-Lukwete N, Katsuoka F, Otsuki A, Kikuchi H, Oshima Y, Suzuki M, et al. (2017) Halofuginone enhances the chemosensitivity of cancer cells by suppressing NRF2 accumulation. Free Radic Biol Med 103:236-247.

Tu J, Zhang X, Zhu Y, Dai Y, Li N, Yang F, Zhang Q, Brann DW, and Wang R (2015) Cell-permeable peptide targeting the Nrf2-Keap1 interaction: a potential novel therapy for global cerebral ischemia. J Neurosci 35:14727-14739.

Tung MC, Lin PL, Wang YC, He TY, Lee MC, Yeh SD, Chen CY, and Lee H (2015) Mutant p53 confers chemoresistance in non-small cell lung cancer by upregulating Nrf2. Oncotarget 6:41692-41705.

Türei D, Papp D, Fazekas D, Földvári-Nagy L, Módos D, Lenti K, Csermely P, and Korcsmáros T (2013) NRF2-ome: an integrated web resource to discover protein interaction and regulatory networks of NRF2. Oxid Med Cell Longev 2013 : 737591.

Tzima S, Victoratos P, Kranidioti K, Alexiou M, and Kollias G (2009) Myeloid heme oxygenase-1 regulates innate immunity and autoimmunity by modulating IFNbeta production. J Exp Med 206:1167-1179.

Ungvari Z, Bagi Z, Feher A, Recchia FA, Sonntag WE, Pearson K, de Cabo R, and Csiszar A (2010) Resveratrol confers endothelial protection via activation of the antioxidant transcription factor Nrf2. Am J Physiol Heart Circ Physiol 299: $\mathrm{H} 18-\mathrm{H} 24$

Ungvari Z, Bailey-Downs L, Gautam T, Jimenez R, Losonczy G, Zhang C, Ballabh P, Recchia FA, Wilkerson DC, Sonntag WE, et al. (2011) Adaptive induction of NF-E2related factor-2-driven antioxidant genes in endothelial cells in response to hyperglycemia. Am J Physiol Heart Circ Physiol 300:H1133-H1140.

Uruno A, Furusawa Y, Yagishita Y, Fukutomi T, Muramatsu H, Negishi T, Sugawara A, Kensler TW, and Yamamoto M (2013) The Keap1-Nrf2 system prevents onset of diabetes mellitus. Mol Cell Biol 33:2996-3010.

Uruno A, Yagishita Y, and Yamamoto M (2015) The Keap1-Nrf2 system and diabetes mellitus. Arch Biochem Biophys 566:76-84

van Horssen J, Drexhage JA, Flor T, Gerritsen W, van der Valk P, and de Vries HE (2010) Nrf2 and DJ1 are consistently upregulated in inflammatory multiple sclerosis lesions. Free Radic Biol Med 49:1283-1289.

van Muiswinkel FL, de Vos RA, Bol JG, Andringa G, Jansen Steur EN, Ross D, Siegel D, and Drukarch B (2004) Expression of NAD(P)H:quinone oxidoreductase in the normal and Parkinsonian substantia nigra. Neurobiol Aging 25:1253-1262.

Vidal M, Cusick ME, and Barabási AL (2011) Interactome networks and human disease. Cell 144:986-998.

von Otter M, Bergström P, Quattrone A, De Marco EV, Annesi G, Söderkvist P, Wettinger SB, Drozdzik M, Bialecka M, Nissbrandt H, et al. (2014) Genetic associations of Nrf2-encoding NFE2L2 variants with Parkinson's disease: a multicenter study. BMC Med Genet 15:131.

von Otter M, Landgren S, Nilsson S, Celojevic D, Bergström P, Håkansson A, Nissbrandt H, Drozdzik M, Bialecka M, Kurzawski M, et al. (2010a) Association of Nrf2-encoding NFE2L2 haplotypes with Parkinson's disease. BMC Med Genet 11: 36 .

von Otter M, Landgren S, Nilsson S, Zetterberg M, Celojevic D, Bergström P, Minthon L, Bogdanovic N, Andreasen N, Gustafson DR, et al. (2010b) Nrf2-encoding NFE2L2 haplotypes influence disease progression but not risk in Alzheimer's disease and age-related cataract. Mech Ageing Dev 131:105-110.

Wang L, Han J, Shan P, You S, Chen X, Jin Y, Wang J, Huang W, Wang Y, and Liang G (2017a) MD2 blockage protects obesity-induced vascular remodeling via activating AMPK/Nrf2. Obesity (Silver Spring) 25:1532-1539.

Wang R, An J, Ji F, Jiao H, Sun H, and Zhou D (2008) Hypermethylation of the Keap1 gene in human lung cancer cell lines and lung cancer tissues. Biochem Biophys Res Commun 373:151-154

Wang X, Chen H, Liu J, Ouyang Y, Wang D, Bao W, and Liu L (2015) Association between the NF-E2 related factor 2 gene polymorphism and oxidative stress, antioxidative status, and newly-diagnosed type 2 diabetes mellitus in a Chinese population. Int J Mol Sci 16:16483-16496.

Wang X, de Rivero Vaccari JP, Wang H, Diaz P, German R, Marcillo AE, and Keane RW (2012) Activation of the nuclear factor E2-related factor 2/antioxidant response element pathway is neuroprotective after spinal cord injury. $J$ Neurotrauma 29 : 936-945.

Wang X, Hausding M, Weng SY, Kim YO, Steven S, Klein T, Daiber A, and Schuppan D (2018) Gliptins suppress inflammatory macrophage activation to mitigate inflammation, fibrosis, oxidative stress, and vascular dysfunction in models of nonalcoholic steatohepatitis and liver fibrosis. Antioxid Redox Signal. 28:87-109.

Wang X, Li M, Cao Y, Wang J, Zhang H, Zhou X, Li Q, and Wang L (2017b) Tenuigenin inhibits LPS-induced inflammatory responses in microglia via activating the Nrf2-mediated HO-1 signaling pathway. Eur J Pharmacol 809:196-202.

Wang XJ, Hayes JD, Henderson CJ, and Wolf CR (2007) Identification of retinoic acid as an inhibitor of transcription factor Nrf2 through activation of retinoic acid receptor alpha. Proc Natl Acad Sci USA 104:19589-19594.

Wang Y, Huang Y, Xu Y, Ruan W, Wang H, Zhang Y, Saavedra JM, Zhang L, Huang $\mathrm{Z}$, and Pang T (2017c) A dual AMPK/Nrf2 activator reduces brain inflammation after stroke by enhancing microglia M2 polarization. Antioxid Redox Signal 28: 141-163.

Wasik U, Milkiewicz M, Kempinska-Podhorodecka A, and Milkiewicz P (2017) Protection against oxidative stress mediated by the Nrf2/Keap1 axis is impaired in primary biliary cholangitis. Sci Rep 7:44769.

Wen X, Thorne G, Hu L, Joy MS, and Aleksunes LM (2015) Activation of NRF2 signaling in HEK293 cells by a first-in-class direct KEAP1-NRF2 inhibitor. $J$ Biochem Mol Toxicol 29:261-266.

Wenzel P, Kossmann S, Münzel T, and Daiber A (2017) Redox regulation of cardiovascular inflammation: immunomodulatory function of mitochondrial and Noxderived reactive oxygen and nitrogen species. Free Radic Biol Med 109:48-60.

Wenzel P, Oelze M, Coldewey M, Hortmann M, Seeling A, Hink U, Mollnau H, Stalleicken D, Weiner H, Lehmann J, et al. (2007) Heme oxygenase-1: a novel key player in the development of tolerance in response to organic nitrates. Arterioscler Thromb Vasc Biol 27:1729-1735.

Wenzel P, Rossmann H, Müller C, Kossmann S, Oelze M, Schulz A, Arnold N, Simsek C, Lagrange J, Klemz R, et al. (2015) Heme oxygenase-1 suppresses a proinflammatory phenotype in monocytes and determines endothelial function and arterial hypertension in mice and humans. Eur Heart $J$ 36:3437-3446.

Winkel AF, Engel CK, Margerie D, Kannt A, Szillat H, Glombik H, Kallus C, Ruf S, Güssregen S, Riedel J, et al. (2015) Characterization of RA839, a noncovalent small molecule binder to Keap1 and selective activator of Nrf2 signaling. J Biol Chem 290:28446-28455.

Winston JT, Strack P, Beer-Romero P, Chu CY, Elledge SJ, and Harper JW (1999) The SCFbeta-TRCP-ubiquitin ligase complex associates specifically with 
phosphorylated destruction motifs in IkappaBalpha and beta-catenin and stimulates IkappaBalpha ubiquitination in vitro. Genes Dev 13:270-283.

Wu Q, Wang Q, Mao G, Dowling CA, Lundy SK, and Mao-Draayer Y (2017) Dimethyl fumarate selectively reduces memory T cells and shifts the balance between Th1/ Th17 and Th2 in multiple sclerosis patients. J Immunol 198:3069-3080.

Wu W, Zhao L, Yang P, Zhou W, Li B, Moorhead JF, Varghese Z, Ruan XZ, and Chen $\mathrm{Y}$ (2016a) Inflammatory stress sensitizes the liver to atorvastatin-induced injury in ApoE-/- mice. PLoS One 11:e0159512.

Wu WJ, Jia WW, Liu XH, Pan LL, Zhang QY, Yang D, Shen XY, Liu L, and Zhu YZ (2016b) S-propargyl-cysteine attenuates inflammatory response in rheumatoid arthritis by modulating the Nrf2-ARE signaling pathway. Redox Biol 10:157-167.

Xia N, Daiber A, Förstermann U, and Li H (2017) Antioxidant effects of resveratrol in the cardiovascular system. Br J Pharmacol 174:1633-1646.

Xiaobo C, Majidi M, Feng M, Shao R, Wang J, Zhao Y, Baladandayuthapani V, Song J, Fang B, Ji L, et al. (2016) TUSC2(FUS1)-erlotinib induced vulnerabilities in epidermal growth factor receptor (EGFR) wildtype non-small cell lung cancer (NSCLC) targeted by the repurposed drug auranofin. Sci Rep 6:35741.

Xie H, Zhou F, Liu L, Zhu G, Li Q, Li C, and Gao T (2016) Vitiligo: how do oxidative stress-induced autoantigens trigger autoimmunity? J Dermatol Sci 81:3-9.

Xiong M, Li B, Zhu Q, Wang YX, and Zhang HY (2014) Identification of transcription factors for drug-associated gene modules and biomedical implications. Bioinformatics 30:305-309.

Xu IM, Lai RK, Lin SH, Tse AP, Chiu DK, Koh HY, Law CT, Wong CM, Cai Z, Wong CC, et al. (2016a) Transketolase counteracts oxidative stress to drive cancer development. Proc Natl Acad Sci USA 113:E725-E734.

Xu J, Donepudi AC, Moscovitz JE, and Slitt AL (2013) Keap1-knockdown decreases fasting-induced fatty liver via altered lipid metabolism and decreased fatty acid mobilization from adipose tissue. PLoS One 8:e79841.

Xu X, Sun J, Chang X, Wang J, Luo M, Wintergerst KA, Miao L, and Cai L (2016b) Genetic variants of nuclear factor erythroid-derived 2-like 2 associated with the complications in Han descents with type 2 diabetes mellitus of Northeast China. $J$ Cell Mol Med 20:2078-2088.

Xu Z, Wei Y, Gong J, Cho H, Park JK, Sung ER, Huang H, Wu L, Eberhart C, Handa JT, et al. (2014) NRF2 plays a protective role in diabetic retinopathy in mice. Diabetologia 57:204-213.

Xu Z, Zhang F, Sun F, Gu K, Dong S, and He D (2015) Dimethyl fumarate for multiple sclerosis. Cochrane Database Syst Rev 4:CD011076.

Xue P, Hou Y, Chen Y, Yang B, Fu J, Zheng H, Yarborough K, Woods CG, Liu D, Yamamoto M, et al. (2013) Adipose deficiency of Nrf2 in ob/ob mice results in severe metabolic syndrome. Diabetes 62:845-854

Yamamoto T, Suzuki T, Kobayashi A, Wakabayashi J, Maher J, Motohashi H, and Yamamoto M (2008) Physiological significance of reactive cysteine residues of Keap1 in determining Nrf2 activity. Mol Cell Biol 28:2758-2770.

Yamamoto T, Yoh K, Kobayashi A, Ishii Y, Kure S, Koyama A, Sakamoto T, Sekizawa $\mathrm{K}$, Motohashi H, and Yamamoto M (2004) Identification of polymorphisms in the promoter region of the human NRF2 gene. Biochem Biophys Res Commun 321: $72-79$

Yang M, Yao Y, Eades G, Zhang Y, and Zhou Q (2011) MiR-28 regulates Nrf2 expression through a Keap1-independent mechanism. Breast Cancer Res Treat 129: 983-991.

Yao W, Zhang JC, Ishima T, Dong C, Yang C, Ren Q, Ma M, Han M, Wu J, Suganuma $\mathrm{H}$, et al. (2016) Role of Keap1-Nrf2 signaling in depression and dietary intake of glucoraphanin confers stress resilience in mice. Sci Rep 6:30659.

Yap JL, Worlikar S, MacKerell AD Jr, Shapiro P, and Fletcher S (2011) Smallmolecule inhibitors of the ERK signaling pathway: towards novel anticancer therapeutics. ChemMedChem 6:38-48.

Yoh K, Hirayama A, Ishizaki K, Yamada A, Takeuchi M, Yamagishi S, Morito N, Nakano T, Ojima M, Shimohata H, et al. (2008) Hyperglycemia induces oxidative and nitrosative stress and increases renal functional impairment in Nrf2-deficient mice. Genes Cells 13:1159-1170.

Yore MM, Kettenbach AN, Sporn MB, Gerber SA, and Liby KT (2011) Proteomic analysis shows synthetic oleanane triterpenoid binds to mTOR. PLoS One 6: e22862.

Yoshizaki Y, Mori T, Ishigami-Yuasa M, Kikuchi E, Takahashi D, Zeniya M, Nomura N, Mori Y, Araki Y, Ando F, et al. (2017) Drug-repositioning screening for Keap1Nrf2 binding inhibitors using fluorescence correlation spectroscopy. Sci Rep 7: 3945

Yu M, Li H, Liu Q, Liu F, Tang L, Li C, Yuan Y, Zhan Y, Xu W, Li W, et al. (2011) Nuclear factor p65 interacts with Keap1 to repress the Nrf2-ARE pathway. Cell Signal 23:883-892.

Zehir A, Benayed R, Shah RH, Syed A, Middha S, Kim HR, Srinivasan P, Gao J, Chakravarty D, Devlin SM, et al. (2017) Mutational landscape of metastatic cancer revealed from prospective clinical sequencing of 10,000 patients. Nat Med 23: $703-713$.

Zeidan TA, Duncan S, Hencken CP, Wynn TA, and Sanrame CN (2014) Prodrugs of Fumarates and Their Use in Treating Various Diseases, Alkermes Pharma Ireland, Dublin, Ireland.

Zhang DD (2013) Bardoxolone brings Nrf2-based therapies to light. Antioxid Redox Signal 19:517-518.

Zhang QY, Chu XY, Jiang LH, Liu MY, Mei ZL, and Zhang HY (2017) Identification of non-electrophilic Nrf2 activators from approved drugs. Molecules 22:1-12.

Zhao C, Zhang Y, Liu H, Li P, Zhang H, and Cheng G (2017) Fortunellin protects against high fructose-induced diabetic heart injury in mice by suppressing inflammation and oxidative stress via AMPK/Nrf-2 pathway regulation. Biochem Biophys Res Commun 490:552-559.

Zhao M, Chen H, Ding Q, Xu X, Yu B, and Huang Z (2016) Nuclear factor erythroid 2-related factor 2 deficiency exacerbates lupus nephritis in B6/lpr mice by regulating Th17 cell function. Sci Rep 6:38619.

Zhou X, Menche J, Barabási AL, and Sharma A (2014) Human symptoms-disease network. Nat Commun 5:4212. 